
Elsevier Editorial System(tm) for Forensic Science International Manuscript Draft

Manuscript Number: FSI-D-14-00955R1

Title: A comparative study of ballpoint ink ageing parameters using GC/MS

Article Type: Original Research Article

Keywords: Questioned documents; ink dating; ageing parameters; solvent drying; phenoxyethanol; GC/MS.

Corresponding Author: Mrs. Agnès Koenig,

Corresponding Author's Institution: université de Lausanne

First Author: Agnès Koenig

Order of Authors: Agnès Koenig; Sophie Magnolon, Msc; Céline Weyermann, Professor

Abstract: For more than a decade scientists tried to develop methods capable of dating ink by monitoring the loss of phenoxyethanol (PE) over time. While many methods were proposed in the literature, few were really used to solve practical cases and they still raise much concern within the scientific community. In fact, due to the complexity of ink drying processes it is particularly difficult to find a reliable ageing parameter to reproducibly follow ink ageing. Moreover, systematic experiments are required in order to evaluate how different factors actually influence the results over time. Therefore, this work aimed at evaluating the capacity of four different ageing parameters to reliably follow ink ageing over time: (1) the quantity of solvent PE in an ink line, (2) the relative peak area (RPA) normalising the PE results using stable volatile compounds present in the ink formulation, (3) the solvent loss ratio (R\%) calculated from PE results obtained by the analyses of naturally and artificially aged samples, (4) a modified solvent loss ratio version ( $\left.\mathrm{R}^{*}\right)$ calculated from RPA results. After the determination of the limits of reliable measurements of the analytical method, the repeatability of the different ageing parameters was evaluated over time, as well as the influence of ink composition, writing pressure and storage conditions on the results. Surprisingly, our results showed that $\mathrm{R} \%$ was not the most reliable parameter, as it showed the highest standard deviation. Discussion of the results in an ink dating perspective suggests that other proposed parameters, such as RPA values, may be more adequate to follow ink ageing over time. 


\section{Acknowledgements}

The authors wish to thank Dr. Valéry Aginsky and Luc Brazeau for fruitful exchanges about their solvent loss ratio methods. They also thank the Swiss National Science Foundation for supporting this work (grant nPP00P1_150742). 


\section{A comparative study of ballpoint ink ageing parameters using GC/MS}

Agnès Koenig ${ }^{1}$, Sophie Magnolon ${ }^{1}$, Céline Weyermann ${ }^{1}$

1 Ecole des Sciences Criminelles, Université de Lausanne, Batochime 1015 LausanneDorigny, Switzerland

Corresponding author: Agnès Koenig (agnes.koenig@unil.ch) 


\section{Highlights}

- Parallel study of four ink solvent ageing parameters

- Evaluation of their reproducibility over time and not only at time $\mathrm{t}=0$

- Investigation of the impact of writing pressure and two storage conditions on the ageing

- First report of two relative peak area parameters using solvent ratios and an alternative $\mathrm{R} \%$ *

- Previously reported solvent loss ratio $(\mathrm{R} \%)$ proved to be the least reproducible 


\title{
A comparative study of ballpoint ink ageing parameters using GC/MS
}

\begin{abstract}
:
For more than a decade scientists tried to develop methods capable of dating ink by monitoring the loss of phenoxyethanol (PE) over time. While many methods were proposed in the literature, few were really used to solve practical cases and they still raise much concern within the scientific community. In fact, due to the complexity of ink drying processes it is particularly difficult to find a reliable ageing parameter to reproducibly follow ink ageing. Moreover, systematic experiments are required in order to evaluate how different factors actually influence the results over time. Therefore, this work aimed at evaluating the capacity of four different ageing parameters to reliably follow ink ageing over time: (1) the quantity of solvent PE in an ink line, (2) the relative peak area (RPA) normalising the PE results using stable volatile compounds present in the ink formulation, (3) the solvent loss ratio $(\mathrm{R} \%)$ calculated from PE results obtained by the analyses of naturally and artificially aged samples, (4) a modified solvent loss ratio version ( $\left.R \%{ }^{*}\right)$ calculated from RPA results. After the determination of the limits of reliable measurements of the analytical method, the repeatability of the different ageing parameters was evaluated over time, as well as the influence of ink composition, writing pressure and storage conditions on the results. Surprisingly, our results showed that $\mathrm{R} \%$ was not the most reliable parameter, as it showed the highest standard deviation. Discussion of the results in an ink dating perspective suggests that other proposed parameters, such as RPA values, may be more adequate to follow ink ageing over time.
\end{abstract}

Keywords: Questioned documents; ink dating; ageing parameters; solvent drying; phenoxyethanol; GC/MS. 


\section{Introduction}

Ink dating is a major issue in the field of questioned document examination [1-5]. For about a century, scientists have addressed more or less successfully the development of methods to date ink entries [6-32]. Indeed, the task proved to be particularly difficult as many parameters have to be studied in order to develop a validated ink dating method accepted by the scientific community. It is not sufficient to select a parameter to monitor the ageing (i.e., an ageing parameter). The resulting ageing dynamics must be reproducible in realistic conditions such as those encountered in forensic caseworks [33]. For example, ink dating methods targeting dyes were highly controverted in forensic science because identified ageing parameters were too dependent on ink composition and exposure to light [34-39]. While most of the methods reported in the literature considered the influence of ink initial composition, many neglected the influence of the substrate and the storage conditions.

Recent research has focused mainly on developing methods based on ink volatile compounds analysis [6-14,16,21-26,28,33,34,40-50]. They generally targeted one specific solvent called phenoxyethanol (PE), because it is present in more than $80 \%$ of the ballpoint pen ink formulations $[28,51,52]$. While measuring the decrease of PE was found problematic in terms of reproducibility and/or small time frame of detection [9,22,28,41], alternative ageing parameters were proposed in order to reduce variability and increase the time frame of reliable measurements $[6,10,14,16,21,22,41,42,48-50,53]$. Among them, methods based on the calculation of a solvent loss ratio $(R \%)$ were reported for practical use in North America $[14,21,41]$. These methods proposed sequential analysis of two samples (which, ideally, contain the same amount of ink) from the questioned ink entry using gas chromatography coupled to mass spectrometry (GC/MS): the first sample is directly extracted, while the second is artificially aged before extraction. The results are used to calculate the ageing parameter referred as $\mathrm{R} \%$. In order to date the ink entry, interpretation of the $\mathrm{R} \%$ values is made through the definition of decision thresholds representing the maximal possible age of a questioned ink entry. While used to solve practical cases, very few researches were published on methods using artificial ageing to calculate $R \%$ values $[14,21,41]$. Thus, the added value of this particular ageing parameter in comparison to others such as the quantity of PE and the calculation of relative peak areas $[22,42,50]$ was never thoroughly evaluated.

This article aims at comparing objectively four ageing parameters to study the decrease of ballpoint pen solvents in ink entries over time. Ink entries from three representative ballpoint inks, chosen in the frame of the International Collaboration on Ink Dating (InCID) [54], were 
studied over one year using GC/MS, including the analysis of naturally and artificially aged samples (in order to be able to calculate $\mathrm{R} \%$ values). Validation criteria, such as sensitivity and repeatability of the method were first determined. Then, the reproducibility of the different ageing parameters was evaluated for the first time over ca. 1 year for samples from one ink as well as for samples from different inks. Influence factors, such as storage conditions and line pressure, were also evaluated over time. Finally, the results were then discussed in an ink dating perspective.

\section{Material and method}

\subsection{Products and material}

Chloroform (99.9\%) was purchased from Sigma Aldrich (Darmstadt, Germany). The reference substance phenoxyethanol (PE) 99.5\% was purchased from Fluka (Buchs, Switzerland) and the internal standard was deuterated phenoxyethanol $\left(P E-D_{2}\right)$ from EGT Chemie (Tägerig, Switzerland).

For sample preparation, $1.5 \mathrm{~mL}$ vials, $300 \mu \mathrm{L}$ and $50 \mu \mathrm{L}$ inserts as well as springs were obtained by Swiss Lab (Basel, Switzerland).

\subsection{Sample preparation}

The analysed samples were drawn with three different inks labelled 1688, 1774 and 1892, supplied in pen cartridges. These were chosen and sent by the Landeskriminalamt (LKA) in Munich in the frame of the International Collaboration on Ink Dating (InCID) of the European Network of Forensic Science Institutes [54]. The LKA Münich has a large collection of inks and ballpoint pens [55] and selected these three inks because they represented different ageing rates (so-called middle,slow and fast respectively).

Lines were drawn on a white copy paper of $80 \mathrm{~g} / \mathrm{m}^{2}$ (Xerox Business paper) with a ruler by a single operator. The pressure was not controlled in order to remain close to real cases conditions. The strokes were made $3 \mathrm{~cm}$ apart and two white pages were inserted between sheets with ink strokes to avoid cross-contaminations. The pages were stored in folders located in an air conditioned laboratory at $23^{\circ} \mathrm{C}$ or in a climatic chamber at $20^{\circ} \mathrm{C}$ and $55 \%$ of humidity with an air fan set at $50 \%$. Additional ink 1688 entries were made at controlled pressure $100 \mathrm{~g}, 250 \mathrm{~g}$ and $350 \mathrm{~g}$ with a homemade device [56].

The principle of the solvent loss ratio method is to compare the quantity of PE extracted from two sets of samples collected from the same ink entry, one being artificially aged at $70^{\circ} \mathrm{C}$ during $2 \mathrm{~h}[14,21]$. Thus, sample collection represented a particularly critical step since both 
sets must contain the same amount of ink for the calculation of the $R \%$. Because questioned ink entries are considered to be inhomogeneous, sample collection from the paper was carried out according to a previously reported procedure [21]. It was performed with a microplunger of $1 \mathrm{~mm}$ diameter (Sigma-Aldrich, Buchs, Switzerland). Two sets of $1 \mathrm{~cm}$ of ink were collected (10 dots/punches for each set). For each dot taken for the "natural" set, a second was collected next to it for the "heated" set, in order to reach a homogeneous distribution of dots in both sets (see Figure 1).

\section{Insert Figure 1}

While the "natural" sample was introduced into a conical insert of $300 \mu \mathrm{L}$ for extraction, the "heated" sample was introduced in a $1.5 \mathrm{~mL}$ vial and aged artificially in a dry bath (VWR, Nyon, Switzerland) for $2 \mathrm{~h}$ at $70^{\circ} \mathrm{C}$. The dots inside the vial were positioned to avoid overlapping between them. After artificial ageing, the dots were transferred from the vial to a $300 \mu \mathrm{L}$ insert. After five minutes (in order for the heated samples to reach again room temperature), the PE of both sets was extracted using $15 \mu \mathrm{L}$ of chloroform containing $P E-D_{2}$ as internal standard $(4 \mathrm{ng} / \mu \mathrm{L})$ during 3 minutes. Every minute the liquid was mixed with the tip of a syringe. Before analysis, the liquid was collected with a syringe and introduced in a $50 \mu \mathrm{L}$ insert that was then placed on a spring in a $1.5 \mathrm{~mL}$ sealed vial in order to avoid the solvent to evaporate too quickly.

\section{3. $\mathrm{GC} / \mathrm{MS}$ analysis}

The analytical method was adapted from the method proposed by Brazeau \& Gaudreau (2002) [14,21]. The analyses were performed with a gas chromatograph (6890 Agilent technologies) coupled with a mass spectrometer (5790C, Agilent technologies). Separation was carried out on a HP5-MS column $(30 \mathrm{~m} \times 0.25 \mathrm{~mm} \times 0.25 \mu \mathrm{m})$ with a flow of $1 \mathrm{~mL} / \mathrm{min}$ of Helium. For each analysis, $1 \mu \mathrm{L}$ of solution were collected and injected in splitless mode in the GC by an autosampler (GC7890; Agilent technologies) with a purge time of $1 \mathrm{~min}$. The injector was settled at $270^{\circ} \mathrm{C}$. The program of temperature started at $50^{\circ} \mathrm{C}$ for $3 \mathrm{~min}$, and then the temperature increased at $25^{\circ} \mathrm{C} / \mathrm{min}$ to $110^{\circ} \mathrm{C}$. A new rate was performed from $110^{\circ} \mathrm{C}$ to $300^{\circ} \mathrm{C}$ at $45^{\circ} \mathrm{C} / \mathrm{min}$ and finally $300^{\circ} \mathrm{C}$ was maintained for $3 \mathrm{~min}$. The whole run lasted 12.6 min with a solvent delay of $4.5 \mathrm{~min}$. The transfer line was maintained at $250^{\circ} \mathrm{C}$ and the electron impact $(\mathrm{EI})$ ion source was maintained at $230^{\circ} \mathrm{C}$. The ions were filtered through a quadrupole set at $150^{\circ} \mathrm{C}$ in single ion monitoring [57]. The main solvents of each ink were actually monitored additionally to phenoxyethanol (see details in Table 1). The following ions were analysed as a function of time: 
- From 4.5 to 6.0 min.: ions 59.1, 85.1 and 103.0 (dwell time $100 \mathrm{~ms}$ );

- From 6.0 to 7.0 min.: ions 59.0, 79.1, 89.1, 103.1, 108.1 (dwell time $80 \mathrm{~ms}$ )

- From 7.0 and 8.0 min.: ions $45.1,138.1$, 47.1; 140.1 (dwell time $80 \mathrm{~ms}$ )

- From 8.0 to $23 \mathrm{~min}$. ions 77.0, 94.0, 182.1 (dwell time $100 \mathrm{~ms}$ ).

In order to control the GC/MS performances, a solution containing $1.7 \mathrm{ng} / \mu \mathrm{L}$ of $\mathrm{PE}$ (26 $\mathrm{ng} / \mathrm{cm}$ ) and $4 \mathrm{ng} / \mu \mathrm{L}$ of $\mathrm{PE}-\mathrm{D}_{2}$ was analyzed daily.

Calibration was performed by analyzing control solutions containing PE at concentrations of $0.005,0.01,0.03,0.05,0.1,0.5,1,5,10,50,100,400,600 \mathrm{ng} / \mu \mathrm{L}$ in chloroform containing 4 $\mathrm{ng} / \mathrm{ul}$ of $\mathrm{PE}-\mathrm{D}_{2}$. The concentrations were extrapolated to $\mathrm{ng} / \mathrm{cm}$, yielding quantities from 0.075 to $9000 \mathrm{ng}$ in $1 \mathrm{~cm}$ of ink.

The limits of detection (LoD) and quantification (LoQ) were estimated by the signal to noise method [58]:

$$
\begin{aligned}
& L o D=\bar{X}_{\text {Blank }}+3 \cdot S D_{\text {Blank }} \\
& L o Q=\bar{X}_{\text {Blank }}+10 \cdot S D_{\text {Blank }}
\end{aligned}
$$

,where $\bar{X}_{\text {Blank }}$ is the mean peak area and $S D_{\text {Blank }}$ is the standard deviation of the background noise at the retention time of the solvent PE calculated on 12 blank analyses.

\subsection{Data treatment}

The peak areas (PA) of the ink solvents were calculated using selected target ions (see Table 1). They were chose because they represented the most abundant ion of the compound spectra. However, the PA calculated for the internal standard PE- $D_{2}$ had to be corrected, because this molecule is a natural isotope of the target compound (PE). According to the software ISOTOPE (BASF AG, 1990), ion $140 \mathrm{~m} / \mathrm{z}$ (molecular and target ion of PE- $\mathrm{D}_{2}$ ) is naturally present at a proportion of $0.78 \%$ in relation to ion $138 \mathrm{~m} / \mathrm{z}$ (molecular ion of $\mathrm{PE}$ ) in $\mathrm{PE}$. As the natural quantity of PE varies a lot between fresh and old samples, the contribution of the natural isotope (ion $140 \mathrm{~m} / \mathrm{z}$ ) significantly modifies the peak area of the internal standard. Therefore the following correction was applied to the PA $\left(P E-D_{2}\right)$ :

$$
P A\left(P E-D_{2}\right)=P A\left(\text { ion 140) }-\frac{0.78 \times P A(\text { ion 138) }}{100}\right.
$$

, where $\mathrm{PA}_{\text {(ion 138) }}$ is the peak area of ion $138 \mathrm{~m} / \mathrm{z}$ and $\mathrm{PA}_{(\text {ion 140) }}$ the peak area of ion $140 \mathrm{~m} / \mathrm{z}$ obtained at a retention time of $7.42 \mathrm{~min}$. 
Relative peak areas (RPA) for the different solvents recorded in the ink samples were calculated as follows in order to monitor their ageing:

$$
\operatorname{RPA}(X / Y)=\frac{P A(X)}{P A(Y)}
$$

, where $X$ is the solvent decreasing over time and $Y$ a stable compound (i.e., it is stable over time and thus does not change with age). Ycan be the internal standard PE-D2 or an ink volatile component such as those listed in Table 1, provided they are shown to be stable (this is considered in more details in section 3.2).

The ratio $\mathrm{R} \%$ was calculated using the quantities of $\mathrm{PE}$ extracted from both natural $\left(P E_{n}\right)$ and heated $\left(P E_{h}\right)$ samples $[21,41,59]$ :

$$
R \%=\frac{P E_{n}-P E_{h}}{P E_{n}} \times 100
$$

Ageing curves were built by plotting the different ageing parameters as a function of time $(t)$. A double exponential regression was used to model the ageing dynamics of the PE quantity extracted from the natural samples $\left(P E_{n}\right), \mathrm{RPA}$ and $\mathrm{R} \%$ values in natural samples, following the model proposed by Cantu (2012) [60]:

$$
Y=Y_{0}+A_{1} \times \exp \left(-\mathrm{t} / \tau_{1}\right)+A_{2} \times \exp \left(-t / \tau_{2}\right)
$$

In order to characterize the obtained ageing curves, an inflexion point was calculated to evaluate the moment when the fast falling rate of Eq. (6) (i.e., $A_{1} \times \exp \left(-\mathrm{t} / \tau_{1}\right)$ ) had no more than $1 \pm 0.5 \%$ contribution in the regression. Accordingly, after the inflexion point, the regression was mainly explained by the second falling rate. The inflexion point intervals were obtained through the following equation:

$$
I P=\mathrm{A} \times \mathrm{T} 1 / 2
$$

. where A was calculated as follows (with $p=$ percentage at which the contribution to the regression is no more than $1 \pm 0.5 \%$ ):

$$
A=\frac{\ln (100 / p)}{\ln (2)}
$$

. T $1 / 2$ was the half-life time calculated for the first exponential decay function as follows:

$$
\mathrm{T} 1 / 2=\ln (2) \times \tau_{1}
$$

A second parameter was used to determine how long the ageing was still significant, through calculation of linear slopes $(m)$ on two sets of data points: (1) from the inflexion point to 1 
year and (2) from 100 days to 1 year. A test was then applied to determine whether or not the slope was indeed significant (i.e. whether a descending trend was detected or not) [19]:

$$
\mathrm{t}_{\exp }=\frac{\mathrm{m}}{\mathrm{sm}}
$$

, where $\mathrm{m}$ was the slope and $\mathrm{sm}$ the standard deviation calculated on the slope. If $t_{\text {exp }}$ was above the student value $t_{(0.05, n-1)}$, then the slope was considered significant.

Table 1 : $\quad$ Solvents detected in ink 1688, 1774 and 1892, as well as their retention time and target ion.

\begin{tabular}{|c|c|c|c|c|c|}
\hline Rt (min) & Solvent & $\begin{array}{c}\text { Mass of } \\
\text { target ion }\end{array}$ & $\mathbf{1 6 8 8}$ & $\mathbf{1 7 7 4}$ & $\mathbf{1 8 9 2}$ \\
\hline 5.45 & hexylene glycol (HG) & 59 & & $\mathrm{x}$ & $\mathrm{x}$ \\
\hline 6.36 & dipropylene glycol 1 (DPG1) & 89 & & & $\mathrm{x}$ \\
\hline 6.42 & benzyl alcohol (BA) & 79 & $\mathrm{x}$ & & $\mathrm{x}$ \\
\hline 6.49 & dipropylene glycol 2(DPG2) & 59 & & & $\mathrm{x}$ \\
\hline 6.51 & dipropylène glycol (DPG3) & 59 & & & $\mathrm{x}$ \\
\hline 6.58 & dimethylcyclohexadienone (DMCH) & 79 & & $\mathrm{x}$ & $\mathrm{x}$ \\
\hline 7.42 & phenoxyethanol (PE) & 138 & $\mathrm{x}$ & $\mathrm{x}$ & $\mathrm{x}$ \\
\hline 8.47 & phenoxyethoxyethanol (PEE) & 94 & $\mathrm{x}$ & $\mathrm{x}$ & $\mathrm{x}$ \\
\hline 7.42 & doubly deuterated phenoxyethanol (PE-D $)^{*}$ & 140 & & & \\
\hline
\end{tabular}

*Internal Standard

\section{Results and discussions}

\subsection{Limits of reliable measurements and repeatability}

Calibration of the instrument for the quantification of PE allowed determining the limits of reliable measurements of the method. Thus, a LoD of $0.05 \mathrm{ng}$ per $\mathrm{cm}$ of ink stroke $(0.003$ $\mathrm{ng} / \mathrm{\mu L})$ and a LoQ of $0.14 \mathrm{ng}$ per $\mathrm{cm}$ of ink stroke $(0.010 \mathrm{ng} / \mu \mathrm{L})$ were obtained.

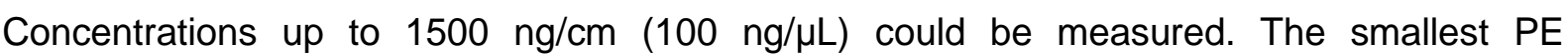
concentration measured in ink entries was $5.49 \mathrm{ng} / \mathrm{cm}$ (ink 1774, 419 days old, heated sample) and the largest reached $1434 \mathrm{ng} / \mathrm{cm}$ (ink 1688, 2 minutes old, natural sample). Hence, the developed method allowed quantification of the solvent fraction in all samples measured in this study whatever their age.

While the limits of reliable measurements were rarely presented in the literature for GC/MS analysis of ink samples, obtained concentrations were comparable to those mentioned in three studies using liquid extraction $[9,14,21]$. In comparison to thermodesorption (TD) - 
GC/MS, the LoQ obtained in this work was approximately 5 times lower $(0.14$ vs $1.1 \mathrm{ng} / \mathrm{cm}$ [19]) and much higher concentrations could be measured (1434 vs $50 \mathrm{ng} / \mathrm{cm}$ ).

The concentration of PE measured in the control solution was repeatable even for analyses carried out on different days. A value of $1.98 \pm 0.02 \mathrm{ng} / \mu \mathrm{L}$ was obtained yielding a RSD of $0.8 \%$ (Table 2). On the other hand, measurements of the quantity of PE within ink strokes (ink 1688) yielded a higher RSD value of $5.1 \%$ for one week old samples, indicating that ink strokes inhomogeneity significantly increased the variability of obtained results (Table 2). It is well known that ink repartition along a stroke may vary significantly even when using a constant writing pressure $[41,50]$. This may be explained by the uneven structure of the paper fibres [61], as well as the fact that the ball of the pen tip can produce random striation or gooping [61]. This also explains the increased RSD value of $21.1 \%$ obtained when different ink lines of the same age (2 minutes) and same composition (ink 1688) were analysed. This demonstrated a significant impact on the PE quantity recovered from different straight ink lines written by the same person using the same pen.

In fact, the high variability within and between ink samples was previously observed. For this reason, ink dating methods proposed to minimize the measurement variation by calculating different ageing parameters $[10,14,19,21,22,41,42,50]$. These are generally under the form of ratios between several ink samples (e.g., $\mathrm{R} \%$ ) and/or endogen compounds within the ink (eg. RPA).

Table 2 : Mean quantity, standard deviation and relative standard deviation (RSD) of $P E$ in a control solution, within samples from the same ink line and between samples from different ink lines (ink 1688).

\begin{tabular}{|l|l|l|}
\hline & PE quantity & RSD \\
\hline Control solution $(\mathrm{n}=40)$ & $1.98 \pm 0.02 \mathrm{ng} / \mu \mathrm{L}$ & $0.8 \%$ \\
\hline Same ink line $(\mathrm{n}=6)(\mathrm{t}=7$ days $)$ & $96.2 \pm 4.9 \mathrm{ng} / \mathrm{cm}$ & $5.1 \%$ \\
\hline $\begin{array}{l}\text { Three different ink lines }(\mathrm{n}=3) \\
(\mathrm{t}=2 \text { min) }\end{array}$ & $1327.5 \pm 280.1 \mathrm{ng} / \mathrm{cm}$ & $21.1 \%$ \\
\hline
\end{tabular}

Insert Figure 2 : 


\subsection{Ageing curves and parameters}

Four different phases were previously described for solvent drying of ink on paper $[9,22,60]$. While the increasing and constant rates of drying last only a few minutes to hours, the next two stages last much longer and can be separated in two phases: the $1^{\text {st }}$ and $2^{\text {nd }}$ falling rates. Those actually are the processes modelled by the ageing curves as proposed by Cantu [60], where each exponential of equation (6) represents a falling rate $[9,22,60]$. Additionally to the decrease in PE quantity, several ageing parameters can potentially be used to reliably model the drying of ink entries on paper over several months to years. In this section, the repeatability (variability of the measurement of ink strokes coming from the same pen, prepared, collected and analysed by the same operator) of four ageing parameters was evaluated and compared over time. For that purpose, samples of ink 1688 were measured by the same operator on the same instrument using different ink lines up to 390 days old $(\mathrm{n}=41$ measurements over time). To compare the different ageing parameters, the inflexion interval (i.e., time at which the regressions are almost exclusively explained by the second falling rate), the detection of significant slopes after the inflexion point and after 100 days, as well as the RSD values were used.

\section{Quantity of PE}

The quantity of PE in ink represents the most basic and used ageing parameter for the monitoring of solvent loss as a function of time $[8,9,22,41,50]$ (see Figure $2 \mathrm{~A}$ ). While it is not the only solvent decreasing over time (see Insert Figure 4 ), it is the most commonly used for ink dating purpose. After an interval of $27 \pm 3$ days, the diminution of PE in ink 1688 entries reached its inflexion point at a value of $57 \pm 8 \mathrm{ng} / \mathrm{cm}$ (see Table 4). After that point the quantity of PE kept decreasing very slowly ( $\left(2^{\text {nd }}\right.$ falling rate), and no decrease was statistically observed anymore after 100 days. The curve levelled off at a quantity of $37 \pm 6 \mathrm{ng} / \mathrm{cm}$ (calculated on samples from 100 to 390 days) (see Table 4). The obtained RSD value varied between 6 to $21 \%$ (Table 3).

\section{Solvent loss ratio $\mathrm{R} \%$}

The calculation of the ageing parameter referred in the literature as the solvent loss ratio $(R \%)[14,21,41]$ theoretically aims at measuring the ageing while minimizing the variability due to ink line inhomogeneity through normalisation. This requires the analysis of a second sample artificially aged at $70^{\circ} \mathrm{C}$ during $2 \mathrm{~h}$. In theory, heating the second sample should accelerates its ageing [14] until the lowest quantity that can be found naturally in old inks on paper is reached (i.e., once the evaporation and migration of solvent theoretically stopped) $[41,62]$. Mathematically speaking, this level should correspond to the constant calculated in 
the regression model of the natural samples ageing curve ( $Y_{0}$ in Eq.6), namely $37 \pm 6 \mathrm{ng} / \mathrm{cm}$ for ink 1688 (level-off value in Table 4). While generally presented as a theoretical flat line in the literature [21,41], the ageing curves built with the quantities of $\mathrm{PE}$ recovered in the artificially aged samples could be modelled using an exponential regression (see Figure 2A). This showed that artificial ageing of ink 1688 samples at $70^{\circ} \mathrm{C}$ for $2 \mathrm{~h}$ did yield PE quantities above the natural samples level-off values up to 166 days old and reached then a lower level-off value of $28 \pm 1 \mathrm{ng} / \mathrm{cm}$. However, the effect of artificial ageing is known to be dependent on the ink composition [62] and indeed, other ink reacted differently (see Figure 3).

Table 3 : Mean ageing parameter values and relative standard deviation calculated on ink 1688 samples of different ages.

\begin{tabular}{|c|cc|cc|rr|rr|}
\hline \multirow{2}{*}{$\begin{array}{c}\text { Ages } \\
\text { [days] }\end{array}$} & \multicolumn{9}{|c|}{$\begin{array}{c}\text { 1688 (RSD) } \\
\text { Quantity PE } \\
\text { [ng/cm] }\end{array}$} & \multicolumn{2}{|c|}{$\mathbf{R} \%$} & \multicolumn{2}{|c|}{ RPA(PE/BA) } & \multicolumn{2}{|c|}{ R\%* $^{*}$} \\
\hline 5 & 85 & $( \pm 18 \%)$ & 40 & $( \pm 12 \%)$ & 6.0 & $( \pm 8 \%)$ & 39 & $( \pm 6 \%)$ \\
\hline 17 & 64 & $( \pm 6 \%)$ & 37 & $( \pm 15 \%)$ & 5.2 & $( \pm 10 \%)$ & 35 & $( \pm 15 \%)$ \\
\hline 55 & 48 & $( \pm 8 \%)$ & 27 & $( \pm 12 \%)$ & 4.3 & $( \pm 6 \%)$ & 28 & $( \pm 8 \%)$ \\
\hline 70 & 47 & $( \pm 11 \%)$ & 29 & $( \pm 14 \%)$ & 4.2 & $( \pm 2 \%)$ & 27 & $( \pm 2 \%)$ \\
\hline 115 & 40 & $( \pm 9 \%)$ & 26 & $( \pm 32 \%)$ & 4.3 & $( \pm 23 \%)$ & 30 & $( \pm 16 \%)$ \\
\hline 200 & 36 & $( \pm 21 \%)$ & 23 & $( \pm 38 \%)$ & 4.0 & $( \pm 4 \%)$ & 23 & $( \pm 11 \%)$ \\
\hline
\end{tabular}

\section{Insert Figure 3}

The resulting $\mathrm{R} \%$ values were fitted with a double exponential decay (see Figure $2 \mathrm{~B}$ ). After an interval of $12 \pm 2$ days, the diminution of $R \%$ values reached its inflexion point at a value of $35 \pm 4 \%$ (see Table 4). The calculated slopes after the inflexion point and after 100 days were both significant and no level-off was identified after 1 year. The calculated RSD for R\% values increased significantly over time. Up to 70 days, RSD values varied between 12 and $15 \%$, while older samples showed RSD up to $38 \%$ (see Figure $2 \mathrm{~B}$ and Table 3 ). This actually is the first time that RSD values were evaluated over time (and not only at time $t=0$ ). Surprisingly, the variation of $R \%$ values increased over time, while PE quantities in the natural and heated samples (used to calculated $\mathrm{R} \%$ ) showed significantly lower variations. This may be due to the fact that after 75 days, both the quantities of PE in natural and heated samples showed very low and close concentrations. Thus, the calculation of $\mathrm{R} \%$ value may yield propagation of the uncertainty because two different samples were used. These results actually showed that the ageing parameter $\mathrm{R} \%$ did not minimize the variability of measurement, but in contrary did yield increased RSD values for older samples compared to PE quantities. This was not expected from earlier publications $[14,21,41]$ and the fact that 
measurements of older samples was less reproducible than fresh ones may represent a particular issue in real case situations (i.e., questioned ink entries are often older than 75 days). On the other hand, $\mathrm{R} \%$ did indeed allow following the ageing over a longer time period as it did not level off after 1 year like the PE quantities in ink samples.

\section{Relative peak areas between compounds (RPA)}

Another solution proposed in the literature to develop "mass-independent" ageing parameters suggests normalising PE quantities using different results recorded from the same ink sample or other endogen compounds. This may be realised either by calculating a ratio based on different amounts of $P E$ measured through sequential extractions of the same sample $[23,34,40-42,62]$ or by calculating the relative peak area (RPA) between different compounds detected in the ink lines $[16,22,41,42,48,50]$. The former solution was first proposed by Aginsky and requires a delicate and complex liquid extractions procedure that was never reproduced in other researches [62]. Later, Bügler et al. proposed sequential extractions of PE using thermal desorption $[10,49]$. For the second proposition based on RPA calculation, the criteria to select appropriate compounds were previously discussed $[22,41]$. Ideally, the numerator is the concentration of a compound that decreases over time (e.g., PE generally remains the selected target), while the denominator should be the concentration of a compound remaining stable over time. So far, proposed compounds for the denominator were dyes $[7,16,24,40,42,48]$ or phthalic anhydride [22,41]. In this study, other volatile compounds detected in ink 1688 were considered and studied over time: Benzyl alcohol (BA) and phenoxyethoxyethanol (PEE). PEE dried very slowly as previously reported [9], it was thus not stable over time (see Insert Figure 4A). On the other hand $B A$ also showed ageing, but so rapid that RPA (BA/PE- $\left.D_{2}\right)$ dropped from $2.4 \pm 0.6$ to $0.13 \pm 0.03$ in the first 3 days, representing a loss of $95 \%$. While its quantity still decreased very slowly to reach a value of $0.075 \pm 0.001$ after 1 year, it was considered as negligible compared to PE. The RPA(BA/PE- $\left.D_{2}\right)$ observed for artificially aged samples showed the same tendency. Thus, for ink 1688 the following new ageing parameter was calculated (Eq. 4):

\section{$\operatorname{RPA}(\mathrm{PE} / \mathrm{BA})$}

The obtained ageing curve presented a strong decrease and reached the inflexion point after $19 \pm 2$ days, representing a decrease of the RPA-value from $7.3 \pm 0.8$ to $4.9 \pm 0.4$ (see Table 4). Significant slopes were obtained (even after 100 days) showing no real level-off until one year (Figure 2C). Thus, this ageing parameter also allowed following the ageing of ink samples over a longer time than when using only PE quantities. In terms of reproducibility, RSD values varied comparatively to PE quantities between 2 and 23\% (Table 3). While this ageing parameter seems particularly promising, its usefulness should be further evaluated by 
considering other ink formulations. Indeed, while PE is found in $85 \%$ of ballpoint pen, the solvent BA is present in only approximately $60 \%$ of the ink formulations [9].

\section{Insert Figure 4}

\section{$\mathbf{R} \%$ *}

Finally, an alternative solvent loss ratio R\%* was proposed in this work using RPA values instead of PE quantities from natural and heated samples, this allowed the parameter to be mass independent. Obtained $\mathrm{R} \%{ }^{*}$ values actually were of the same magnitude as the original $\mathrm{R} \%$ (Table 3 ) and the ageing curve showed comparable regression parameters (Figure 2B and D and Table 4), as well as similar inflexion point and slopes values. Additionally, the RSD values were significantly better than the one calculated for the other parameters with a maximal value well under $20 \%$ (Table 3 ). Thus, the proposed new R\%* seemed particularly promising compared to the other ageing parameters. Indeed, it did not level off after one year and actually allowed minimizing significantly the variability. However, it presupposed the identification of stable volatile compounds whatever the ink in order to be applicable to casework situations (i.e. particularly when the ink is unknown).

\subsection{Factors influencing the ageing}

\subsubsection{Ink formulation}

Ink formulation is one of the factors known to influence greatly the ageing dynamics $[9,10,14,19,21,33,40,41,43,45]$. Thus, the influence of three different inks on the ageing parameters was evaluated using samples stored in an air conditioned laboratory. These inks were selected by the InCID group as representative of slow (1774), middle (1688) and fast (1892) ageing dynamics. As expected three considerably different ageing curves were obtained for each ink no matter the calculated ageing parameter (Figure 5).

\section{Quantity of PE}

The initial quantities of PE were significantly different between the inks confirming previous results [28]:

- $1276 \pm 228 \mathrm{ng} / \mathrm{cm}$ for ink 1688 ,

- $682 \pm 38 \mathrm{ng} / \mathrm{cm}$ for ink 1774 ,

• $603 \pm 61 \mathrm{ng} / \mathrm{cm}$ for ink 1892 .

These amounts decreased very quickly the first hours, and after 1 day, the amounts were only 7 to $16 \%$ of the initial quantities (see start values in Table 4). After that, the decrease 
slowed down and the residual amount of PE in ink lines after one year reached (see level-off values in Table 4):

- $37 \pm 6 \mathrm{ng} / \mathrm{cm}$ for ink 1688

$\cdot 22 \pm 4$ for ink 1774 ,

- $16 \pm 5 \mathrm{ng} / \mathrm{cm}$ for ink 1892

The inflexion intervals were also significantly different and non-correlated to the initial amounts:

- $27 \pm 3$ days for ink 1688 ,

$\cdot 81 \pm 10$ days for ink 1774

$\cdot 9 \pm 1$ days for ink 1892 .

These values actually corroborated the classification established by the InCID with ink 1688 as middle, 1774 as slow and 1892 as fast ageing inks. After the inflexion point, inks 1688 and 1892 still presented significant slopes, while after 100 days, no ageing was statistically detected in any of the investigated inks (Table 4).

In terms of intervariability (i.e., variability between different inks), the RSD reached $42 \%$ (1 day) and $43 \%$ (level-off values).

\section{Relative peak areas between compounds (RPA)}

While the RPA previously determined for ink 1688 was applicable to ink 1892, the solvent BA was not contained in the formulation of ink 1774. Thus, new RPA had to be defined and evaluated. In order to identify as many candidates as possible to calculate alternative RPA, the solvents contained in inks 1774 and 1892 were studied over time (Figure 4B and C): dimethylcyclohexadienone (DMCH), hexylene glycol (HG) and dipropylene glycols isomers (DPG1, 2 and 3) were additionally detected (see Table 1). The DMCH was indeed stable over time in both inks (Figure 4B and C). While for ink 1774, RPA(DMCH/IS) value was 0.29 \pm 0.06 from 0 to 1 year, for ink 1892, this value quickly decreased the first day (approximate loss of $90 \%$ ) to reach a stable value of $0.12 \pm 0.02$ up to 1 year. $\mathrm{DMCH}$ was thus considered as a suitable denominator. In opposition, the amount of solvent HG detected in ink 1774 and 1982 decreased over time until approximately 100 days as well as DPG 1-3 in ink 1892 (Insert Figure $14 \mathrm{~B}$ and $\mathrm{C}$ ). Thus, only $\mathrm{DMCH}$ was considered as additional compound to calculate RPA. As ink 1892 possessed both BA and DMCH, two RPA were calculated for this ink in order to compare their reliability. The following RPA were calculated: 
- For ink 1688 and 1892:

$$
R P A(P E / B A)=\frac{P A(P E)}{P A(B A)}
$$

- For ink 1774 and 1892:

$$
R P A(P E / D M C H)=\frac{P A(P E)}{P A(D M C H)}
$$

The amounts used as denominator were very different (Figure 4) and yielded RPA that were not only different between inks, but also within ink 1892 (see Figure 5B). The obtained inflexion intervals varied between $19 \pm 2$ days for ink 1688, $64 \pm 8$ days for ink 1774, $5 \pm 1$ and $4 \pm 1$ days only for ink 1892 (Table 4), again confirming the InCID classification. After this point, the RPA calculated for inks 1688, 1774 and 1892 (PE/DMCH) still showed significant slopes (Table 4). After 100 days, only ink 1688 still presented a significant slope. The obtained correlation coefficients $R^{2}$ calculated for the regressions were particularly high showing the potential of such ageing parameters to reduce variability (Table 4).

\section{Solvent loss ratios $\mathrm{R} \%$ and $\mathrm{R} \%$ *}

$\mathrm{R} \%$ and $\mathrm{R} \%{ }^{*}$ values also showed large differences between inks (Figure $5 \mathrm{C}$ ). Ink 1774 possessed the highest values going from $70 \pm 3 \%$ (1 day) to $59 \pm 6 \%$ (level-off), while ink 1892 possessed the smallest values from $36 \pm 5 \%$ ( 1 day) to $7 \pm 5 \%$ (level-off) (Table 4). The inflexion intervals were lower than for the quantity of PE with $12 \pm 2$ days for ink 1688, $22 \pm 3$ days for ink 1774 and $6 \pm 1$ days for ink 1892 (Table 4), but still corroborated the InCID classification. A significant slope was detected only for ink 1688 irrespective of the period considered in the calculation. While this visually seemed correct for ink 1892, the values obtained for ink 1774 did not distinctively level off for ink 1774 after 100 days (Figure 5C). This may be explained by a lower regression correlation coefficient $R^{2}$ (Table 4), indicating a lower reproducibility of measurements for this ink. The alternative proposition $\mathrm{R} \%{ }^{*}$ yielded values comparable to $\mathrm{R} \%$ (see Table 4). The only exception was the calculated inflexion interval for ink 1774 that extended to $65 \pm 8$ days, as well as a higher $R^{2}$ value. This may indicate a significant reduction of the variability of data points (visible in Figure $5 \mathrm{C}$ ). As a direct consequence, a significant slope was observed after the inflexion point for ink 1774 (Table 4).

In terms of intervariability, the calculation of RSD between inks confirmed the tendency to increased RSD for R\%* values over time going from $23 \%$ (start values) to $120 \%$ (level-off or values after ca. 1 year). The same order of magnitude was observed for $\mathrm{R} \%$.

\section{Insert Figure 5 and 6 as follows if possible}



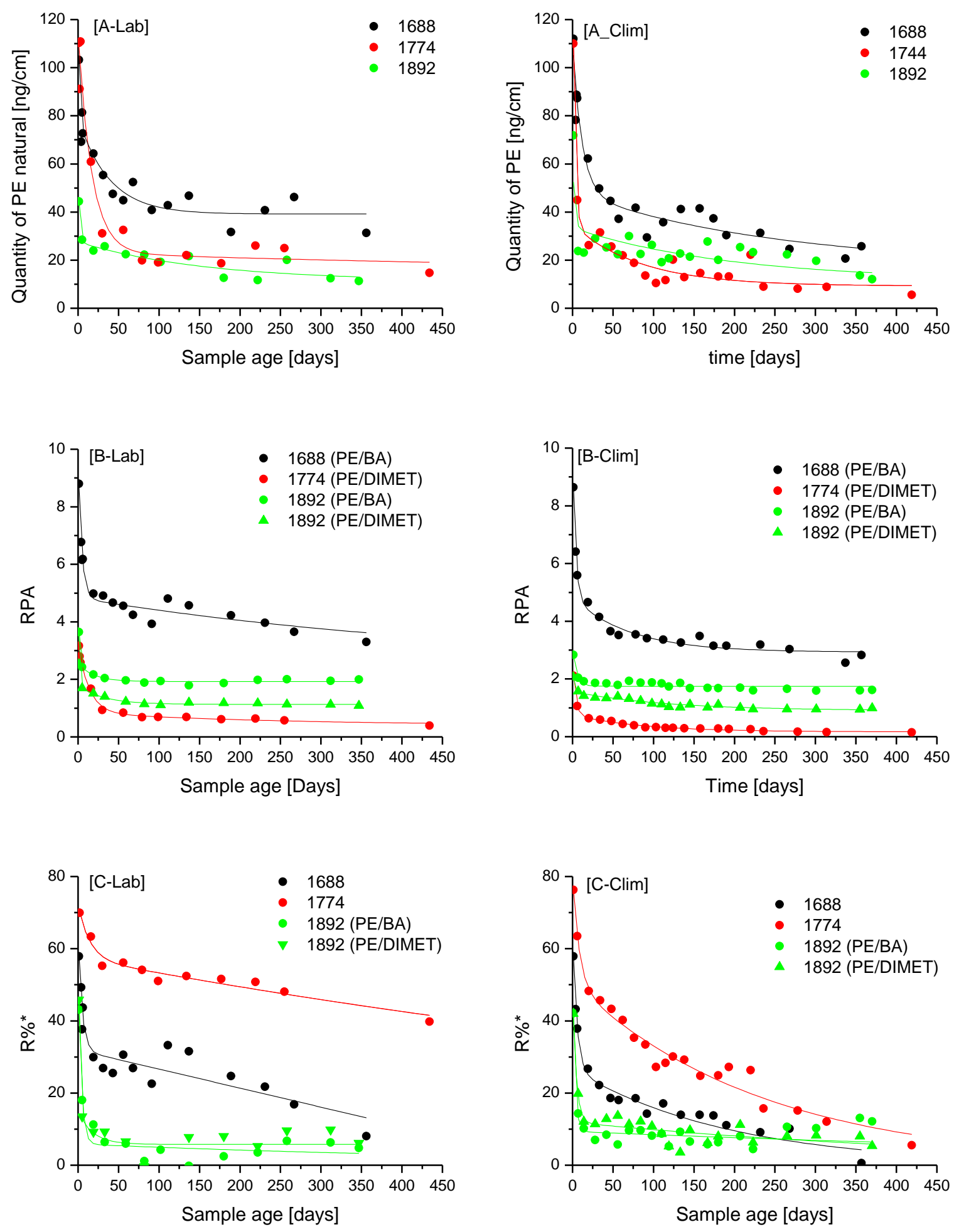

Figure 5: $\quad$ Ageing curve of ink 1688, 1774, 1892 stored in the laboratory and built with $A$ : the natural quantities of $P E, B$. ratios of ink compounds, C. R\% calculated with RPA.

Figure 6 : $\quad$ Ageing curve of ink 1688, 1774, 1892 stored in the climatic chamber and built with $A$ : the natural quantities of $P E$, B. ratios of ink compounds, C. R\% calculated with RPA. 
Table 4 : Data extracted from the calculated regressions for three inks 1688,1774 and 1892: ageing parameter $(A P)$ values, correlation coefficient of the fit $\left(R^{2}\right)$, start value ( $\mathrm{t}=1$ day), level-off value ( $\mathrm{t}=1$ year), inflexion point value and interval (IP), and obtained slopes after IP interval and 100 days.

\begin{tabular}{|c|c|c|c|c|c|c|c|c|}
\hline \multirow[b]{2}{*}{ AP } & \multirow[b]{2}{*}{ ink } & \multirow[b]{2}{*}{$\mathrm{R}^{2}$} & \multirow{2}{*}{$\begin{array}{l}\text { Start AP } \\
\text { value } \\
(\mathrm{t}=1 \text { day })\end{array}$} & \multirow{2}{*}{$\begin{array}{l}\text { Level-off } \\
\text { AP value } \\
\text { (1 year) }\end{array}$} & \multicolumn{2}{|c|}{ Inflexion point } & \multicolumn{2}{|c|}{ Slope } \\
\hline & & & & & AP value & $\begin{array}{l}\text { Interval } \\
\text { [days] }\end{array}$ & $\begin{array}{c}\text { IP }-356 \\
\text { days }\end{array}$ & $\begin{array}{c}100-365 \\
\text { days }\end{array}$ \\
\hline \multirow{3}{*}{$\begin{array}{c}\mathrm{PE} \\
{[\mathrm{ng} / \mathrm{cm}]}\end{array}$} & 1688 & 0.93 & $103 \pm 15$ & $37 \pm 6$ & $57 \pm 8$ & $27 \pm 3$ & -0.0730 & n.s. \\
\hline & 1774 & 0.97 & $110 \pm 11$ & $22 \pm 4$ & $23 \pm 10$ & $81 \pm 10$ & n.s. & n.s. \\
\hline & 1892 & 0.91 & $44 \pm 6$ & $16 \pm 5$ & $27 \pm 5$ & $9 \pm 1$ & -0.0400 & n.s. \\
\hline \multirow{3}{*}{ RPA } & 1774 (PE/DMCH) & 0.99 & $3.2 \pm 0.1$ & $0.6 \pm 0.1$ & $0.8 \pm 0.2$ & $64 \pm 8$ & -0.0006 & n.s. \\
\hline & 1892 (PE/BA) & 0.99 & $3.6 \pm 0.1$ & $1.9 \pm 0.1$ & $2.7 \pm 0.3$ & $5 \pm 1$ & n.s. & n.s. \\
\hline & 1892 (PE/DMCH) & 0.99 & $2.5 \pm 0.1$ & $1.1 \pm 0.0$ & $2.1 \pm 0.1$ & $4 \pm 1$ & -0.0010 & n.s. \\
\hline \multirow[b]{2}{*}{$\mathrm{R} \%$} & 1688 & 0.92 & $62 \pm 8 \%$ & n.l. $(16 \%)$ & $35 \pm 4 \%$ & $12 \pm 2$ & -0.0580 & -0.0580 \\
\hline & 1774 & 0.80 & $70 \pm 3 \%$ & $59 \pm 6 \%$ & $63 \pm 10 \%$ & $22 \pm 3$ & n.s. & n.s. \\
\hline \multirow{4}{*}{$\mathrm{R} \%$ * } & 1688 (PE/BA) & 0.90 & $58 \pm 8 \%$ & n.l. $(8 \%)$ & $35 \pm 5 \%$ & $14 \pm 2$ & -0.0540 & -0.0810 \\
\hline & 1774 (PE/DMCH) & 0.96 & $70 \pm 3 \%$ & $50 \pm 1 \%$ & $55 \pm 1 \%$ & $65 \pm 8$ & -0.0240 & n.s. \\
\hline & 1892 (PE/BA) & 0.97 & $43 \pm 5 \%$ & $5 \pm 2 \%$ & $33 \pm 13 \%$ & $4 \pm 0$ & n.s. & n.s. \\
\hline & 1892 (PE/DMCH) & 0.99 & $48 \pm 7 \%$ & $6 \pm 4 \%$ & $12 \pm 7 \%$ & $7 \pm 1$ & n.s. & n.s. \\
\hline
\end{tabular}

n.l no level off observed

n.s. not significant 


\subsubsection{Writing pressure}

The pressure applied to the ballpoint pen when a questioned ink entry is written is an important influence factor. In fact, questioned ink entries will never be straight lines applied with controlled pressure on paper, but will be applied with uncontrolled and varying form and pressure along the line (i.e., it is more a specimen than a sample [63]). Thus, the ageing parameters should ideally be unaffected by the pressure. However, preliminary results on the subject indicated a significant influence on some ageing parameters [10]. In order to evaluate this influence, ink 1688 samples were applied at different controlled pressure of 100, 250 and $350 \mathrm{~g}[56]$, as well as uncontrolled pressure from two different writers.

\section{Quantity of PE}

Logically, the more pressure was applied to draw the line, the more PE was transferred on paper (Insert Figure 7A). After 2 minutes, the quantity of PE in the $100 \mathrm{~g}$ ink lines was $195 \pm$ $19 \mathrm{ng} / \mathrm{cm}$, for $250 \mathrm{~g}$ it was of $557 \pm 125 \mathrm{ng} / \mathrm{cm}$, and for $350 \mathrm{~g}$ it was $992 \pm 16 \mathrm{ng} / \mathrm{cm}$, namely 5 times more than the quantity in $100 \mathrm{~g}$ ink lines. The difference between the different pressures was more important for fresh samples than for older samples (see 1 and 98 days values in Table 5). While, RSD values between different pressures reached $69 \%$ initially, it decreased to $22 \%$ for 1 day old inks and $13 \%$ for 98 days old inks. The resulting ageing curves were indeed different especially the $100 \mathrm{~g}$ pressure curve that yielded an inflexion interval of $8 \pm 1$ days (Insert Figure 7A). Curves for 250 and $350 \mathrm{~g}$ were more similar, since both sets of measurements overlapped after 20 days and their inflexion intervals were both at $12 \pm 1$ days. The quantities obtained from two different writers using uncontrolled pressure showed the considerable differences obtained in realistic conditions. While the first writer drew lines with a pressure lower than $100 \mathrm{~g}$, the second writer yielded results between $100 \mathrm{~g}$ and $250 \mathrm{~g}$ pressures (Insert Figure 7A).

In addition, it was also observed that the ink line width changed with the pressure $(n=12)$ : $100 \mathrm{~g}$ pressure yielded an ink line width of $269 \pm 13 \mu \mathrm{m}, 250 \mathrm{~g}$ yielded $351 \pm 20 \mu \mathrm{m}$ and 350 $g$ yielded $396 \pm 13 \mu \mathrm{m}$. Thus, normalisation of the quantity of PE by the mean ink line surface was used to significantly reduce the influence of different writing pressures (Insert Figure 8 A). Indeed, normalised data for 1 day old samples yielded values of $19 \pm 4,24 \pm 2$ and $26 \pm$ $3 \mathrm{ng} / \mathrm{mm}^{2}$ of ink line for 100,200 and $350 \mathrm{~g}$ respectively (RSD of 7\%). Normalisation for 98 days old samples yielded values of $9 \pm 3,10 \pm 2$ and $11 \pm 2 \mathrm{ng} / \mathrm{mm}^{2}$ of ink line for 100,200 and $350 \mathrm{~g}$ respectively $(\mathrm{RSD}=7 \%)$. In practice, calculating the ink line surface may thus help to considerably reduce the influence of uncontrolled writing pressure. However, as pressure and width are rarely homogeneous along writing, it should then be calculated for each 
sampled microplug or averaged for a given questioned ink. This might be a difficult task and it should be tested on realistic samples such as signature to insure its practical feasibility.

\section{RPA}

The calculation of RPA (PE/BA) allowed obtaining values and ageing curves that were very close from each other, even overlapping (Figure 7B). This was shown with the values for 1 day-old samples that were of $8.8 \pm 0.6,8.0 \pm 0.2$ and $8.2 \pm 0.2$ for 100,250 and $350 \mathrm{~g}$ respectively (RSD of $8.0 \%$ ) (Table 5). The values for 98 days samples were of $2.9 \pm 0.2$ (100 g) and $3.1 \pm 0.2(250$ and $350 \mathrm{~g}$ ), namely a RSD of $3.4 \%$ (Table 5). This variability was actually lower than the one obtained for the quantity of PE normalised to the ink line surface. The inflexion intervals were also comparable: $5.7 \pm 0.2(100 \mathrm{~g}), 5.3 \pm 0.3(200 \mathrm{~g})$ and $5.7 \pm 0.5$ $(300 \mathrm{~g})$ days (Table 5$)$. In terms of uncontrolled pressures, samples from both writers were logically more variable, but still showed values close to those of controlled pressures (see Figure 7B). These results showed that writing pressure had little influence on RPA values and these can thus be considered as mass-independent ageing parameters.

\section{Solvent Loss Ratio R\% and $\mathrm{R} \%{ }^{*}$}

Like for PE quantity, low pressure affected more significantly the solvent loss ratios $(\mathrm{R} \%$ and $\mathrm{R} \%{ }^{*}$ ) than higher pressures (see Insert Figure $7 \mathrm{C}$ and Table 5). The R\%* values obtained for 1 day-old sample were $46 \pm 9 \%$ (100g), $52 \pm 4 \%$ (250g) and $51 \pm 2 \%(350 \mathrm{~g})$, yielding a RSD of $12 \%$. For 98 days samples, the $\mathrm{R} \%{ }^{*}$ were $5 \pm 2,7 \pm 4$ and $12 \pm 3 \%$, yielding a RSD of $47 \%$. On the contrary to PE quantities, these results indicated that $\mathrm{R} \%{ }^{*}$ of older sample were more influenced by the pressure than younger samples. This was also confirmed by the results obtained for two different writers, yielding similar values for 1 day old samples $(50 \pm 6$ and $51 \pm 6$ ), while values obtained for older samples were significantly different $(15 \pm 4$ against $26+2$ ). In terms of ageing curves, the calculated inflexion intervals for the different pressure remained comparable: $7 \pm 1$ days (for $100 \mathrm{~g}$ and $250 \mathrm{~g}$ ) and $9 \pm 1$ days (for $350 \mathrm{~g}$ ).

As $R \%{ }^{*}$ was significantly influenced by the writing pressure and not RPA (from which the ratio is calculated), this indicated that pressure influenced more particularly the artificial ageing step. In fact the heated RPA values obtained for $100 \mathrm{~g}$ were distinctly above the others. More research will be needed to determine exactly if it is possible to reduce pressure influence in uncontrolled conditions. One possibility would be to reduce the variation through normalisation of $\mathrm{R} \%$ and $\mathrm{R} \%{ }^{*}$ values using the ink line surface. Similarly to PE quantity, this allowed reducing the differences between the $100 \mathrm{~g}$ curve and the 250 and $350 \mathrm{~g}$ curves (see Figure 8B). However, RSD remained significant. 
Table 5 : $\quad$ Data extracted from the calculated regressions for ink 1688 at different writing pressures: ageing parameter values (AP), correlation coefficient of the fit $\left(R^{2}\right)$, start value $(t=1$ day), end value $(t=98$ days), inflexion point value and interval (IP).

\begin{tabular}{|c|c|c|c|c|c|c|}
\hline \multirow[b]{2}{*}{ AP } & \multirow[b]{2}{*}{$\begin{array}{c}\text { Pressure } \\
\text { [g] }\end{array}$} & \multirow[b]{2}{*}{$\mathrm{R}^{2}$} & \multirow{2}{*}{$\begin{array}{c}\text { Start AP } \\
\text { value } \\
\text { (1 day) }\end{array}$} & \multirow{2}{*}{$\begin{array}{l}\text { End AP value } \\
\text { (98 days) }\end{array}$} & \multicolumn{2}{|c|}{ Inflexion point } \\
\hline & & & & & $\begin{array}{c}\text { AP } \\
\text { value }\end{array}$ & $\begin{array}{c}\text { Interval } \\
\text { [days] }\end{array}$ \\
\hline \multirow{3}{*}{$\begin{array}{c}\mathrm{PE} \\
{[\mathrm{ng} / \mathrm{cm}]}\end{array}$} & 100 & 0.92 & $107 \pm 23$ & $28 \pm 7$ & $56 \pm 7$ & $8 \pm 1$ \\
\hline & 250 & 0.90 & $123 \pm 11$ & $36 \pm 10$ & $82 \pm 15$ & $12 \pm 1$ \\
\hline & 350 & 0.95 & $161 \pm 21$ & $36 \pm 6$ & $97 \pm 12$ & $12 \pm 1$ \\
\hline \multirow{3}{*}{ RPA } & 100 & 0.98 & $8.8 \pm 0.6$ & $2.9 \pm 0.2$ & $5.7 \pm 0.2$ & $5 \pm 1$ \\
\hline & 250 & 0.96 & $8.0 \pm 0.2$ & $3.1 \pm 0.2$ & $5.3 \pm 0.3$ & $9 \pm 1$ \\
\hline & 350 & 0.98 & $8.2 \pm 0.3$ & $3.1 \pm 0.2$ & $5.7 \pm 0.5$ & $5 \pm 1$ \\
\hline \multirow{3}{*}{$\mathrm{R} \%$} & 100 & 0.55 & $47 \pm 8 \%$ & $18 \pm 7 \%$ & $36 \pm 7 \%$ & $2 \pm 0$ \\
\hline & 250 & 0.88 & $48 \pm 4 \%$ & $15 \pm 5 \%$ & $42 \pm 6 \%$ & $14 \pm 2$ \\
\hline & 350 & 0.91 & $47 \pm 3 \%$ & $28 \pm 4 \%$ & $42 \pm 8 \%$ & $13 \pm 2$ \\
\hline \multirow{3}{*}{$R \%$ * } & 100 & 0.9 & $46 \pm 10 \%$ & $5 \pm 2 \%$ & $31 \pm 6 \%$ & $7 \pm 1$ \\
\hline & 250 & 0.94 & $44 \pm 4 \%$ & $7 \pm 4 \%$ & $41 \pm 5 \%$ & $7 \pm 1$ \\
\hline & 350 & 0.90 & $47 \pm 4 \%$ & $12 \pm 3 \%$ & $40 \pm 3 \%$ & $9 \pm 1$ \\
\hline
\end{tabular}

\section{Insert Figure 7}

\section{Insert Figure 8}

\subsubsection{Storage conditions:}

While the effect of temperature on the solvent ageing dynamics was previously studied $[9,62]$, the influence of different kind of realistic conditions was never evaluated. Therefore, entries from inks 1688, 1774 and 1892 were stored in a laboratory (air conditioned at $23 \pm$ $\left.1^{\circ} \mathrm{C}\right)$ and in a climatic cupboard $\left(20^{\circ} \mathrm{C}\right.$ and $55 \%$ of humidity). The results showed that the influence of the storage conditions was complex and difficult to characterize. In fact, it differed depending from the ageing parameter and ink considered (see Figure 6)

\section{PE quantity}

The quantities of PE recovered in samples stored in a climatic cupboard were slightly lower than those in samples stored in the laboratory for all inks until 100 days (see Figure $6 \mathrm{~A}$ and 
level-off values in Table 6 compared to Table 4). After 1 year, no more differences between storage conditions could be observed for ink 1892. The obtained inflexion intervals were significantly different for ink 1688 and 1774 indicating two different ageing dynamics:

- For ink 1688 , the mean value raised from $27 \pm 3$ (laboratory) to $51 \pm 6$ days (climatic cupboard),

- For ink 1774 , the mean value decreased from $81 \pm 10$ (laboratory) to $20 \pm 2$ days (climatic cupboard),

- For ink 1892, the mean value remained comparable with $9 \pm 1$ (laboratory) and $7 \pm 1$ days (climatic cupboard).

The quantity of PE found in ink 1892 samples stored in the climatic cupboard after 1 year was similar to the quantity found in the laboratory (Table 4 and 6), while it was 1.4 and 2.5 times smaller for inks 1688 and 1774 respectively. These results showed that the influence of storage conditions was lower for the fast ageing ink (1892). For samples from ink 1774, the inflexion interval was lower than for ink 1688 in the climatic cupboard (thus inversing the InCID classification). In addition descending slopes were observed longer for all inks.

The main difference between the two storage conditions lies in the presence of an air fan in the climatic cupboard to maintain a constant humidity. This induces air movements inside the chamber that may considerably accelerate the solvent evaporation, explaining why the PE quantity in ink stroke decreased more significantly in the climatic cupboard (particularly for inks 1688 and 1744). This may also explain why decreasing slopes could be detected over longer periods of time.

\section{RPA}

The RPA values obtained for samples stored in the climatic cupboard were also lower than for samples stored in the laboratory (see Figure 6B and Table 6). Their inflexion intervals were reached before 20 days:

- For ink 1688, the inflexion point values and intervals remained comparable between the different storage conditions (18-19 days). However after that point, the ageing dynamics were significantly faster in the climatic cupboard. After 100 days, the values differed of $30 \%$ between the two storage conditions.

- For ink 1774, the inflexion interval decreased from $64 \pm 8$ (laboratory) to $18 \pm 2$ days (climatic cupboard). After that point the RPA values kept decreasing for samples stored in the climatic cupboard, while it stopped after 100 days for sample stored in the laboratory. 
- For ink 1892, the inflexion interval increased from $5 \pm 1$ (laboratory) to $11 \pm 2$ days (climatic cupboard) for both calculated RPA. After those points, values kept decreasing after 100 days, indicating that the ageing occurred over longer periods of time compared to samples stored in the laboratory.

Interestingly, the "stable" compounds BA and DMCH were not influenced significantly by the storage conditions proving their actual stability. These results show a similar impact of the storage conditions on the RPA ageing kinetic compared to PE quantity. Indeed, the level-off values for inks 1688 and 1774 were 1.2 and 3 times lower in the climatic cupboard. For ink 1892, the level-off RPA (PE/BA) were 1.2 times lower in the climatic cupboard, while the level-off RPA (PE/DMCH) were similar between storage conditions.

\section{Solvent Loss Ratio $\mathrm{R} \%$ and $\mathrm{R} \%$ *}

The solvent loss ratios were also influenced by the storage conditions; especially inks 1688 and 1774 (see Figures 5 and 6; and Table 6). The obtained values as well as the ageing dynamics were significantly different. For example, obtained inflexion intervals for $\mathrm{R} \%$ * differed as follows between the storage conditions:

- For ink 1688, the interval increased from $14 \pm 2$ (laboratory) to $25 \pm 3$ days (climatic cupboard).

- For ink 1774 , the interval decreased from $65 \pm 8$ (laboratory) to $43 \pm 2$ days (climatic cupboard).

- For ink 1892, the interval increased from $4 \pm 0$ (laboratory) to $13 \pm 2$ days (climatic cupboard) for RPA(PE/BA). A comparable diminution was observed for RPA(PE/DMCH) (see Table 6).

While the inflexion intervals were similar for $\mathrm{R} \%$ values, the inflexion values obtained for $\mathrm{R} \%$ generally differed from the $\mathrm{R} \%{ }^{*}$ (see Table 6 ). This may partly be explained by lower correlation coefficient values obtained for this parameter compared to $R \%{ }^{*}\left(R^{2}\right.$ values, Table $6)$, thus influencing the regression parameters.

While globally the InCID classification was confirmed for samples stored in the climatic chamber, the $\mathrm{R} \%$ and $\mathrm{R} \%{ }^{*}$ values were significantly affected by this kind of storage. In fact, the values found at the level-off stage for the climatic cupboard was 4 times lower for 1774 and 8 times lower for ink 1688 than the values obtained for the laboratory. No differences was observed for ink 1892 irrespective of the RPA used in the R\% and R\%* calculation. These differences may be explained by the fact that PE quantities in the heated samples used to calculate the $\mathrm{R} \%$ and $\mathrm{R} \%{ }^{*}$ were only slightly influenced by storage conditions in 
comparison to PE quantities in natural samples, thus yielding lower $R \%$ and $R \%$ * for the climatic cupboard. This was more pronounced for slower ageing inks.

These results were similar to those obtained in a previous study that tested the influence of storage conditions using the TD-GC/MS [49]. The calculated ageing parameter V\% was also significantly influenced by the storage in the climatic chamber with the same conditions $\left(20^{\circ} \mathrm{C}, 55 \%\right.$ humidity, and air fan at $\left.50 \%\right)$. 
Table 6 : Characteristics of ageing curves of ink 1688, 1774 and 1892 stored in the climatic cupboard for the ageing parameter PE, RPA, and R\%*.

\begin{tabular}{|c|c|c|c|c|c|c|c|c|}
\hline \multirow[b]{2}{*}{ AP } & \multirow[b]{2}{*}{ ink } & \multirow[b]{2}{*}{$\mathrm{R}^{2}$} & \multirow{2}{*}{$\begin{array}{l}1 \text { day AP } \\
\text { value }\end{array}$} & \multirow{2}{*}{$\begin{array}{l}\text { Level-off } \\
\text { AP value } \\
\text { (1 year) }\end{array}$} & \multicolumn{2}{|c|}{ Inflexion point } & \multicolumn{2}{|c|}{ Slope } \\
\hline & & & & & AP Value & Interval [days] & $\begin{array}{c}\text { IP }-365 \\
\text { days }\end{array}$ & $\begin{array}{c}100-365 \\
\text { days }\end{array}$ \\
\hline \multirow{3}{*}{$\begin{array}{c}\mathrm{PE} \\
{[\mathrm{ng} / \mathrm{cm}]}\end{array}$} & 1688 & 0.95 & $112 \pm 22$ & n.l (26) & $42 \pm 8$ & $51 \pm 6$ & -0.0556 & -0.0746 \\
\hline & 1774 & 0.93 & $73 \pm 14$ & $9 \pm 3$ & $30 \pm 6$ & $20 \pm 2$ & -0.0542 & n.s. \\
\hline & 1892 & 0.92 & $71 \pm 14$ & n.l (12) & $32 \pm 12$ & $7 \pm 1$ & -0.028 & -0.031 \\
\hline \multirow{4}{*}{ RPA } & 1688 (PE/BA) & 0.99 & $8.6 \pm 0.2$ & n.l.(2.8) & $4.5 \pm 0.4$ & $18 \pm 2$ & -0.0040 & -0.0028 \\
\hline & 1774 (PE/DMCH) & 0.98 & $2.1 \pm 0.1$ & n.l. $(0.2)$ & $0.7 \pm 0.1$ & $18 \pm 2$ & -0.0016 & -0.0008 \\
\hline & 1892 (PE/BA) & 0.96 & $2.8 \pm 0.2$ & n.l.(1.6) & $2.0 \pm 0.1$ & $11 \pm 2$ & -0.0009 & -0.0008 \\
\hline & 1892 (PE/DMCH) & 0.98 & $2.1 \pm 0.1$ & n.l.(1.0) & $1.5 \pm 0.2$ & $12 \pm 1$ & -0.0013 & -0.0005 \\
\hline \multirow{3}{*}{$\mathrm{R} \%$} & 1688 & 0.86 & $58 \pm 6 \%$ & $11 \pm 3 \%$ & $15 \pm 4 \%$ & $56 \pm 6$ & n.s. & n.s. \\
\hline & 1774 & 0.71 & $55 \pm 5 \%$ & n.l. (2 \%) & $55 \pm 10 \%$ & $24 \pm 3$ & -0.1117 & -0.1270 \\
\hline & 1892 & 0.52 & $34 \pm 7 \%$ & $7 \pm 7 \%$ & $11 \pm 7 \%$ & $12 \pm 2$ & n.s. & n.s. \\
\hline \multirow{4}{*}{$\mathrm{R} \%$ * } & 1688 (PE/BA) & 0.97 & $58 \pm 6 \%$ & n.l.(1 \%) & $24 \pm 4 \%$ & $25 \pm 3$ & -0.0630 & -0.0714 \\
\hline & 1774 (PE/DMCH) & 0.96 & $76 \pm 6 \%$ & n.l.(12 \%) & $42 \pm 5 \%$ & $43 \pm 5$ & -0.1017 & -0.0818 \\
\hline & 1892 (PE/BA) & 0.98 & $42 \pm 5 \%$ & $8 \pm 2 \%$ & $10 \pm 6 \%$ & $13 \pm 2$ & n.s. & n.s. \\
\hline & 1892 (PE/DMCH) & 0.91 & $42 \pm 6 \%$ & $7 \pm 2 \%$ & $13 \pm 6 \%$ & $20 \pm 2$ & n.s. & n.s. \\
\hline
\end{tabular}

n.l. no level off observed

n.s. not significant 
Table 7 : Summary of the advantages and disadvantages of four ageing parameters (IP = inflexion point)

\begin{tabular}{|c|c|c|c|c|}
\hline \multirow{2}{*}{ Ageing parameter } & \multirow{2}{*}{ PE quantity } & \multirow{2}{*}{ RPA } & \multicolumn{2}{|c|}{ Solvent loss ratio } \\
\hline & & & $\mathrm{R} \%$ & $\mathrm{R} \%{ }^{*}$ \\
\hline Mass independence & no & yes & no & yes \\
\hline Reproducibility (RSD) & $6<x<21 \%$ & $2<x<23 \%$ & $12<x<38 \%$ & $2<x<16 \%$ \\
\hline $\begin{array}{l}\text { Slope detection [days] } \\
\text { ink } 1688 \\
\text { Ink } 1744 \\
\text { Ink } 1892\end{array}$ & $\begin{aligned} \mathrm{IP}<\mathrm{x} & <100 \\
\mathrm{x} & <\mathrm{IP} \\
\mathrm{IP}<\mathrm{x} & <100\end{aligned}$ & $\begin{aligned} 100 & <x \\
I P & <x<100 \\
I P & <x<100\end{aligned}$ & $\begin{array}{r}100<x \\
x<I P \\
x<I P\end{array}$ & $\begin{array}{c}100<x \\
I P<x<100 \\
x<I P\end{array}$ \\
\hline $\begin{array}{l}\text { Influenced by: } \\
\text { Ink composition } \\
\text { Pressure } \\
\text { Storage conditions }\end{array}$ & $\begin{array}{c}\text { yes } \\
\text { yes } \\
\text { (possibility to } \\
\text { normalise) } \\
\text { ves }\end{array}$ & $\begin{array}{l}\text { yes } \\
\text { no } \\
\text { ves }\end{array}$ & $\begin{array}{r}y^{\prime} \\
\text { (possibility }\end{array}$ & normalise) \\
\hline
\end{tabular}

\subsection{From an ageing parameter study through an ink dating method}

Each ageing parameters has practical advantages and disadvantages (see Table 7). While the PE quantity and RPA do require only $1 \mathrm{~cm}$ samples, the $\mathrm{R} \%$ and $\mathrm{R} \%{ }^{*}$ approaches require $2 \mathrm{~cm}$ samples. In terms of repeatability, the R\% yielded the highest RSD values particularly for older samples (such as may be encountered in practical cases), while RPA gave the lowest RSD values. All parameters were significantly influenced by ink composition and storage conditions, while the writing pressure only influenced PE quantities and R\% and $\mathrm{R} \%{ }^{*}$. However, the influence of the writing pressure could be significantly reduced by normalising the results to the sampled ink surface. In terms of time range of ageing, the decrease of PE could generally be observed over shorter range compared to the other ageing parameters (see Table 7). Detection of slopes could be detected over longer time range for RPA values compared to $\mathrm{R} \%$ and $\mathrm{R} \%$ *.

Previous studies proposed interpretation models applicable for $\mathrm{R} \%$ and $\mathrm{R} \%{ }^{*}$. Thus, the use of other ageing parameters would require new studies on representative ink populations in order to define appropriate interpretation approaches. Three main interpretation models were proposed so far in the literature to interpret ink dating results in a legal perspective [33]. These approaches are discussed below considering the specificities of each proposed ageing parameters. 


\section{Decision thresholds}

Decision threshold values generally indicate the maximal possible age for a questioned ink entry $[14,21,41,43]$. These values are determined on a population of representative inks within a confidence interval (ideally taking into consideration influence factors). Among the proposed ageing parameters, threshold values were only proposed for the solvent loss ratio $\mathrm{R} \%$ so far in the literature. Previous studies indicated that a R\% value above $50 \%$ meant that the ink entry was less than 6 months old [14,21], and a value above $35 \%$ meant that the ink entry was less than 18 months [14]. As the $R \%$ * yielded comparable absolute values, the same model could be used. However, application of such thresholds on the presented results showed that, for slow ageing curves such as the one obtained for samples from ink 1774 stored in an air-conditioned laboratory, $\mathrm{R} \%$ and $\mathrm{R} \%{ }^{*}$ values above $50 \%$ were obtained until 7 to 8 months (namely up to 255 and 217 days respectively). These values would correspond to false positive results (i.e., using the pre-defined threshold of 6 months, one might conclude wrongly that a 255 days old ink 1774 entry is actually less than ca. 186 days). Other studied influence factors did not yield problematic results as they induced a faster decrease of the $\mathrm{R} \%$ and $\mathrm{R} \%{ }^{*}$ values, preventing the occurrence of false positive conclusions. In order to evaluate the potential of threshold values for the other ageing parameters, namely $\mathrm{PE}$ quantity and RPA values, a representative population of ink should be investigated. However, such interpretation models do not allow explicitly taking into account outliers and limit the range of application (e.g., it does not work for fast ageing inks as their values falls too quickly under the thresholds).

\section{Trend tests}

The trend tests are based on several measurements over time in order to evaluate if the sample still ages within a confidence interval. It was previously proposed to sample the question ink every two weeks after its reception (corresponding to 5 samples over 2 months) $[19,33,64]$. The Neumann test and the calculation of linear slopes were proposed to evaluate if an ink entry was still significantly ageing. In theory, such tests could be applied on all ageing parameters evaluated in this work. However, since they require the collection of several samples at regular time intervals, they do not seem adapted to the $\mathrm{R} \%$ and $\mathrm{R} \%{ }^{*}$. Indeed, it would require the analysis of $10 \mathrm{~cm}$ samples to calculate such ratios and this seems excessive in the perspective of a practical case (especially when investigating a questioned signature). Trend tests should then preferably be considered for the quantity of PE and RPA values (i.e. it still requires $5 \mathrm{~cm}$ ink). This type of interpretation model is negatively influenced by large RSD (i.e., high error rate may yield false positive or negative results [19]). Thus, normalised ageing parameters seemed to be more appropriate for these 
tests as they present a lower variability. Studied influencing factors did not yield problematic results as they induced a faster decrease of the ageing parameter values, preventing the detection of a trend or slope after a shorter time and also limiting the range of application. This model should also be evaluated on a population of representative inks in order to determine its actual potential to interpret dating results. More thoughts should be given to standardised storage conditions between the measurements in order to harmonise the conditions between reference population and questioned documents.

\section{Likelihood ratios}

Likelihood ratio calculations were proposed in order to determine under which alternative hypotheses the obtained results were more probable [65]. While this probabilistic model has the advantage of considering explicitly the error rate and can be applied in all kind of practical cases for all proposed ageing parameters, it also requires a population of representative inks. Moreover, at least two alternatives hypotheses about the age of the questioned inks should be formulated. These are generally the date on the document (hypothesis of the defence) and an ulterior date (hypothesis of the accusation). Such models still need to be tested on practical data.

\section{Conclusion}

This work confirmed that ink dating methods using liquid extraction followed by GC/MS analysis were easily applicable in a laboratory, proved to be sensitive enough for dating purpose and allowed measuring a wide range of concentrations corresponding to the concentrations commonly found in ink strokes. Four different ageing parameters were evaluated: the quantity of PE, the relative peak area (RPA) between different solvents and two solvent loss ratios calculated respectively from the PE quantity $(\mathrm{R} \%)$ and the RPA values $\left(\mathrm{R} \%{ }^{*}\right)$. Among those, two particularly interesting parameters, RPA and $\mathrm{R} \%{ }^{*}$ values for slow, medium, and fast drying inks were reported for the first time in the literature. In terms of variability, $R \%{ }^{*}$ proved to be the most repeatable parameter as the maximal RSD obtained was $16 \%$. In opposition, the R\% showed the highest variability with RSD values going up to $38 \%$ for older samples. Thus when RPA can be calculated, the R\%* should always be preferred to the $\mathrm{R} \%$ in order to reduce significantly the variability for the analysis of older ink samples.

Three influence factors were then tested: ink composition, writing pressure and storage conditions. As expected, the ink composition significantly influenced all tested parameters. This confirmed the need to extend this study to a representative ink reference population. 
RPA values were the most robust parameter as the pressure showed no influence, while normalisation should be considered to reduce the influence of varying writing pressure on the other parameters. Finally, the effect of storage conditions was correlated to the ink composition, as slow ageing inks were generally more influenced than the fast ageing ink. Although all ageing parameters were influenced by the storage conditions, $\mathrm{R} \%$ and $\mathrm{R} \%$ * values proved to be the most sensitive to storage in the climatic chamber.

If we assume that a good ageing parameter should:

- require as little ink sampling as possible,

- be repeatable for sample written and stored in similar conditions,

- present a large time frame of reliable measurements,

- be influenced as little as possible by the different factors typically encountered in caseworks,

- should work for as many ink formulations as possible

Then, the calculation of RPA values proved to be the most promising ageing parameter in this study, while the least reproducible was astonishingly the R\%. The parameters RPA and $\mathrm{R} \%{ }^{*}$ (which is built from RPAs) require the identification of a stable volatile component in the analysed ink. This requirement will have to be tested on a larger and representative population of inks to evaluate its feasibility.

Thus, further work will focus on the testing of the proposed ageing parameters using a larger population of inks, and on the development of a reliable interpretation model for ink dating results. 


\section{References}

[1] R.L. Brunelle, K.R. Crawford, Advances in the Forensic Analysis and Dating of Writing Ink. Charles C. Thomas Publisher, Ltd. Springfield, (2003).

[2] A.A. Cantu, A sketch of analytical methods for document dating Part I. The static approach: determining age independent analytical profiles. International Journal of Forensic Document Examiners 1 (1) (1995) 40-51.

[3] A.A. Cantu, A sketch of analytical methods for document dating part II. The dynamic approach: determining age dependent analytical profiles. International Journal of Forensic Document Examiners 2 (3) (1996) 192-208.

[4] M. Ezcurra, J.M.G. Góngora, I. Maguregui, R. Alonso, Analytical methods for dating modern writing instrument ink on paper. Forensic Science International 197 (1-3) (2010) 1-20.

[5] C. Weyermann, Revue des méthodes de datation de l'encre: Est-il possible de déterminer l'âge d'un document en analysant l'encre? Revue Internationale de Criminologie et de Police Technique et Scientifique 3 (LXI) (2008) 359-376.

[6] Y. Wang, L. Yao, P. Zhao, J. Wang, Y. Wang, Determining the relative age of blue ballpoint ink by gas chromatography. Frontiers of Chemistry in China 1 (2) (2006) 223-226.

[7] Y. Xu, J. Wang, L. Yao, Dating the writing age of black roller and gel inks by gas chromatography and UV-vis spectrophotometer. Forensic Science International 162 (1-3) (2006) 140-143.

[8] L. Brazeau, M. Gaudreau, Ballpoint pen inks: The quantitative analysis of ink solvents on paper by solid-phase microextraction. Journal of Forensic Sciences 52 (1) (2007) 209-215.

[9] C. Weyermann, D. Kirsch, C. Costa-Vera, B. Spengler, A GC/MS study of the drying of ballpoint pen ink on paper. Forensic Science International 168 (2-3) (2007) 119-127.

[10] J.H. Bugler, H. Buchner, A. Dallmayer, Age determination of ballpoint pen ink by thermal desorption and gas chromatography-mass spectrometry. Journal of Forensic Sciences 53 (4) (2008) 982-988.

[11] J. Andrasko, Some Examples of Applications of a Microthermal Desorption Device in the Forensic Laboratory. Journal of Forensic Sciences 54 (5) (2009) 1055-1058.

[12] M. Ezcurra, I. Velasco, J.M.G. Góngora, I. Maguregui, R. Alonso, Analysis of bic crystal medium ball point pen inks. Journal of the American Society of Questionned Document Examiners 12 (2) (2009) 57-68.

[13] Y.-T. Yao, J. Song, J. Yu, X.-F. Wang, F. Hou, A.-L. Zhang, Y. Liu, J. Han, M.-X. Xie, Differentiation and dating of red ink entries seals on document by HPLC and GC/MS. Journal of Separation Science 32 (17) (2009) 2919-2927. 
[14] M. Gaudreau, V. Aginsky, Essentials of the solvent loss ratio method, 68th Annual Conference of the American Society of Questionned Document Examiners (ASQDE), Victoria, USA, 2010.

[15] P.M. Lalli, G.B. Sanvido, J.S. Garcia, R. Haddad, R.G. Cosso, D.R.J. Maia, J.J. Zacca, A.O. Maldaner, M.N. Eberlin, Fingerprinting and aging of ink by easy ambient sonic-spray ionization mass spectrometry. Analyst 135 (4) (2010) 745-750.

[16] D. Kirsch, P. Seiler, B. Anheier, F. Koehler, A new approach for dating of ballpoint ink entries, 69th Annual Conference of the American Society of Questionned Document Examiners (ASQDE), Philadelphia, USA, 2011.

[17] Y. Wu, C.X. Zhou, J. Yu, H.L. Liu, M.X. Xie, Differentiation and dating of gel pen ink entries on paper by laser desorption ionization- and quadruple-time of flight mass spectrometry. Dyes and Pigments 94 (3) (2012) 525-532.

[18] B. Li, P. Xie, Y.-m. Guo, Q. Fei, GC Analysis of Black Gel Pen Ink Stored under Different Conditions. Journal of Forensic Sciences (2013) n/a-n/a.

[19] A. Koenig, J. Bügler, D. Kirsch, F. Köhler, C. Weyermann, Ink dating using thermal desorption and gas chromatography / mass spectrometry: Comparison of results obtained in two laboratories. Journal of Forensic Sciences In press (2014).

[20] B. Li, P. Xie, Y.-m. Guo, Q. Fei, GC Analysis of Black Gel Pen Ink Stored under Different Conditions. Journal of Forensic Sciences 59 (2) (2014) 543-549.

[21] M. Gaudreau, L. Brazeau, Ink dating, a solvent loss ratio method, 6th Annual Conference of the American Society of Questioned Document Examiners, San Diego, California, 2002.

[22] S. Lociciro, L. Dujourdy, W. Mazzella, P. Margot, E. Lock, Dynamic of the ageing of ballpoint pen inks: quantification of phenoxyethanol by GC-MS. Science and Justice 44 (3) (2004) 165171.

[23] J.H. Bügler, H. Buchner, A. Dallmayer, Age Determination of Ballpoint Ink by Thermal Desorption and Gas Chromatography-Mass Spectrometry, in: ASQDE (Ed.), 63 rd Annual Conference of the American Society for Questioned Document Examination (ASQDE), Montréal, Canada, 2005.

[24] Y. Wang, L. Yao, P. Zhao, J. Wang, Y. Wang, Determination of the Writing Age of Blue Ballpoint Ink by Gas Chromatography. Chinese Journal of Chromatography 23 (2) (2005) 202204.

[25] J. Andrasko, A simple microthermal desorption device. Journal of Forensic Sciences 51 (4) (2006) 925-928.

[26] J.H. Bügler, H. Buchner, A. Dallmayer, Age Determination of Ballpoint Pen Inks, in: I. ENFSI (Ed.), 4th Conference of the European Document Examiners Working Group (EDEWG), The Hague, Netherlands, 2006. 
[27] V.F. Samanidou, K.I. Nikolaidou, I.N. Papadoyannis, Development and validation of a gradient-HPLC-PDAD method for the identification of ballpoint pen ink components: Study of their decomposition on aging for forensic science applications. Journal of Liquid Chromatography \& Related Technologies 27 (2) (2004) 215-235.

[28] C. Weyermann, Mass spectrometric investigation of aging processes of ballpoint ink for the examination of questioned documents [dissertation], Faculty of biology and chemistry, JustusLiebig-University, 2005.

[29] D. Kirsch, F. Köhler, B. Spengler, Mass spectrometric investigation of resins in ballpoint ink, in: I. ENFSI (Ed.), European Academy of Forensic Science, Helsinki, 2006.

[30] C. Weyermann, D. Kirsch, C. Costa-Vera, B. Spengler, Photofading of Ballpoint Dyes Studied on Paper by LDI and MALDI MS. Journal of the American Society for Mass Spectrometry 17 (3) (2006) 297-306.

[31] P.C. Zhao, Y.J. Wang, Y.Y. Xu, J.H. Wan, Investigation of Accelerated Aging in Light and Writing Age of Roller Pen Inks. Spectroscopy and Spectral Analysis 28 (10) (2008) 23482351.

[32] V. Freidenfelds, P. Mekss, Determination of the relative age of ballpoint pen ink by HPLC, ENFSI, 6th European Document Examiners Working Group conference, Dubrovnik, Croatia, 2010.

[33] C. Weyermann, J. Almog, J. Bügler, A.A. Cantu, Minimum requirements for application of ink dating methods based on solvent analysis in casework. Forensic Science International 210 (13) (2011) 52-62.

[34] V.N. Aginsky, Measuring ink extractability as a function of age - why the relative aging approach is unreliable and why it is more correct to measure ink volatile components than dyes. International Journal of Forensic Document Examiners 4 (3) (1998) 214-230.

[35] T. Andermann, Solvent extraction techniques-possibilities for dating ball point pen inks. International Journal of Forensic Document Examiners 4 (3) (1998) 231-239.

[36] T. Hicks Champod, A. Khanmy, P. Margot, Ink aging: perspectives on standardization, in: W.B. B. Jacob, W. Huckenbeck \& P. Pieper (eds) (Ed.), 13th Meeting of the International Association of Forensic Sciences, Duesseldorf, 1993, Advances in Forensic Sciences 3, Forensic Criminalistics 1, Verlag Dr. Koester, Berlin, Duesseldorf, 1995, pp. 304-309.

[37] P. Margot, T. Hicks Champod, A. Khanmy, Ink Dating Up-Dated and Up-Ended Correspondance of Prof. Starrs. . International Journal of Forensic Document Examiners 1 (1) (1995) 2-5.

[38] C.R. Midkiff, J.E. Starrs, Ink dating - in footsteps of cold fusion. Scientific Sleuthing Review 18 (1) (1994) 1-6. 
[39] J.E. Starrs, Ink Dating Up-Dated and Up-Ended. International Journal of Forensic Document Examiners 1 (1) (1995) 3 - 5.

[40] V. Aginsky, Determination of the age of ballpoint pen ink by gas and densitometric thin-layer chromatography. Journal of Chromatography A 678 (1994) 119-125.

[41] V. Aginsky, Dating and characterizing writing, stamp, pad, and jet printer inks by gas chromatography/mass spectrometry. International Journal of Forensic Document Examiners 2 (2) (1996) 103-116.

[42] V.N. Aginsky, Some new ideas for dating ballpoint inks-a feasibility study Journal of Forensic Sciences 38 (5) (1993) 1134-1150.

[43] V.N. Aginsky, Current Methods for Dating Ink On Document, 60th annual Conference of the American Society of Questionned Document Examiner, San Diego, 2002.

[44] V.N. Aginsky, Using TLC and GC/MS to Determiner Wheteher Inks Came from the Same Manufacturing Batch. The American Society of Questioned Document Examiners 9 (1) (2006) 19-27.

[45] V.N. Aginsky, Current Methods for Dating Ink on Documents, 65th Annual Conference of the American Society of Questioned Document Examiners, Boulder, Colorado, 2007.

[46] J. Andrasko, Ink Dating Using SPME and Methanol Extraction, 3rd meeting of the European Network of Forensic Science Institutes, Istanbul, 2003.

[47] M. Ezcurra, J.M.G. Góngora, I. Maguregui, R. Alonso, Evaluation of loss of phenoxyethanol from a ballpoint pen ink over time by GC/MS depending on the location of the signature on the document. Journal of the American Society of Questionned Document Examiners 13 (1) (2010) 9-14.

[48] D. Kirsch, V. Guillou, B. Anheier, P. Seiler, F. Köhler, Different analytical methods of dating ball point ink entries, in: ENFSI, 6th European Document Examiners Working Group (EDEWG) conference, Dubrovnik, Croatia, 2010.

[49] A. Koenig, J. Bügler, D. Kirsch, F. Köhler, C. Weyermann, Ink dating using thermal desorption and gas chromatography / mass spectrometry: Comparison of results obtained in two laboratories. Forensic Science International Submitted the 30th of September 2012 (2012).

[50] L.F. Stewart, Ballpoint ink age determination by volatile component comparison - a preliminary study. Journal of Forensic Sciences 30 (2) (1985) 405-411.

[51] J.H. Bugler, H. Buchner, A. Dallmayer, Characterization of ballpoint pen inks by thermal desorption and gas chromatography-mass spectrometry. Journal of Forensic Sciences 50 (5) (2005) 1209-1214.

[52] G.M. LaPorte, J.D. Wilson, A.A. Cantu, S.A. Mancke, S.L. Fortunato, The identification of 2phenoxyethanol in ballpoint inks using gas chromatography/mass spectrometry-relevance to ink dating. Journal of Forensic Sciences 49 (1) (2004) 155-159. 
[53] V. Aginsky, A new Approch to determining the age of ballpoint ink using densitometric thinlayer chromatography, 1993.

[54] ENFSI, http://www.enfsi.eu/about-enfsi/structure/working-groups/documents, 03.2015.

[55] J.H. Bügler, M. Graydon, B. Ostrum, The parctical use of the Munich ink reference collection in daily casework, 6th European Document Examiners Working Group (EDEWG) Conference, Dubrovnik, Croatia, 2010.

[56] I. Montani, W. Mazzella, M. Guichard, R. Marquis, Examination of heterogeneous Crossing Sequeneces Between Toner and Rollerball Pen Strokes by Digital Microscopy and *-D Laser Profilometry. Journal of Forensic Sciences 57 (4) (2012) 997-1002.

[57] S. Sami, Electrical Properties, Handbook of Physical Testing of Paper, CRC Press, 2001.

[58] J.N. Miller, J.C. Miller, Statistics and chemometrics for analytical chemistry fifth edition, Pearson Education Limited, Harlow, 2005.

[59] D.M. Grim, J. Siegel, J. Allison, Does ink age inside of a pen cartridge? Journal of Forensic Sciences 47 (6) (2002) 1294-1297.

[60] A.A. Cantu, A study of evaporation of a solvent from a solution-Application to writing ink aging. Forensic Science International 219 (1-3) (2012) 119-128.

[61] B.S. Lindblom, Pens and Pencils, Scientific Examination of Questioned Documents, Second Edition, CRC Press, 2006, pp. 147-158.

[62] V.N. Aginsky, Accelerated Aging- Its Use in Methods for Dating Ink. International Journal of Forensic Document Examiners 2 (3) (1996) 179-181.

[63] P. Margot, Traceology: The trace as the fundamental vector of police science/forensic science. Revue Internationale de Criminologie et de Police Technique et Scientifique 67 (1) (2014) 72-97.

[64] J.H. Bügler, Method validation for age determination of ballpoint inks, in: i. ENFSI (Ed.), 5th Annual Conference of the European Document Experts Working Group (EDEWG), Bunratty, Ireland, 2008.

[65] C. Weyermann, B. Schiffer, P. Margot, A logical framework to ballpoint ink dating interpretation. Science and Justice 48 (3) (2008) 118-125. 


\section{Figure Captions}

Figure 9 : Sample collection procedure [14,21]

Figure 10 : Ageing curves obtained for 1 to 395 days-old samples from ink 1688: A. quantities of PE recovered in natural and heated samples.; B. calculated R\%; C. RPA(PE/BA), D. R\%* calculated from $\operatorname{RPA}(\mathrm{PE} / \mathrm{BA})$. The inflexion intervals at which the 1 st falling rate did not significantly contribute to the regression anymore are indicated with grey dotted lines.

Figure 11: Ageing curves of the quantity of PE recovered in the heated samples of ink 1688, 1774 and 1892.

Figure 12 : Ageing curve of the different solvents present in ink 1688 (A), in ink 1774 (B) and in ink 1892 (C). IS = Internal standard; PEE = Phenoxyethoxyethanol; BA = Benzyl alcohol; HG = Hexylene glycol; $\mathrm{DPG}=$ dipropylene glycol; $\mathrm{DMCH}=$ dimethylcyclohexadienone

Figure 13 : Ageing curve of ink 1688, 1774, 1892 stored in the laboratory and built with A: the natural quantities of PE, B. ratios of ink compounds, C. R\% calculated with RPA.

Figure 14 : Ageing curve of ink 1688, 1774, 1892 stored in the climatic chamber and built with A: the natural quantities of PE, B. ratios of ink compounds, C. R\% calculated with RPA

Figure 15 : Influence of different initial writing pressures on the ageing curve of ink 1688: $100 \mathrm{~g}, 250 \mathrm{~g}, 350 \mathrm{~g}$ as well as lines written with uncontrolled pressure from two different $\bullet$ writers. Three ageing parameters were represented A. Quantity of PE, B. RPA(PE/BA) C. R\%*.

Figure 16 : Normalisation of the ageing curves obtained for different writing pressures using the ink line surfaces of ink $1688\left(\mathrm{~mm}^{2}\right)$ for: $\mathbf{A}$. the quantity of PE, and B. the R\%*. 
Click here to download high resolution image

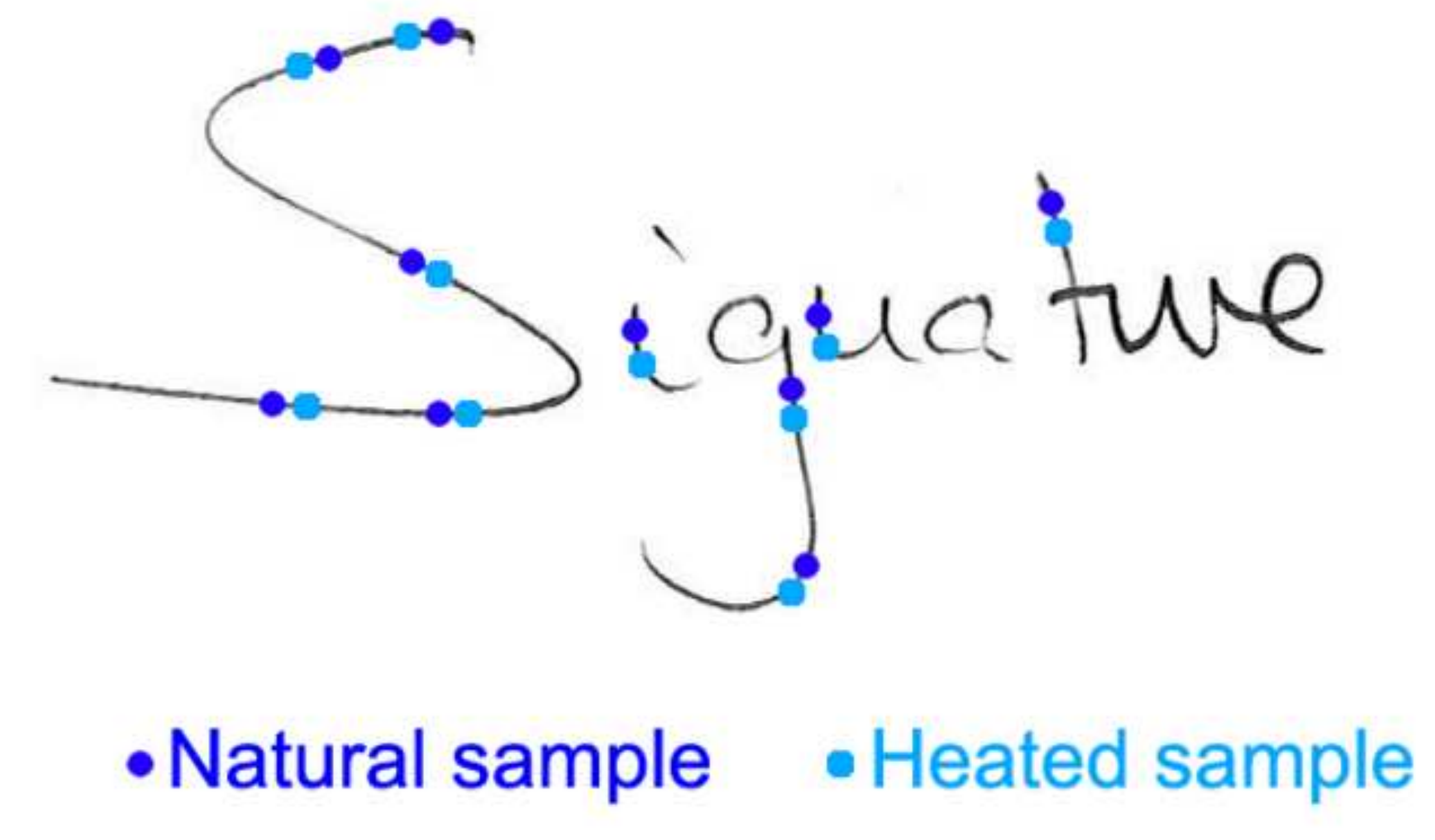

- Natural sample

- Heated sample

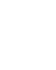




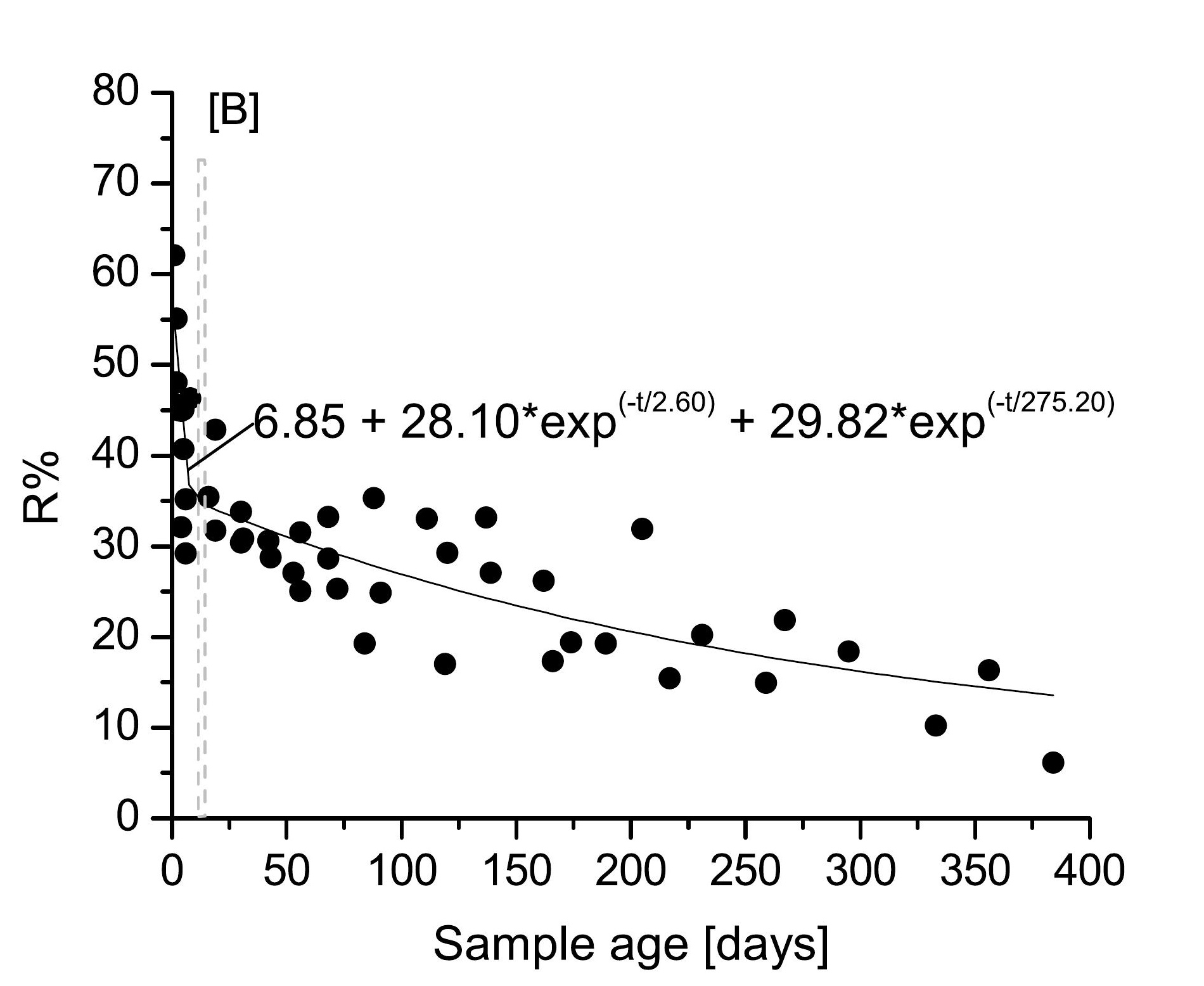

Figure 2B: R\%

Figure 2B: R\%
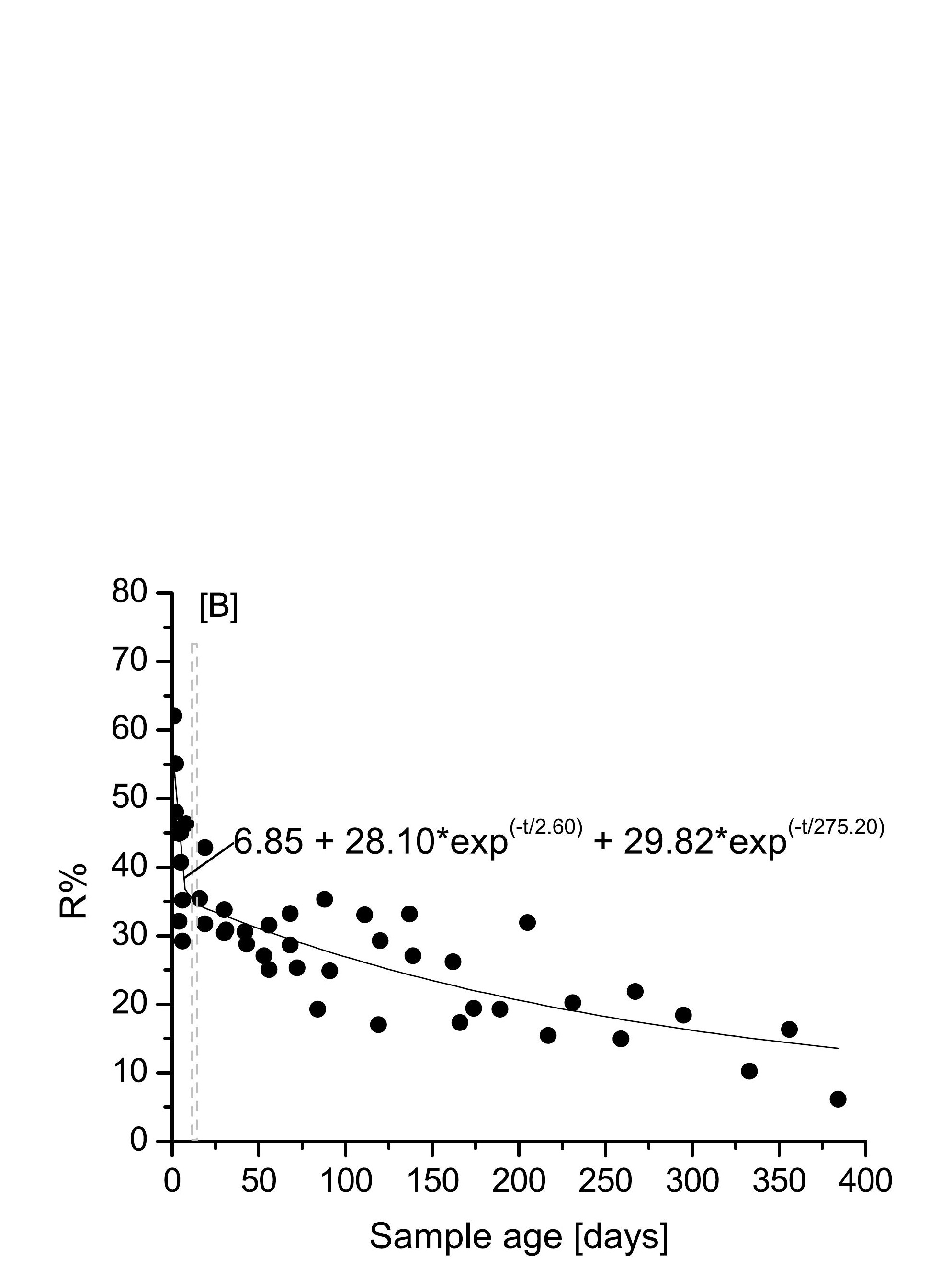

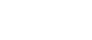

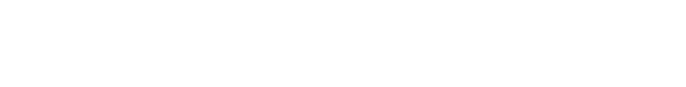

$\%$

de
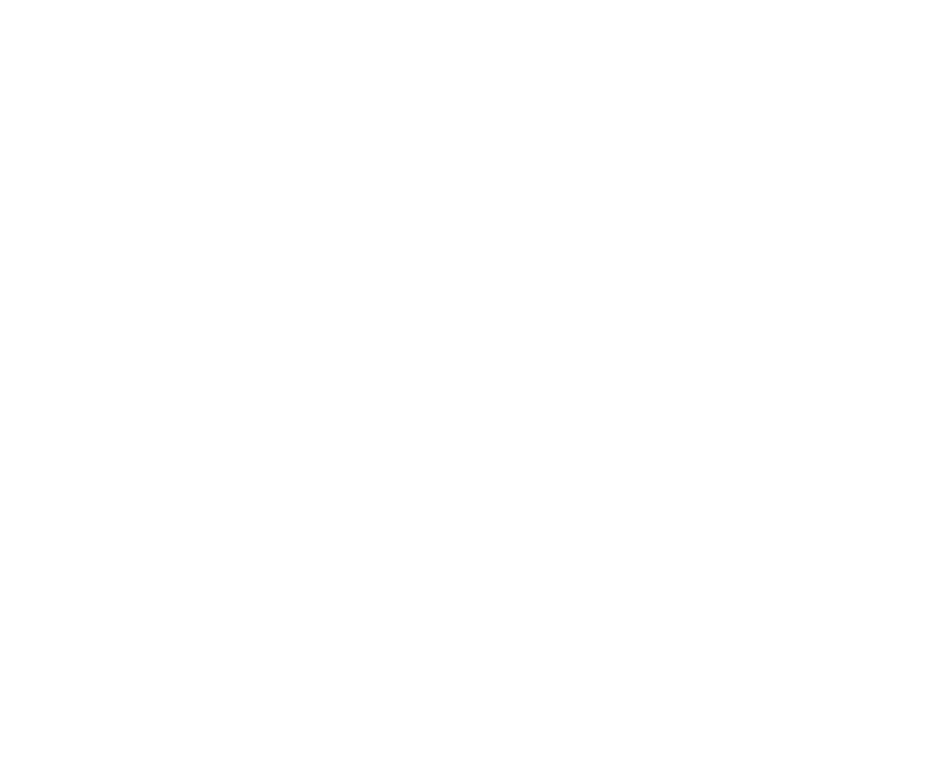


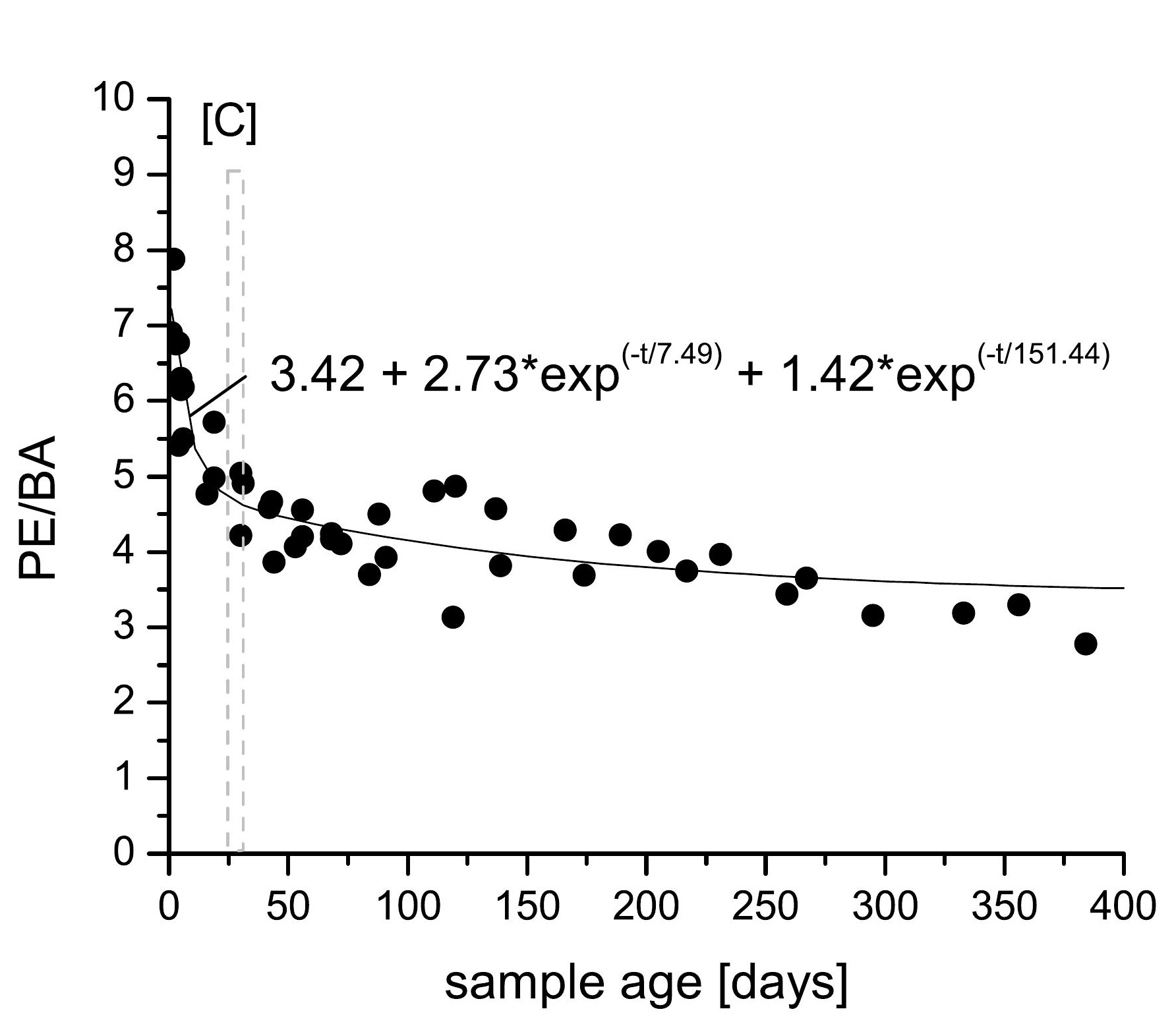

Figure 2C: RPA

Figure 2 : RPA

.

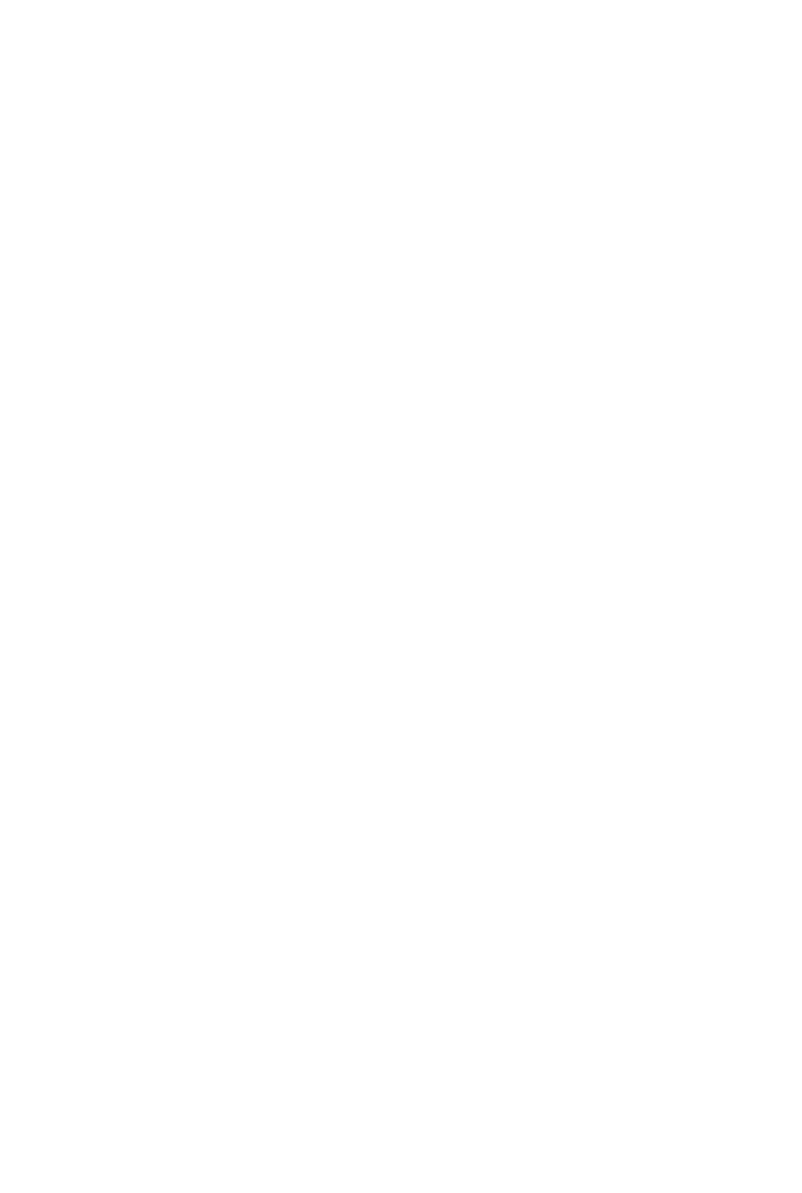

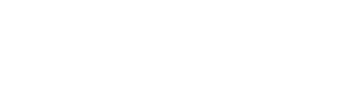

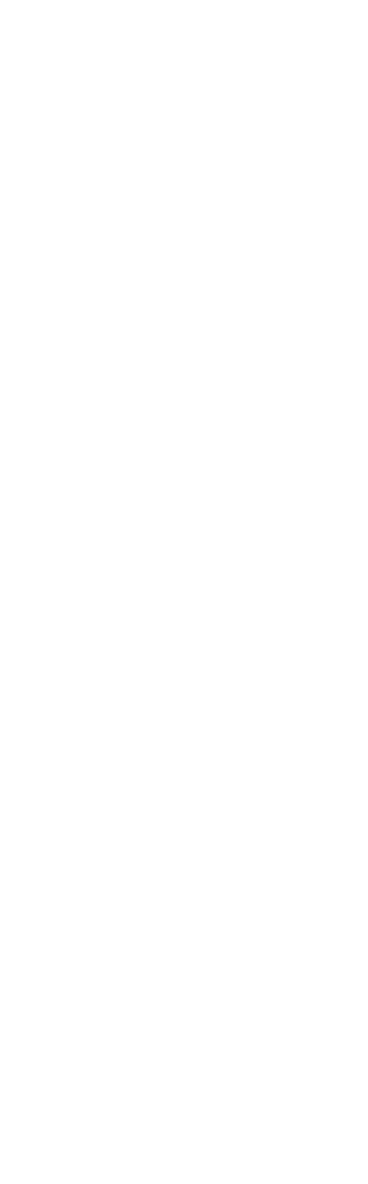

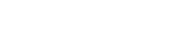
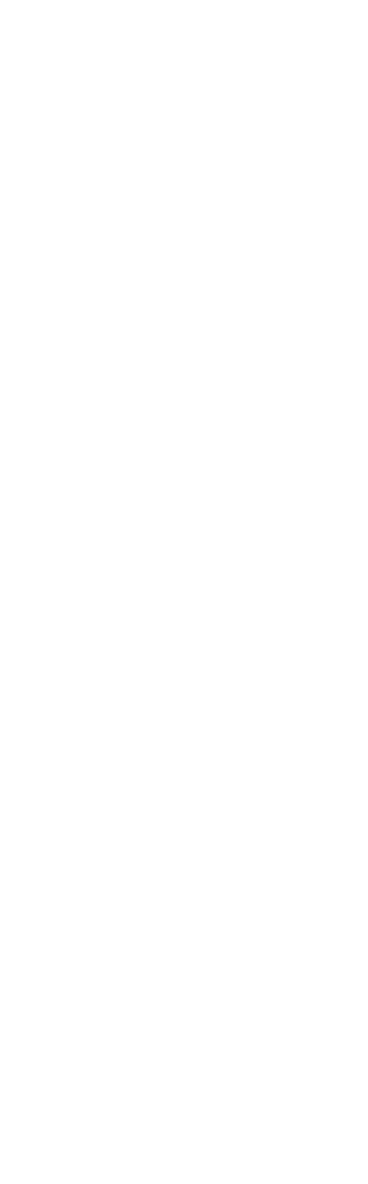
Figure 2D: R\%*

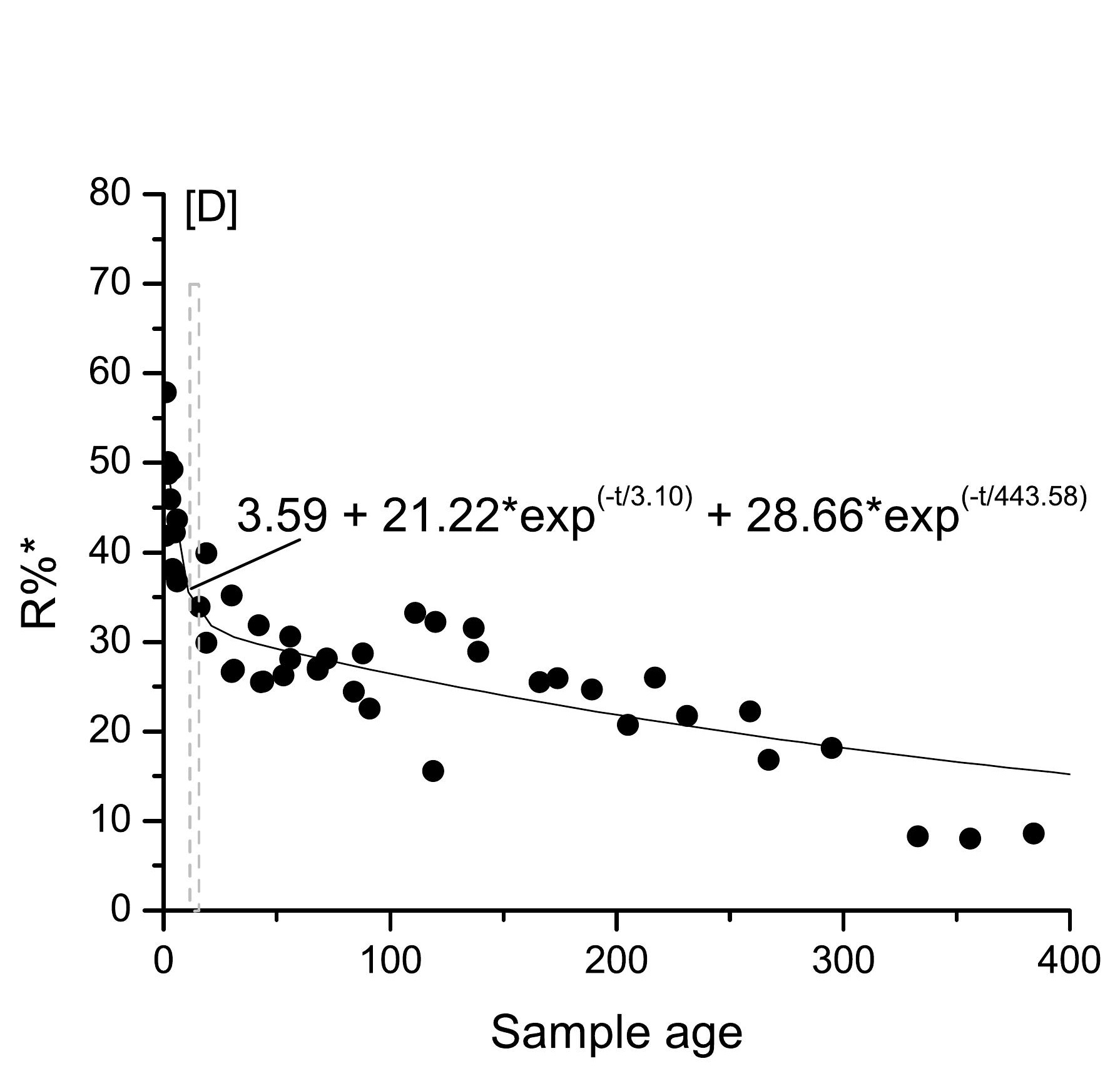

Figure

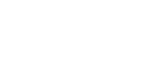

.

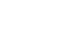
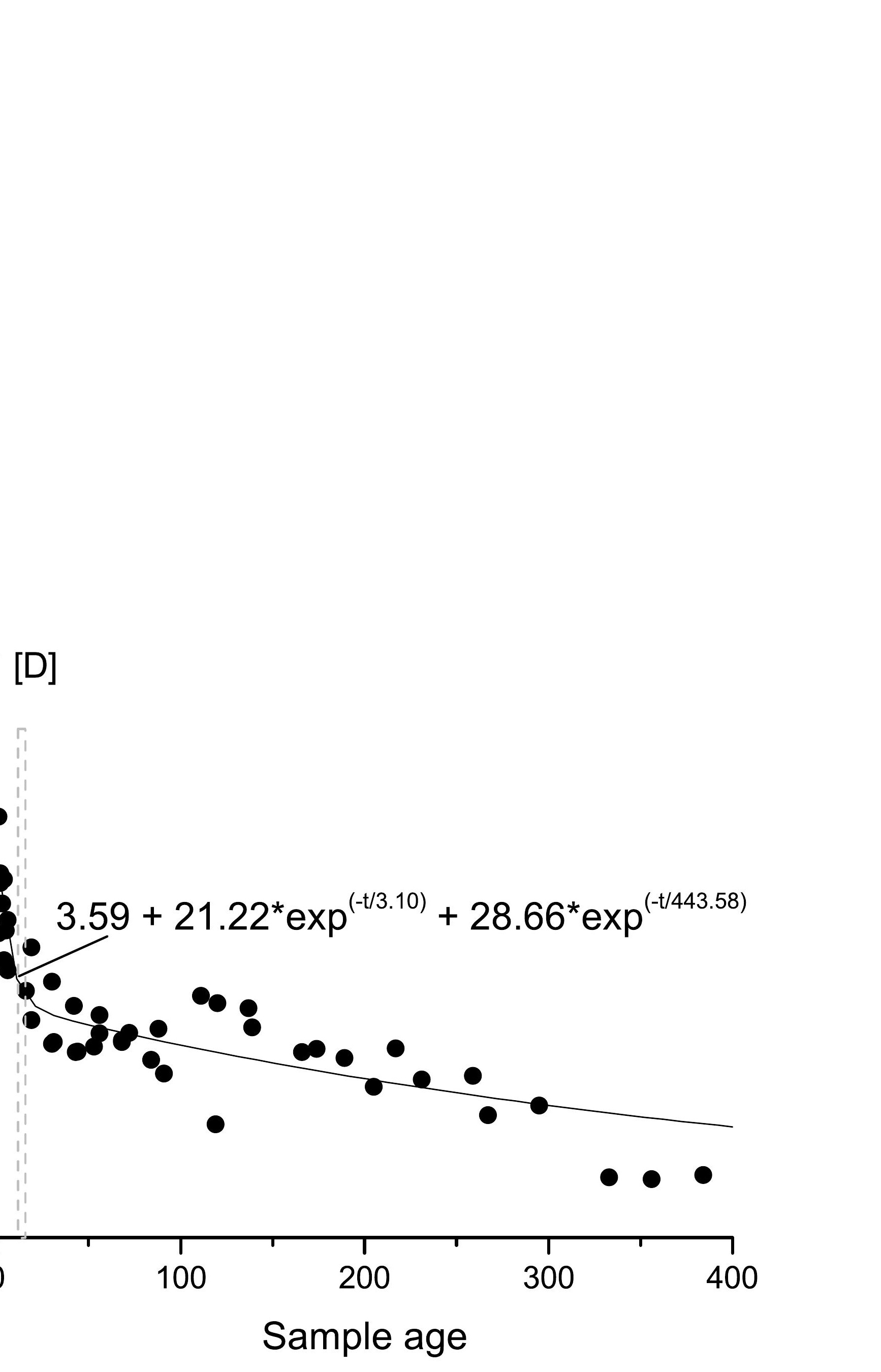


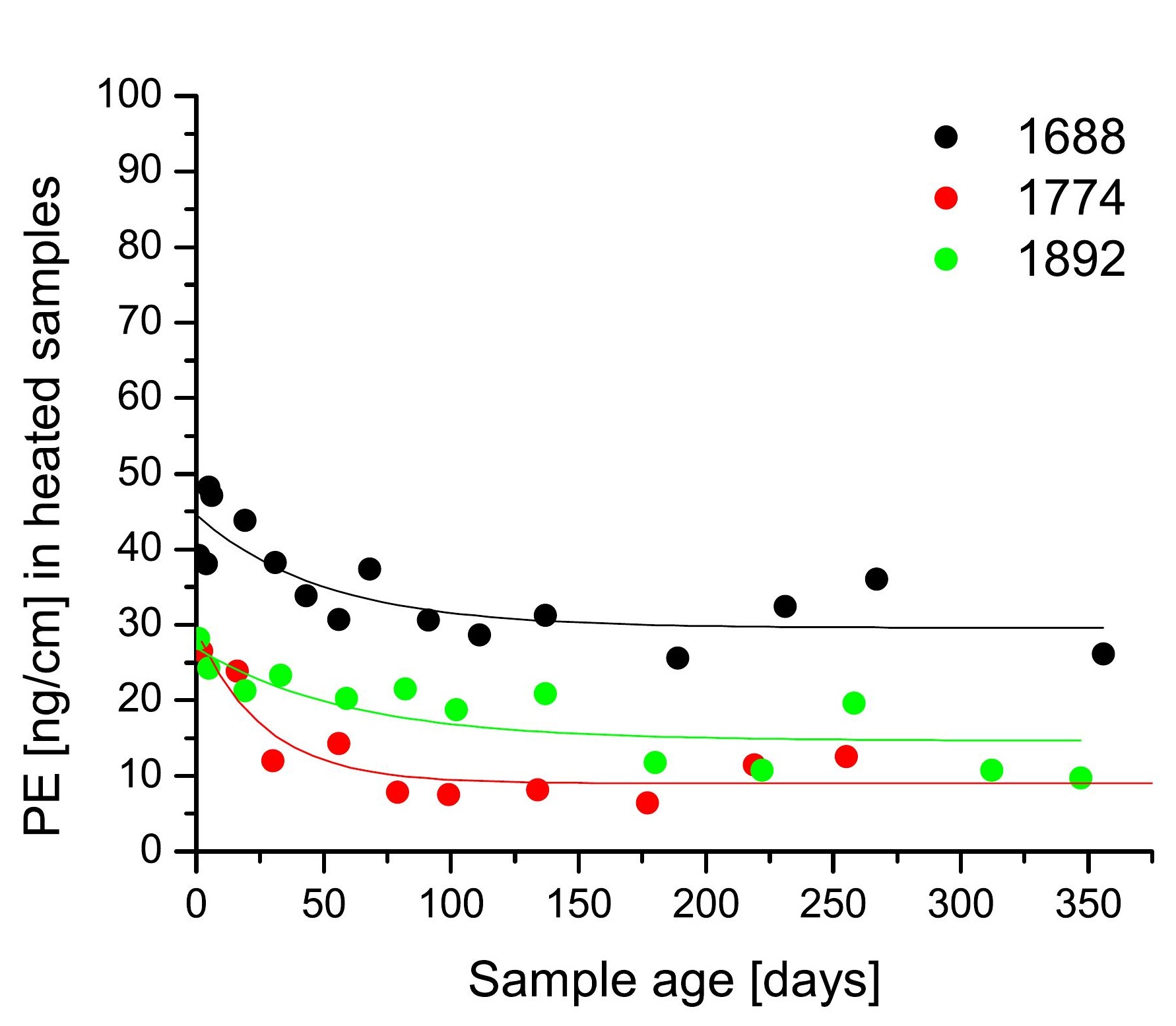

Figure 3 : Ageing curves of heated samples

Figure 3 : Ageing curves of heated samples 


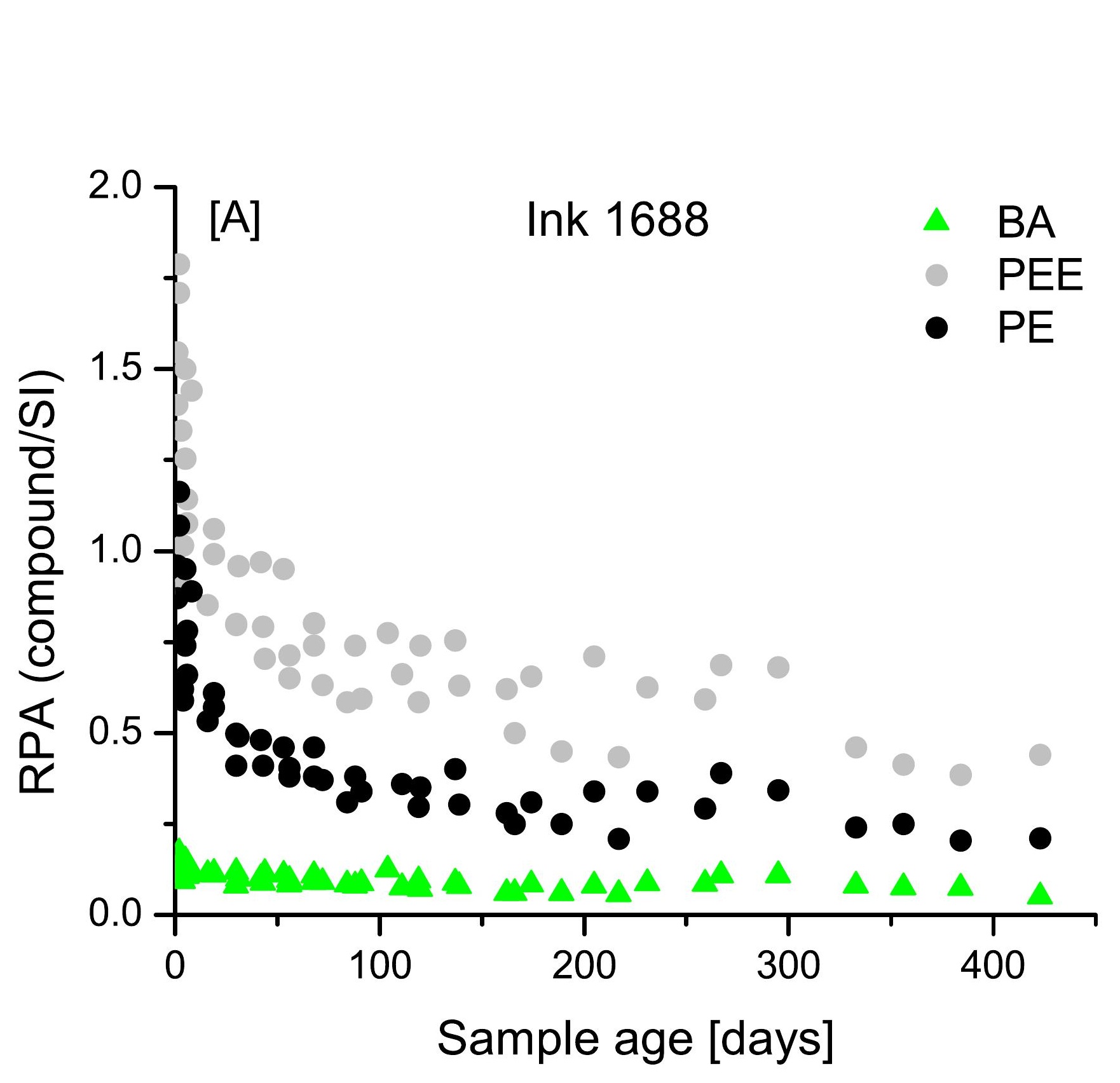

Figure 4A: Ink 1688

\section{Figure 4A: Ink 1688}

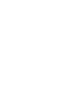
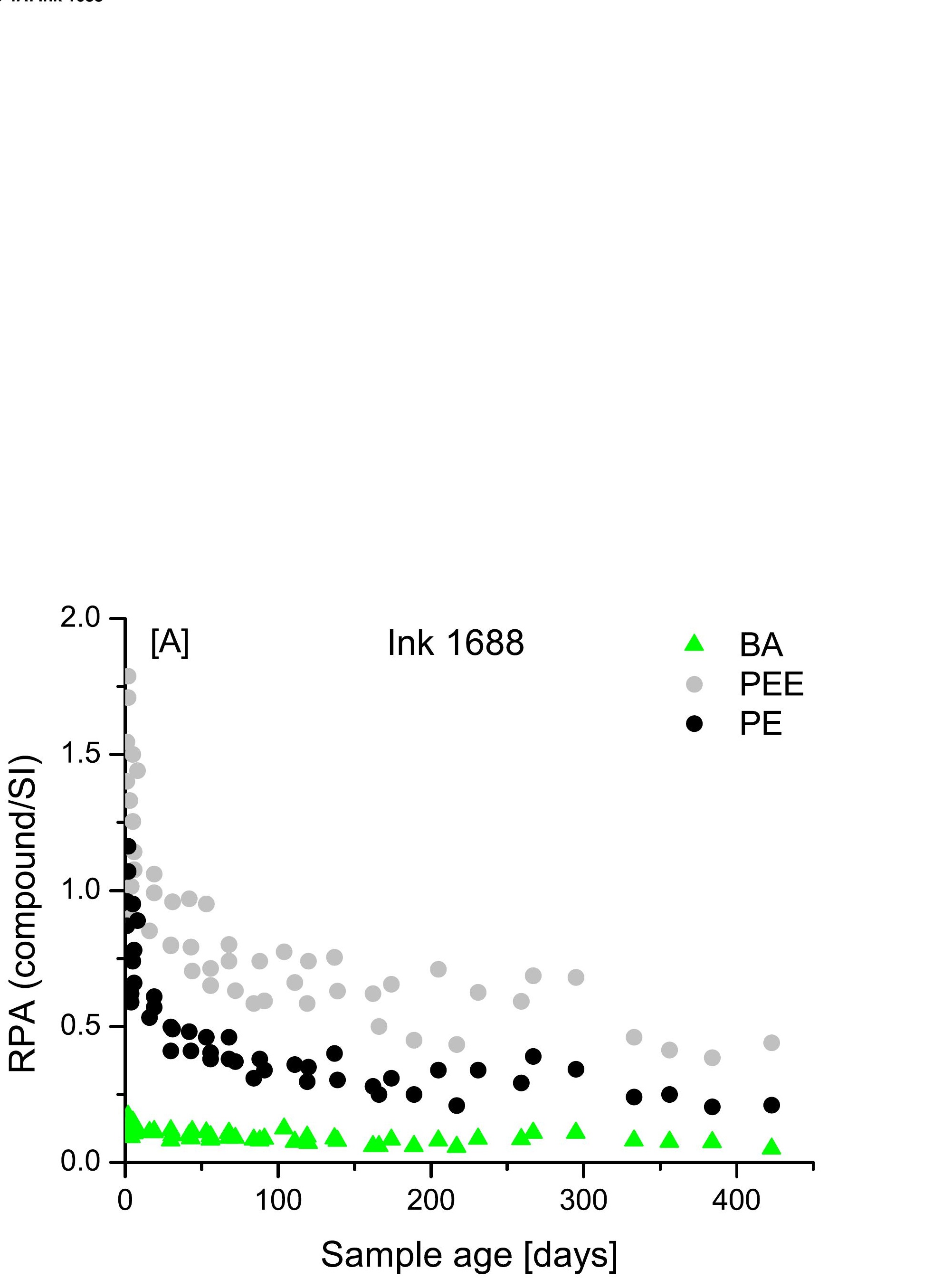
Figure 4B: Ink 1744

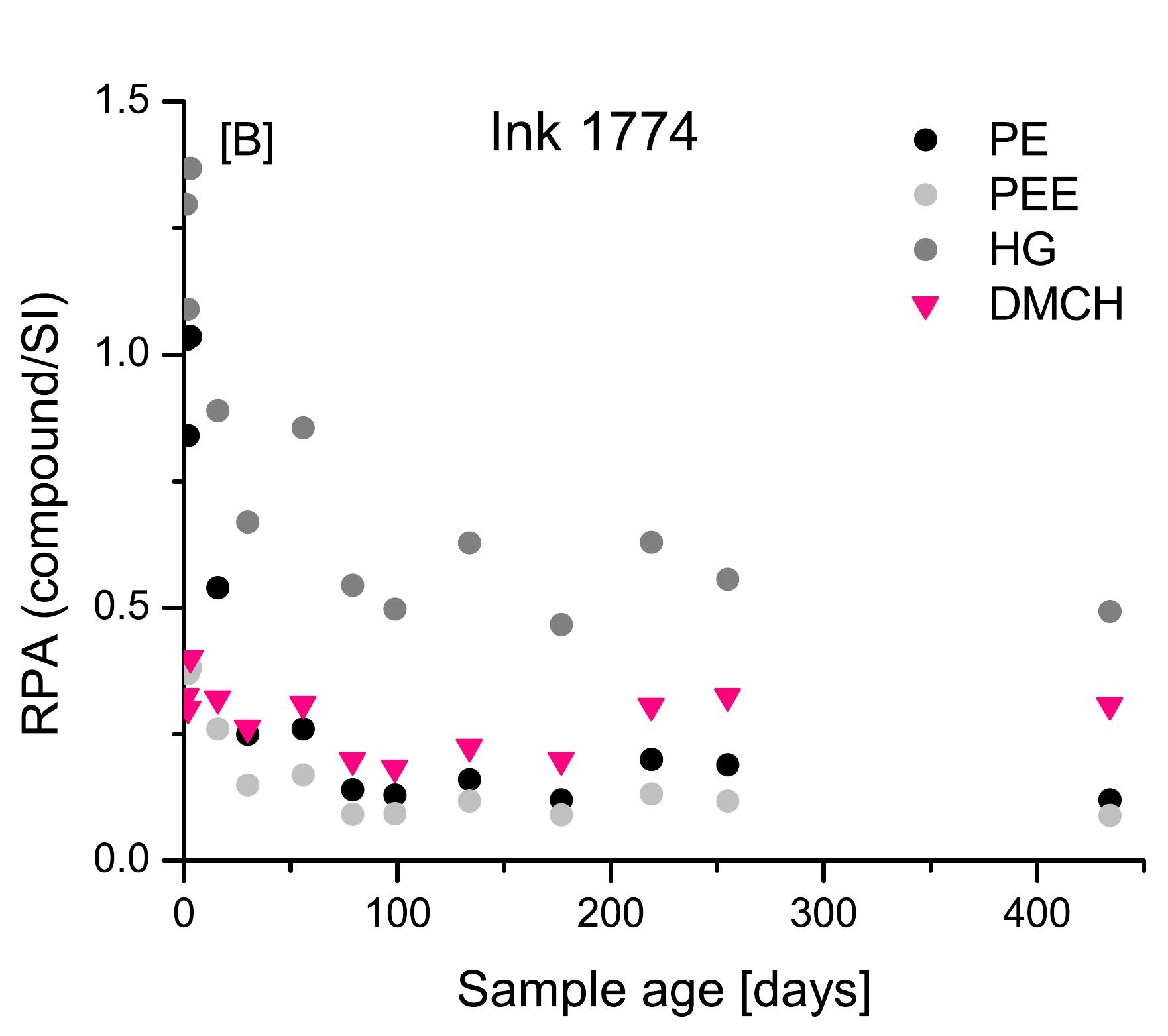

列

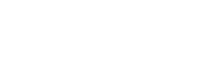

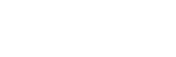

(

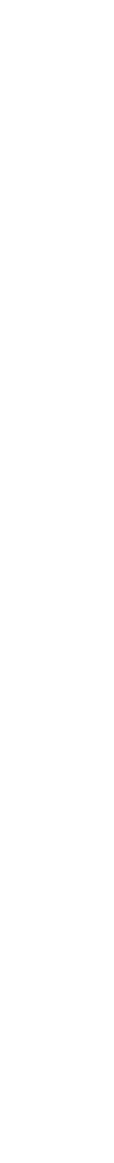


Figure 5A: Laboratory inks- Quantity of PE

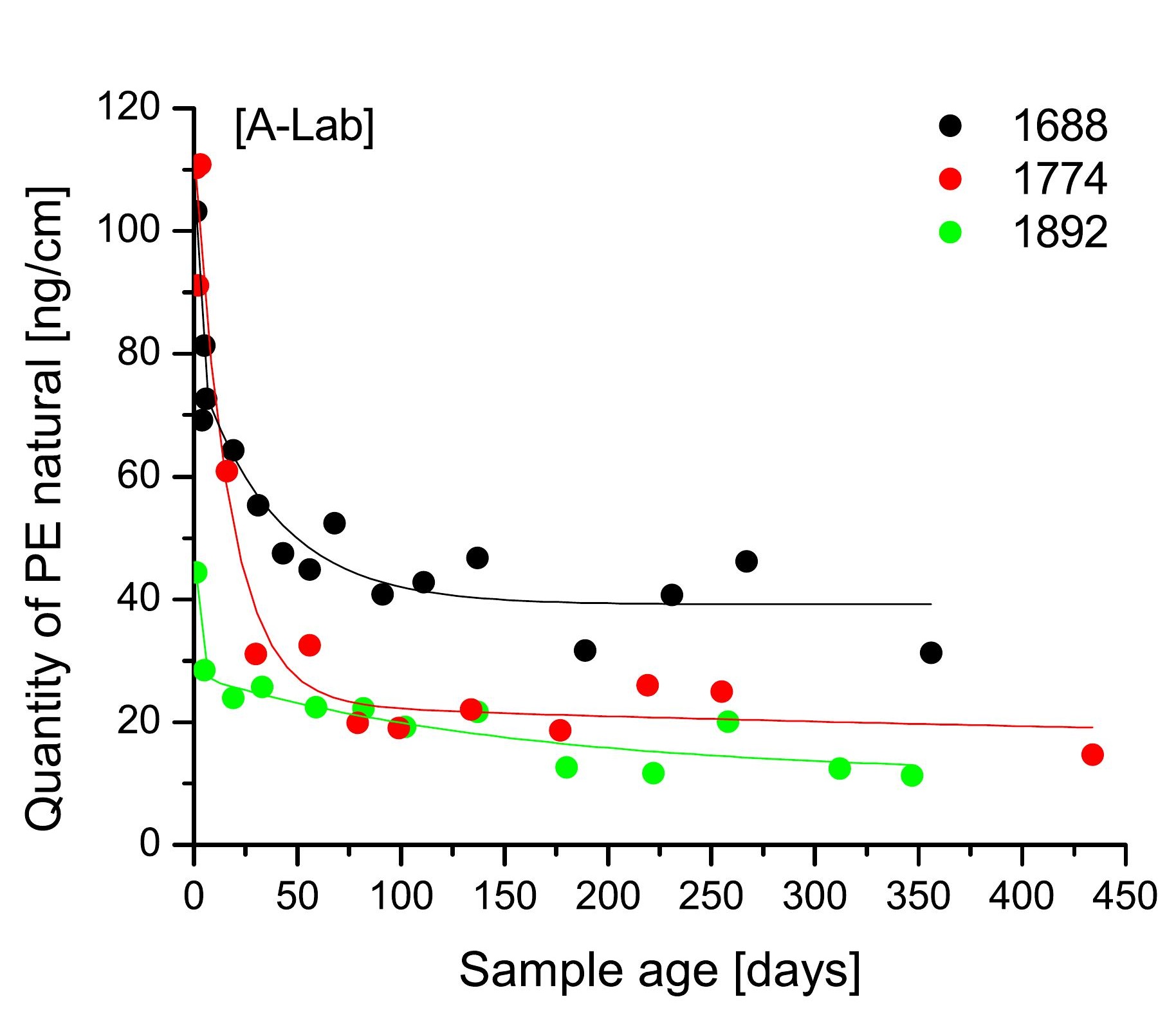

Figure 5A: Laboratory inks- Quantity of PE

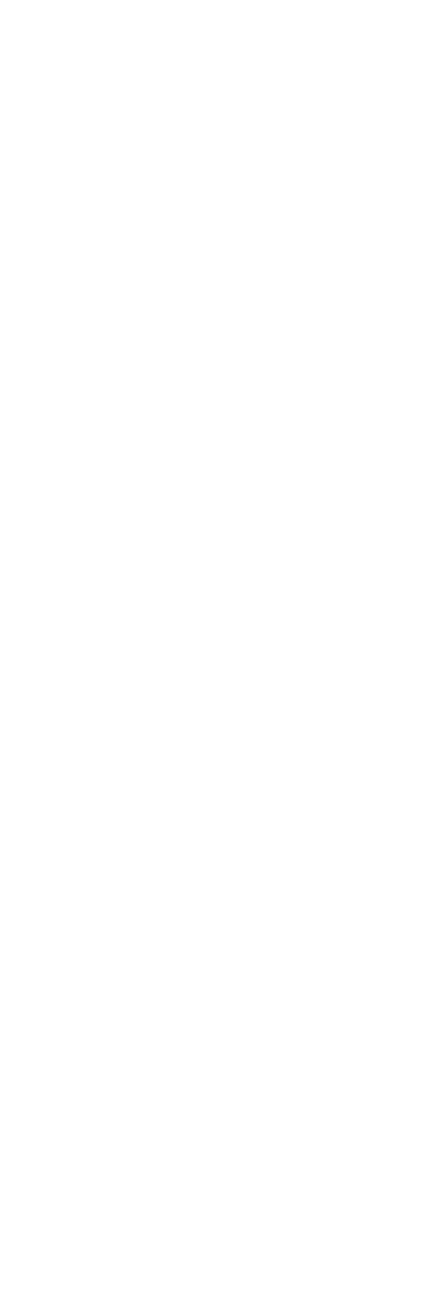




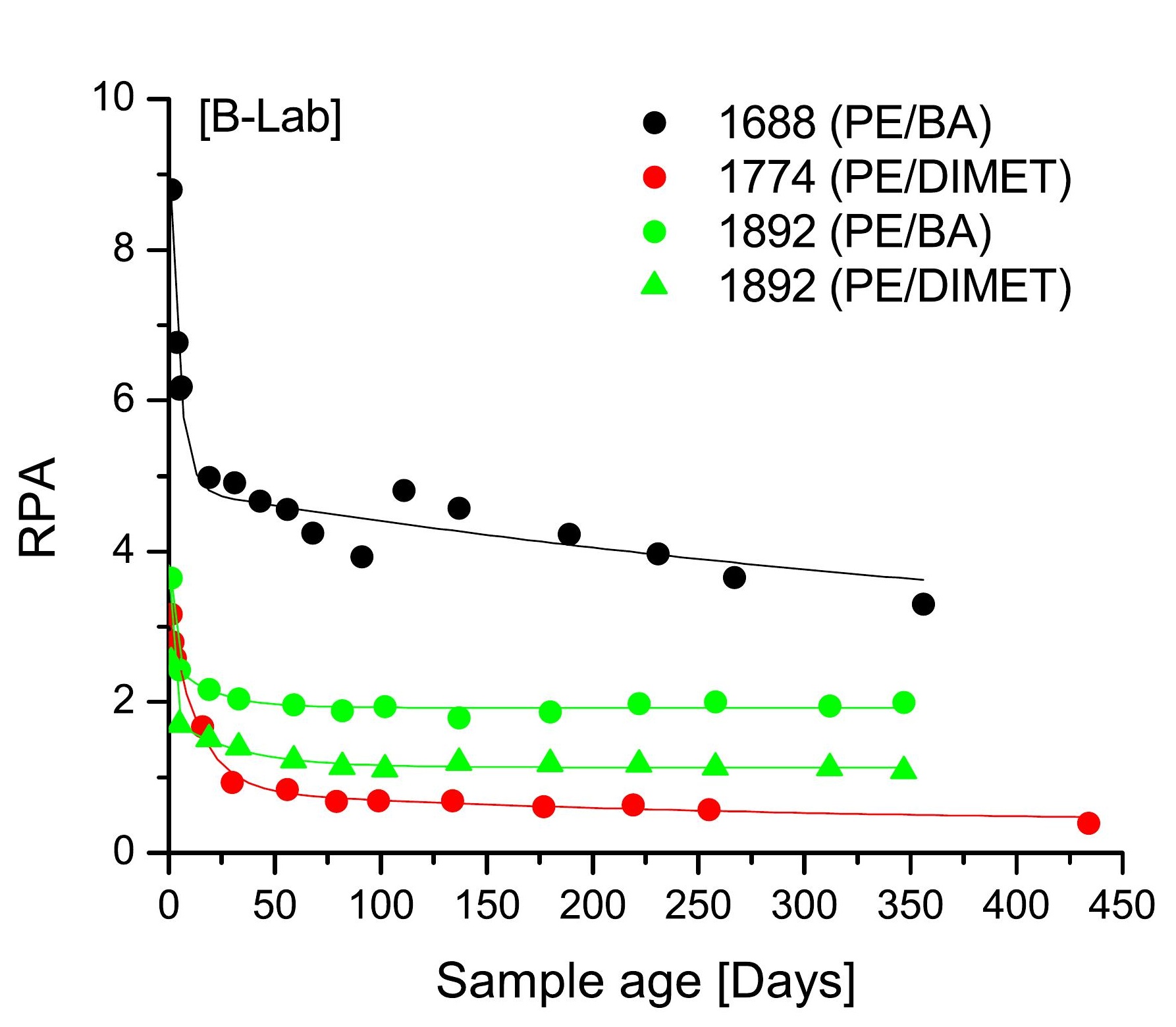

Figure 5B: Laboratory inks- RPA

Figure 5B: Laboratory inks- RPA

Figure 5B: Laboratory inks- RPA
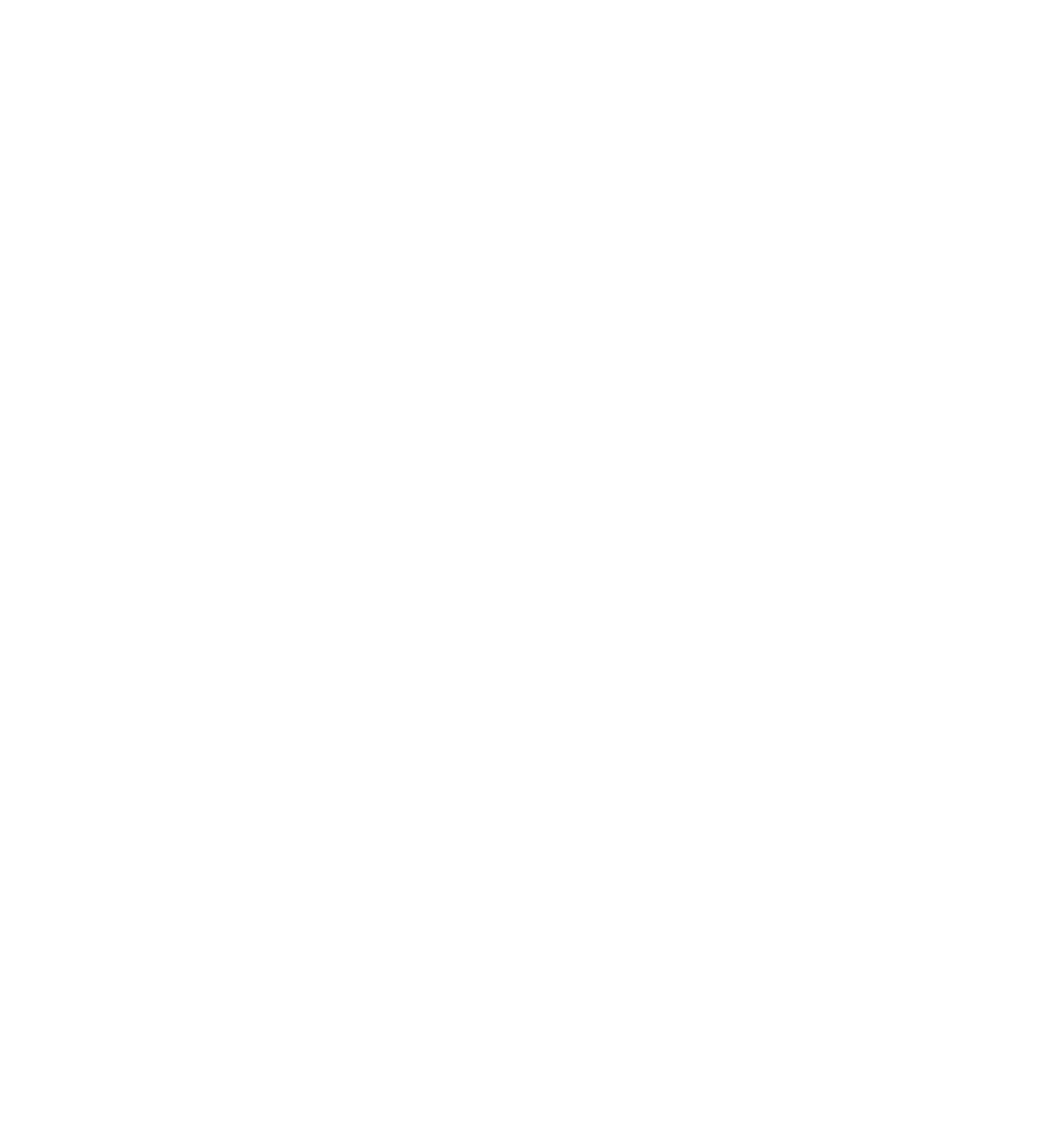
Figure 5C: Laboratory inks- R\%*

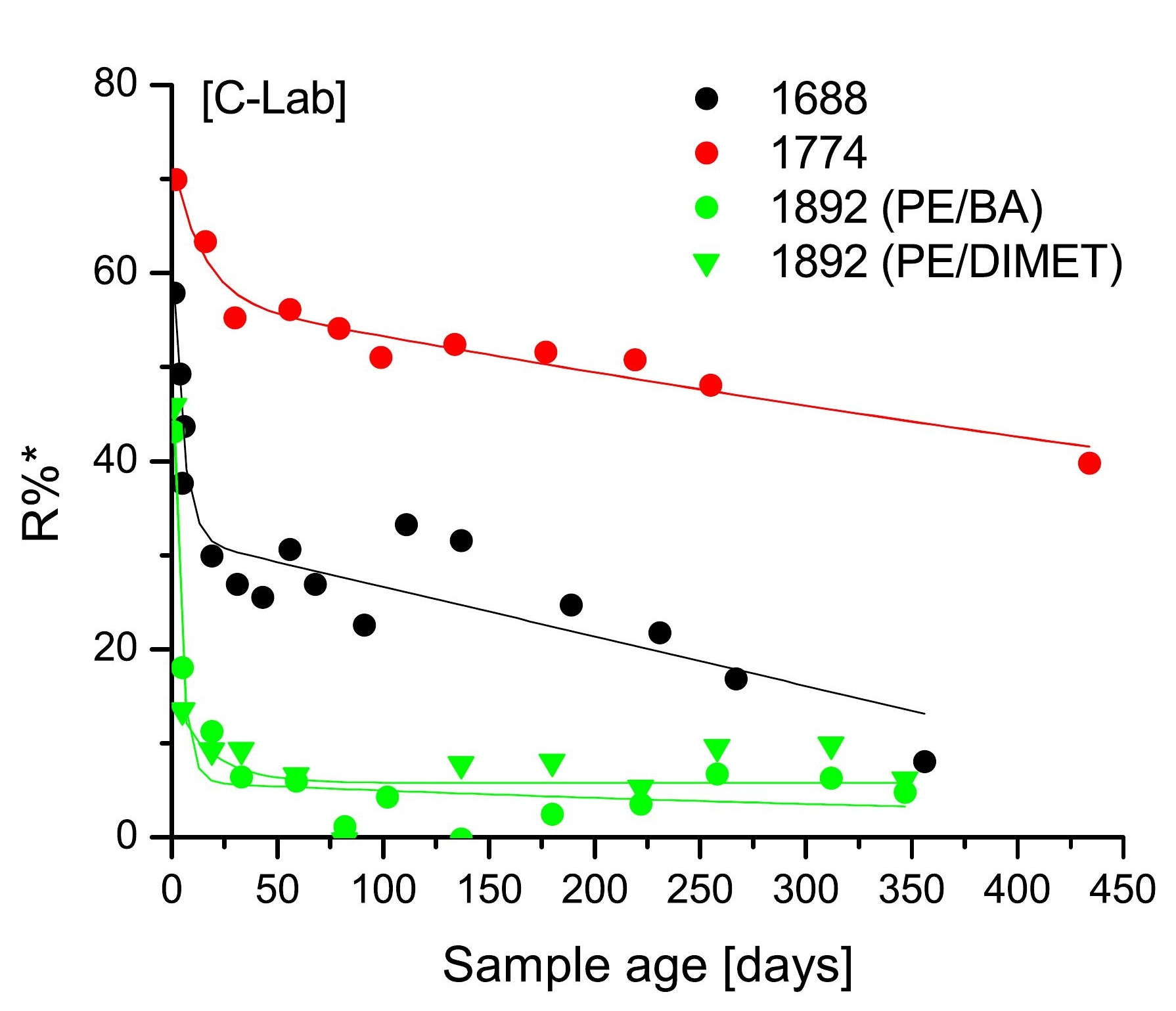

Figure 5C: Laboratory inks- R\%* 


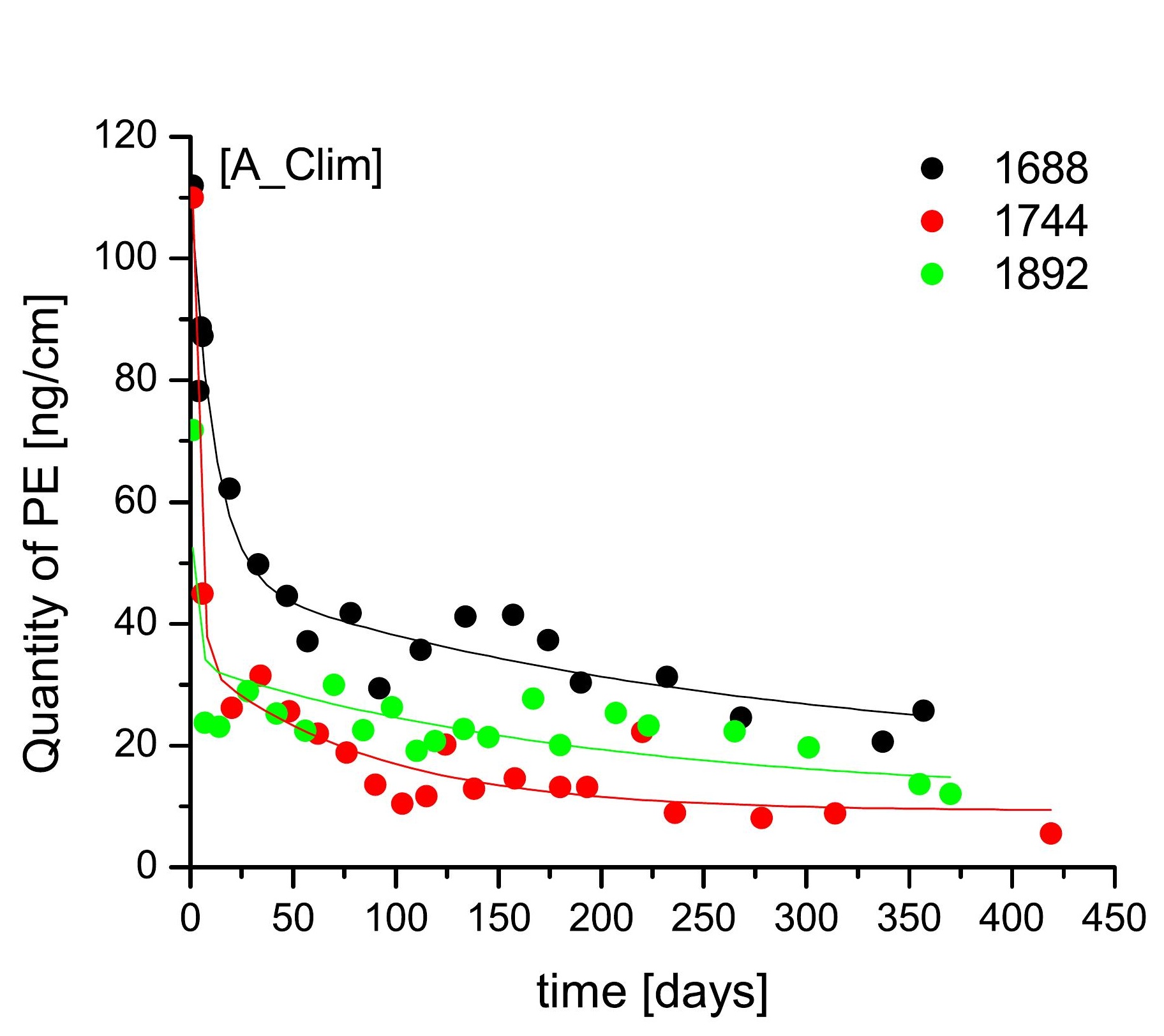

Figure 6A: climatic cupboard inks- Quantity of PE

Figure 6A: climatic cupboard inks- Quantity of PE
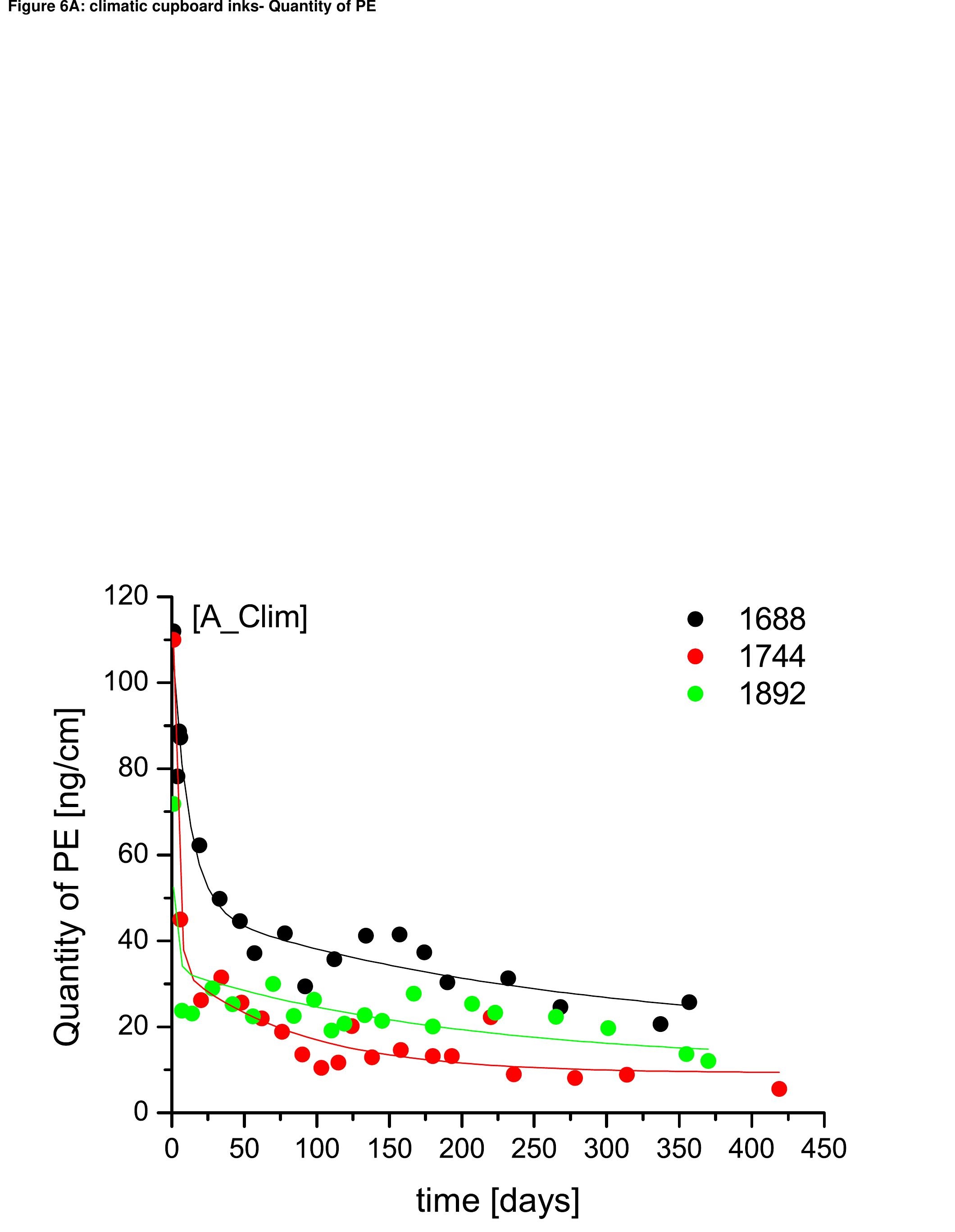
Figure 6B: climatic cupboard inks- RPA

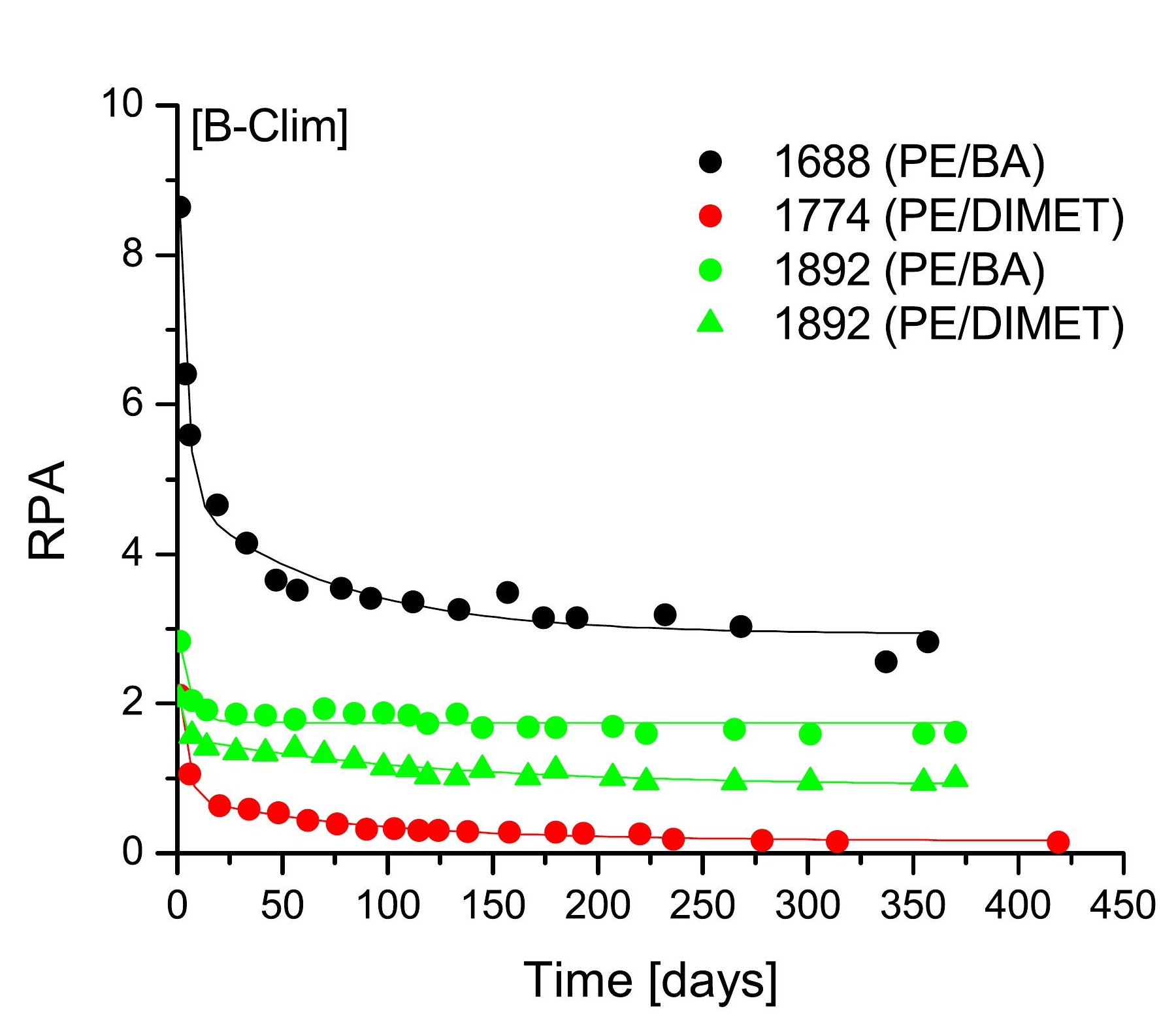

Figure 6B: climatic cupboard inks- RPA

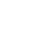

\footnotetext{
6
}

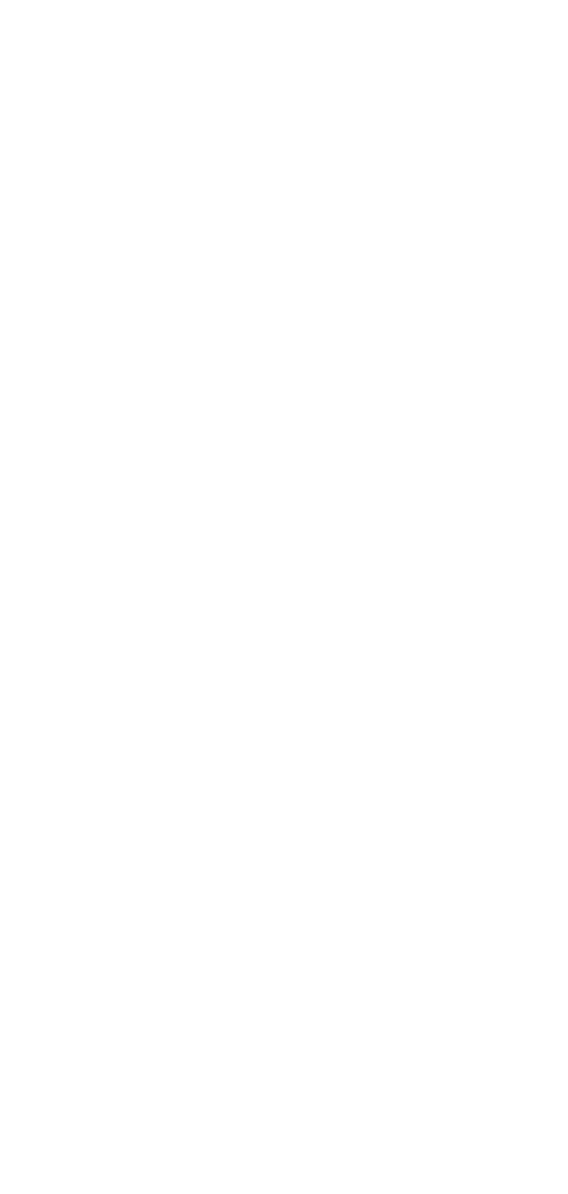

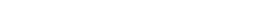

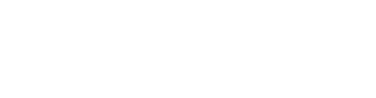
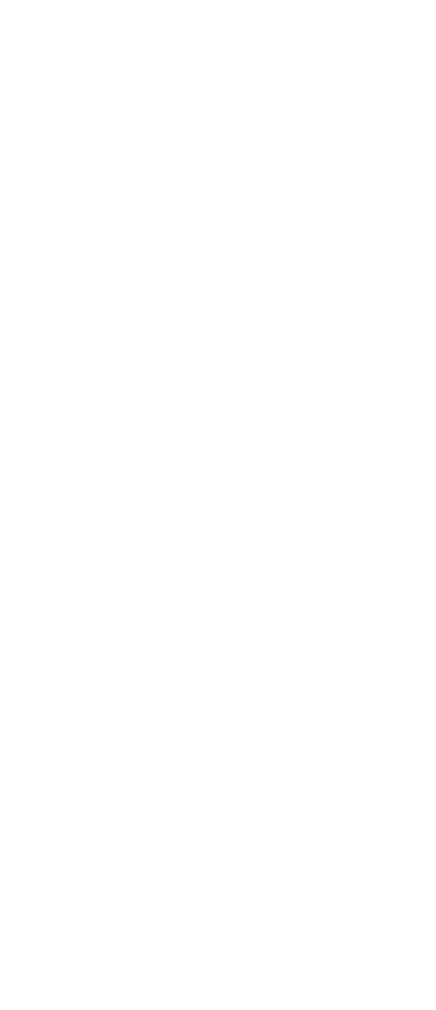


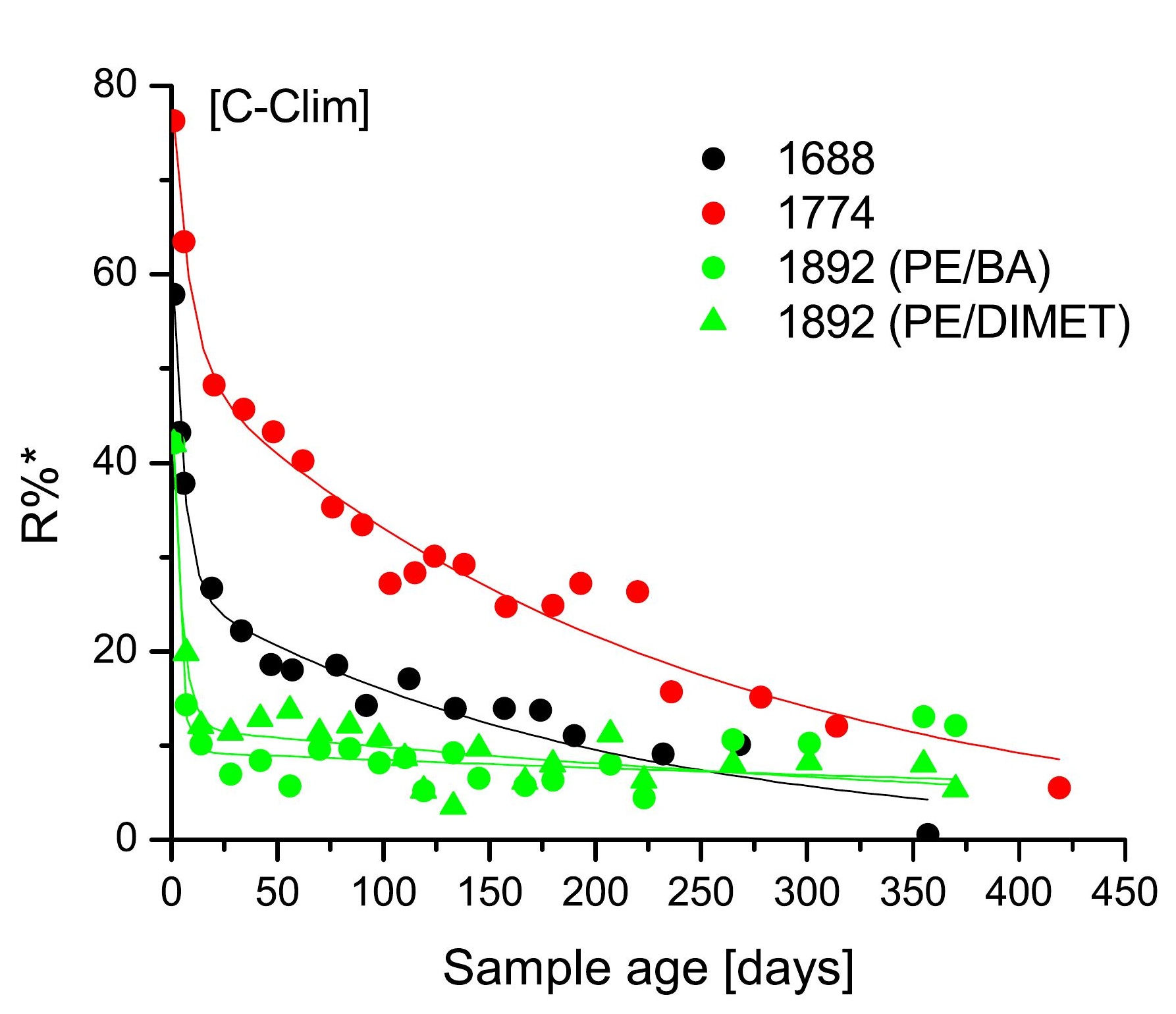

Figure $6 \mathrm{C}$ : climatic cupboard inks- $\mathrm{R} \%{ }^{*}$

Figure 6C: climatic cupboard inks- R\%

(2)
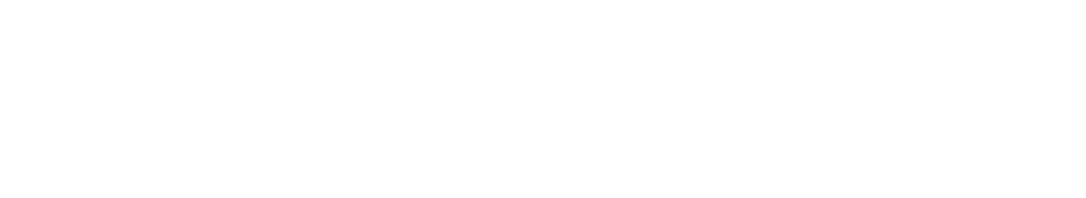

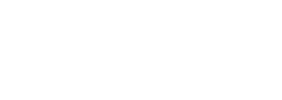

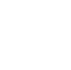

(1)
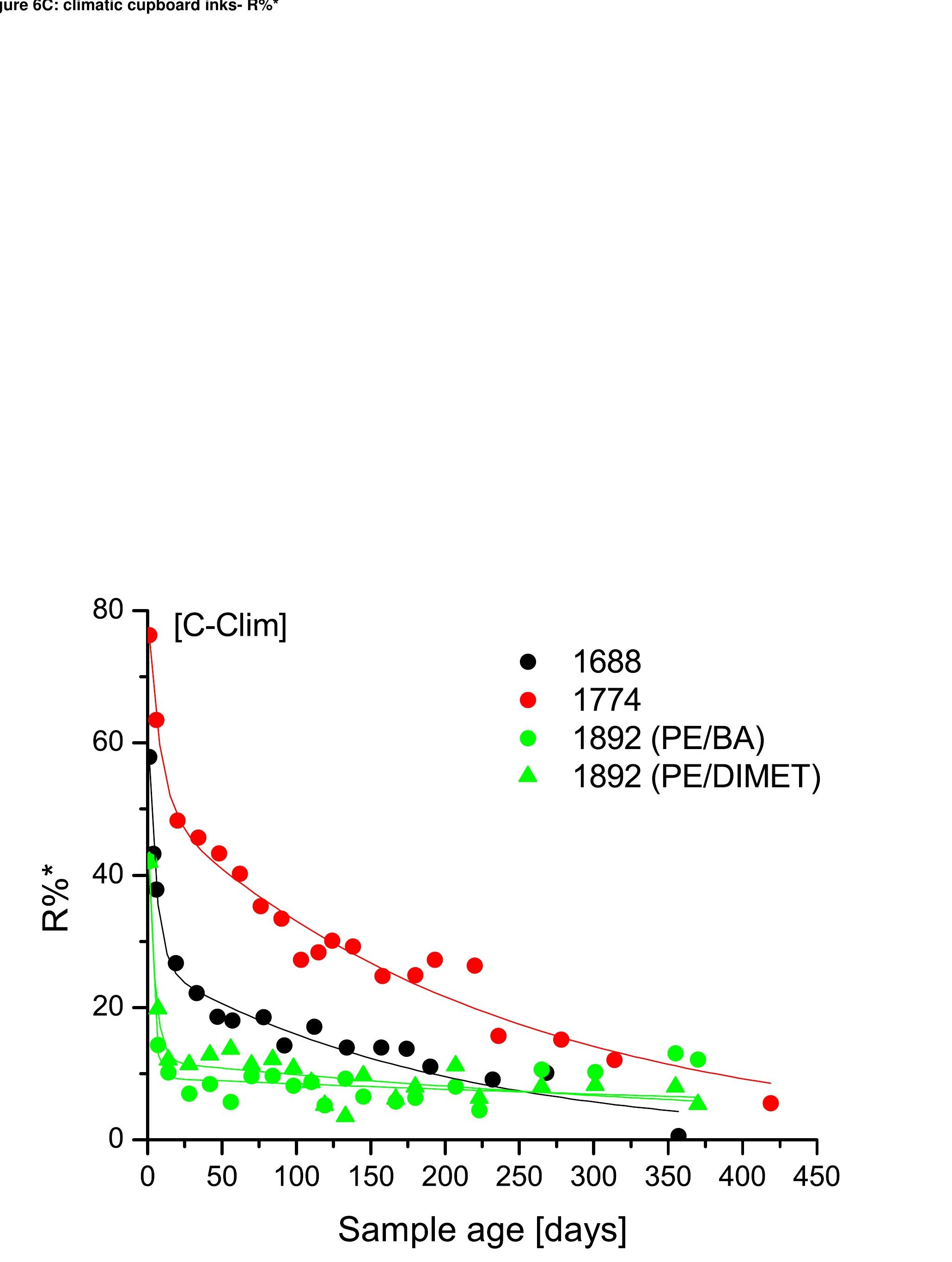


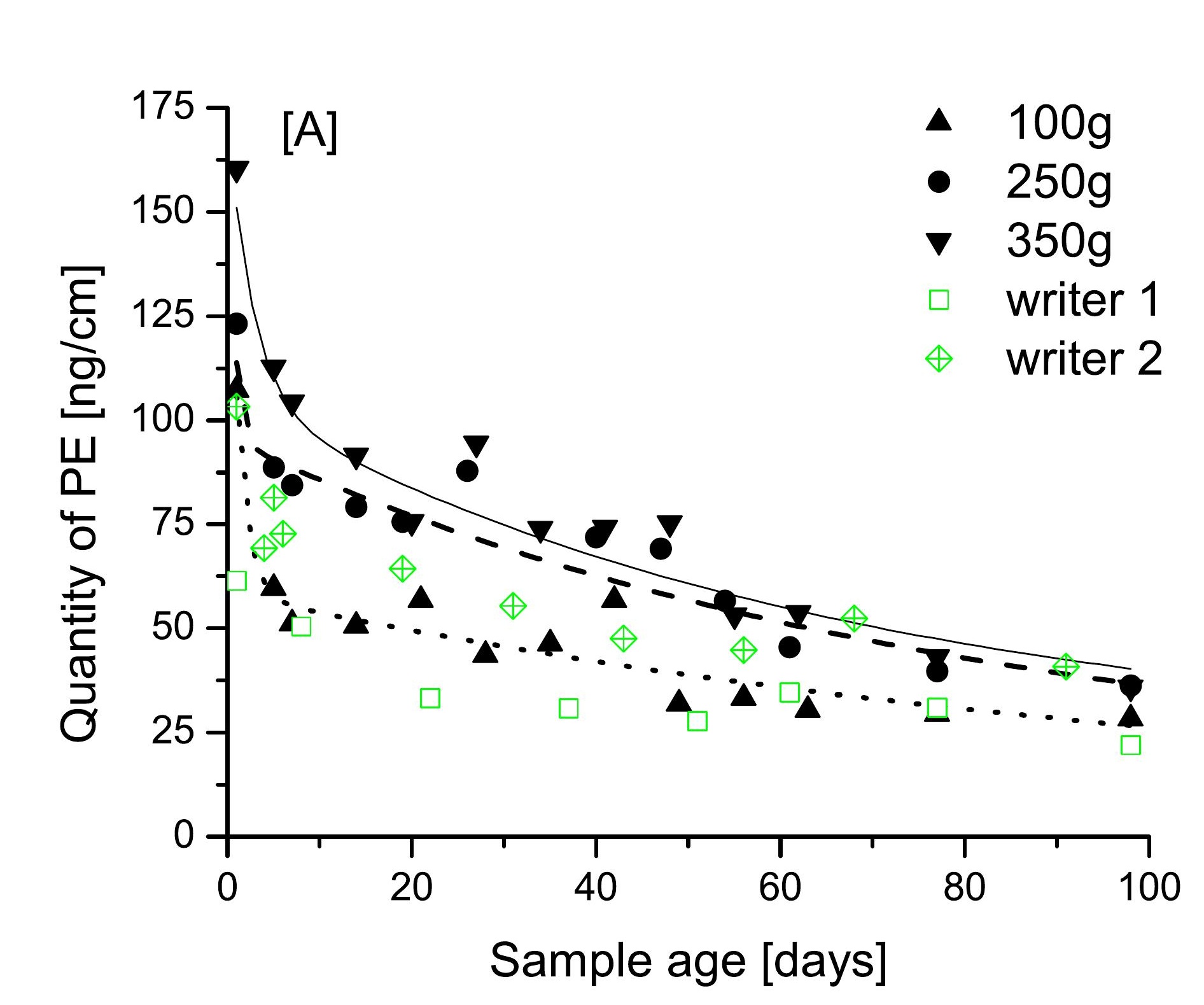

Figure 7A: Pressure - Quantity of PE

(n)

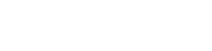
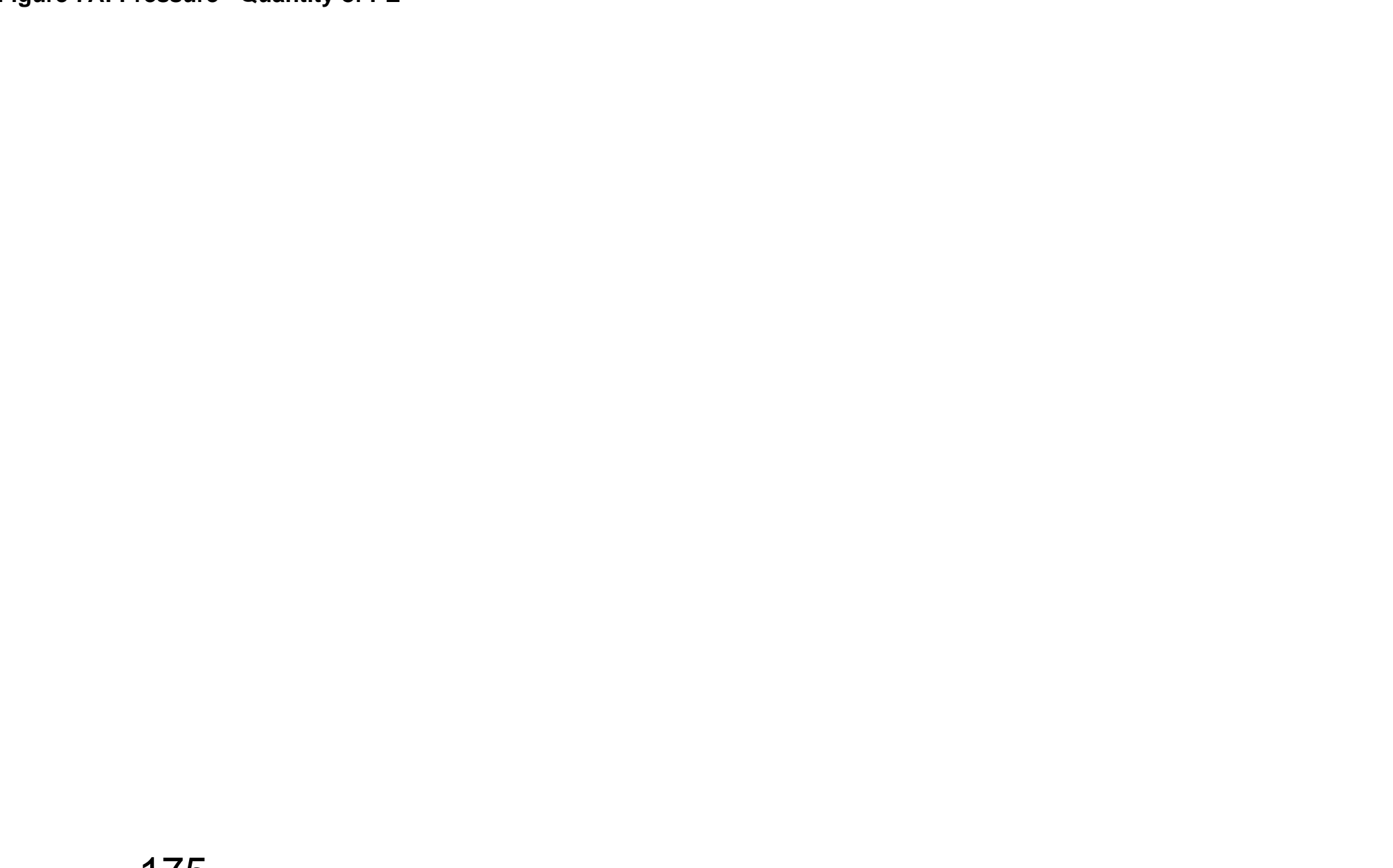
Figure 7B: Pressure - RPA

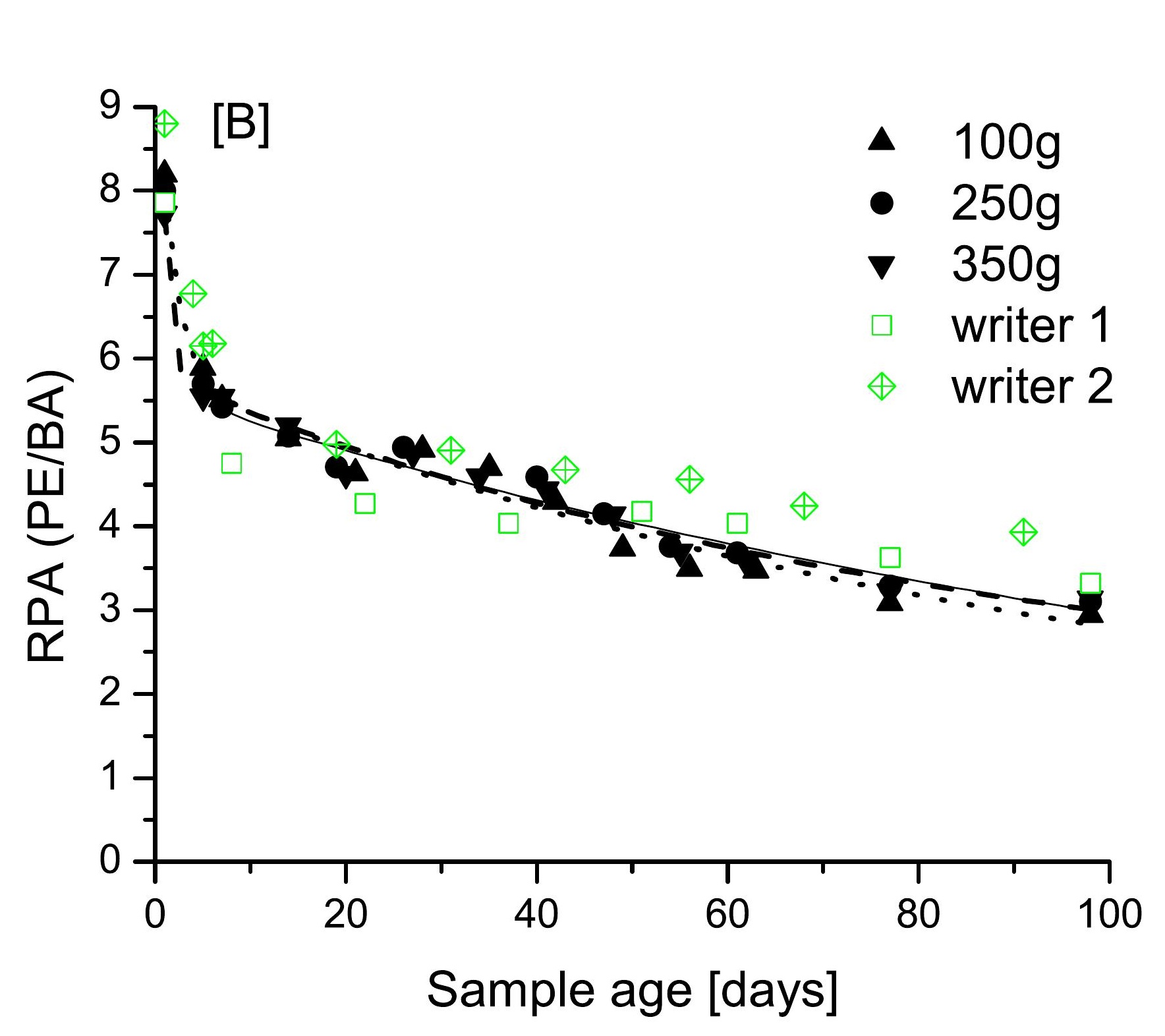

Fure 7B: Pressure - RPA
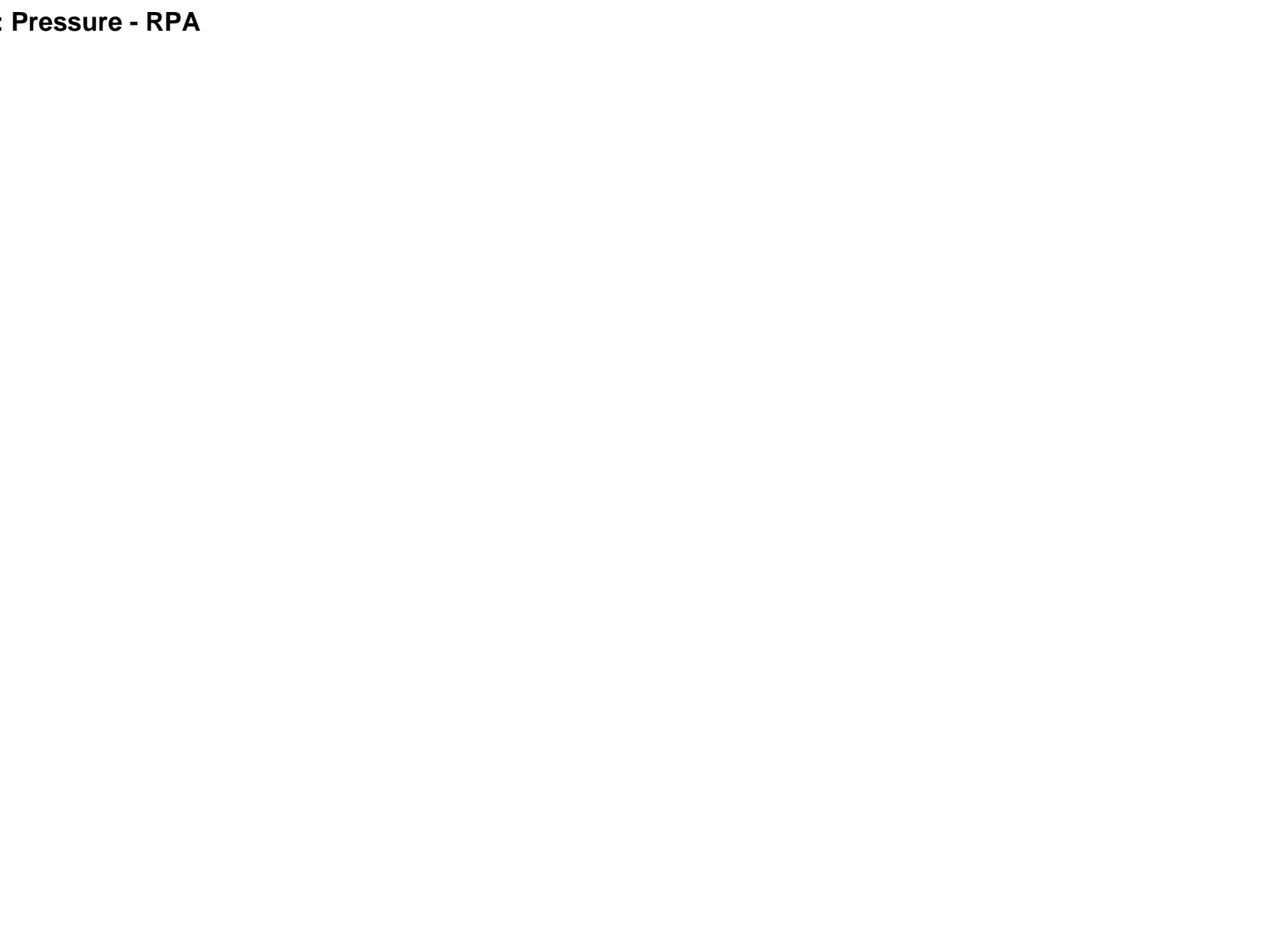

(20)
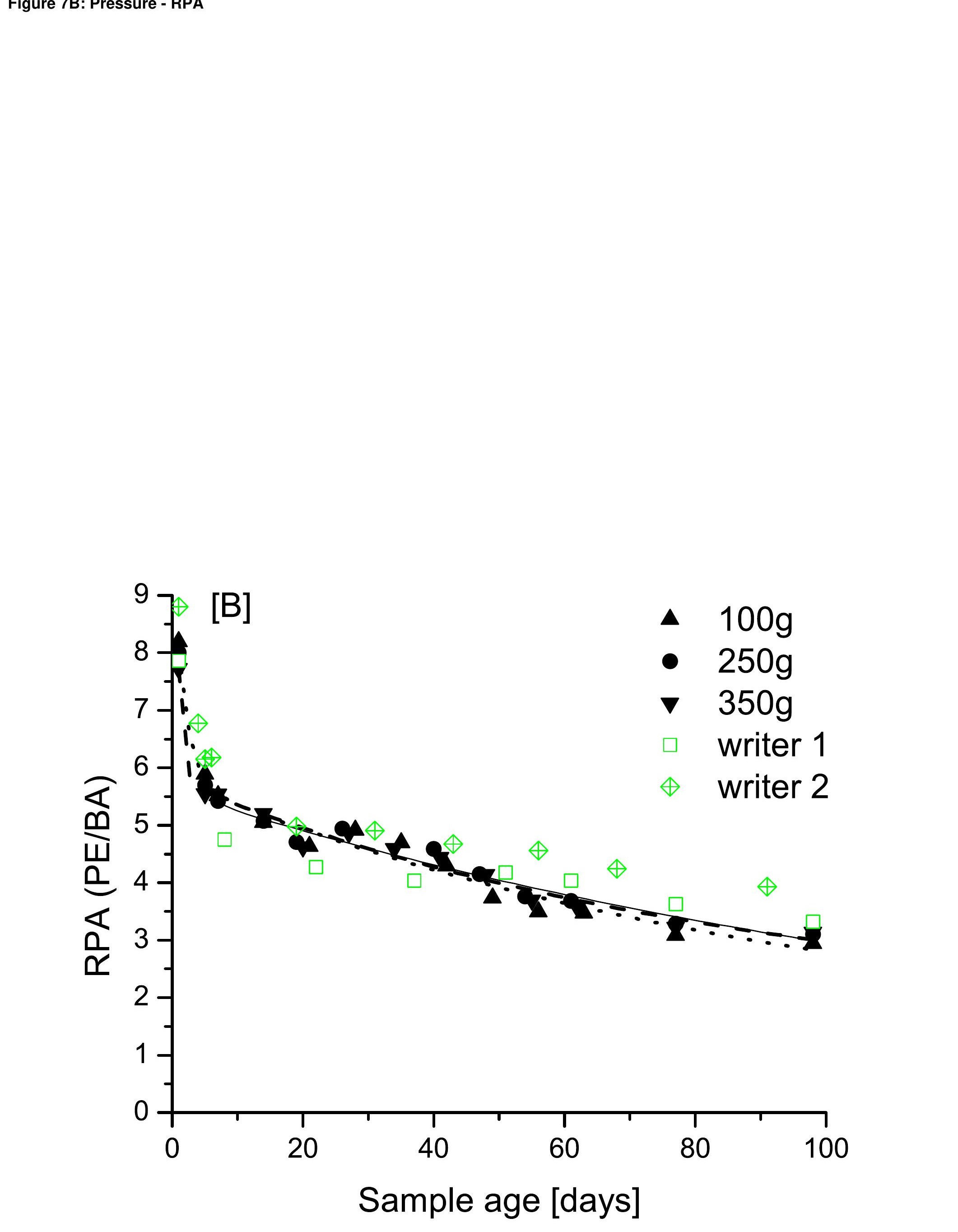

-

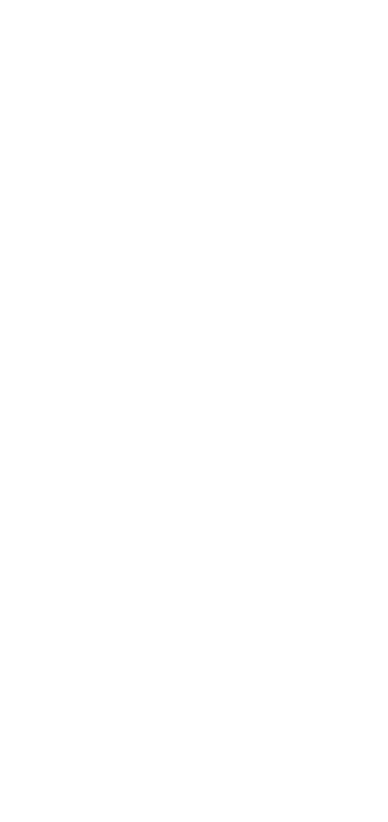




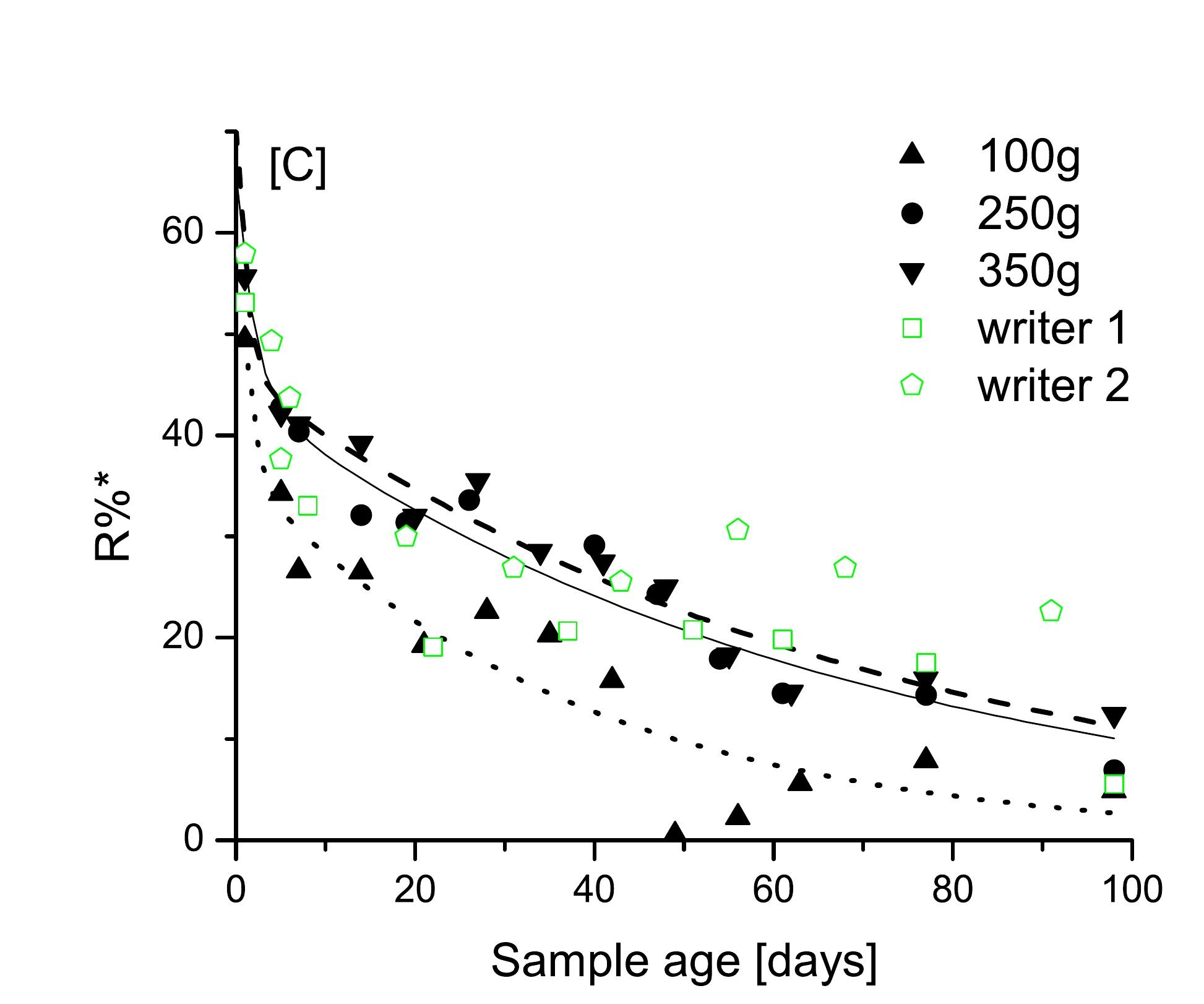

Figure 7C: Pressure - R\%*

Figure 7C: Pressure - R\%
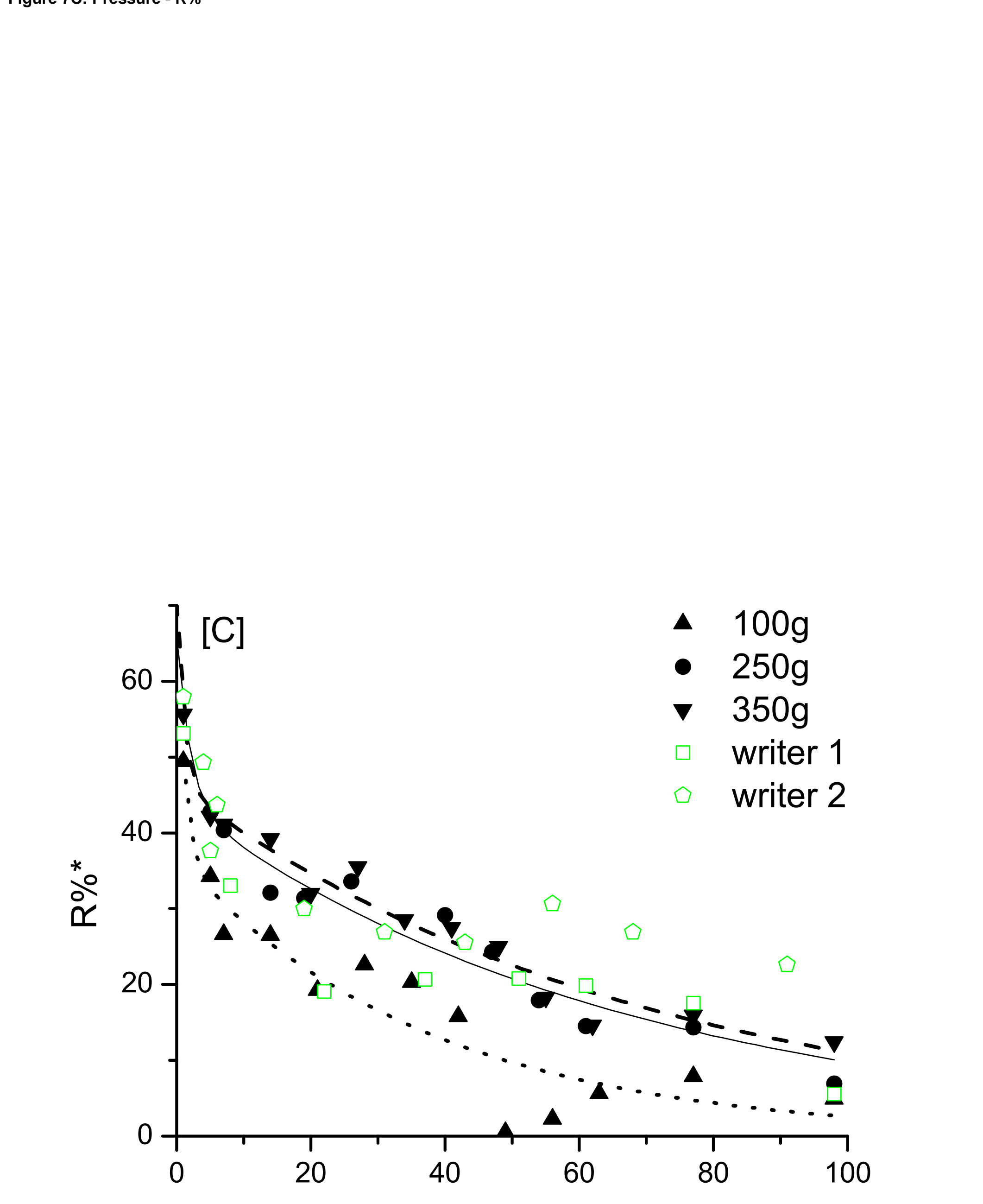


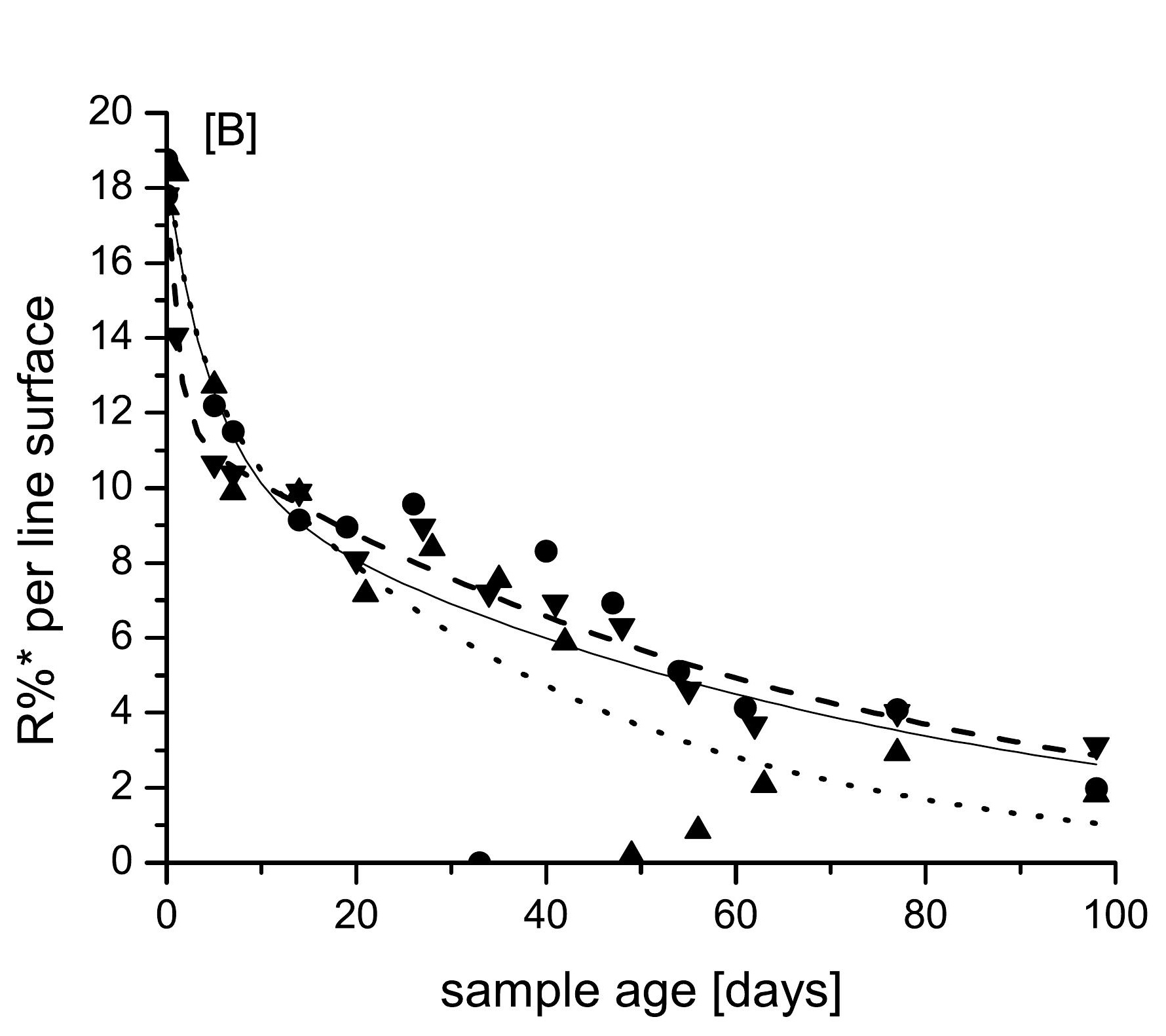

Figure 8B: Pressure normalised-Quantity of PE

Figure 8B: Pressure normalised-Quantity of PE

(1)

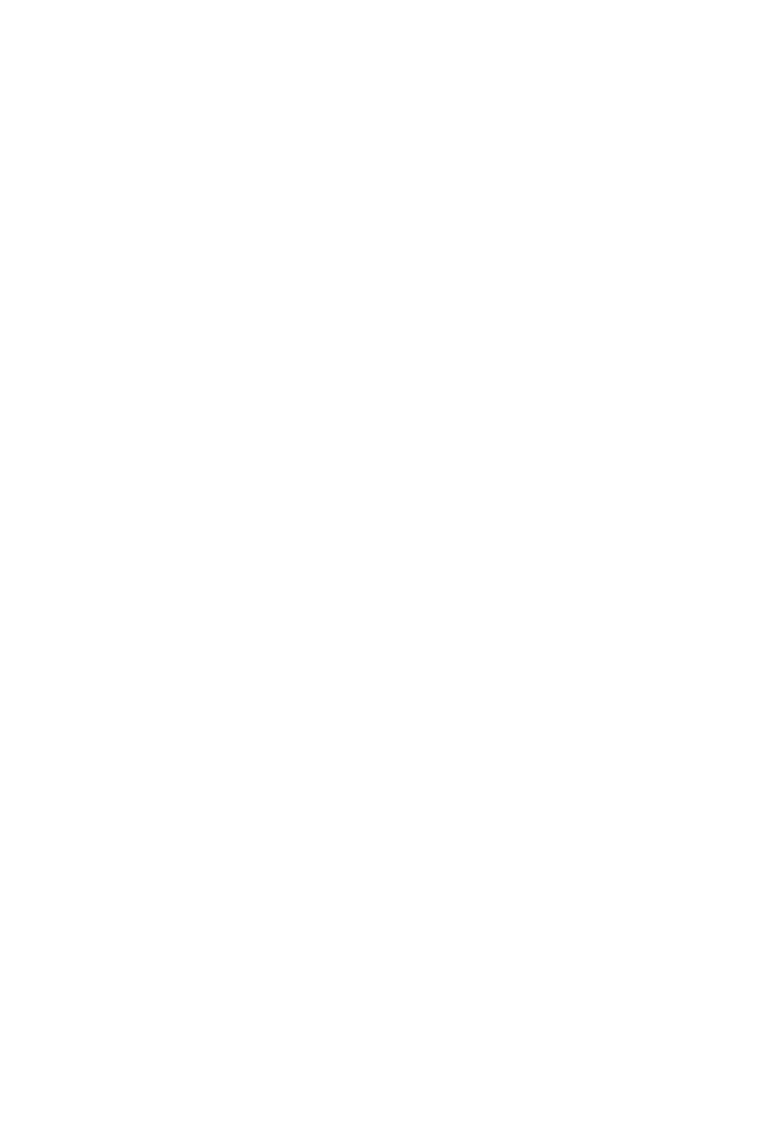

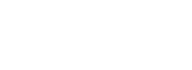

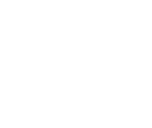

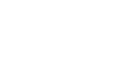$$
\text { (a) }
$$ 
Dear reviewers,

We wish to thank you for your very useful comments / remarks and corrections that helped us considerably improve our paper. We modified the paper accordingly. See below our answers and correcting actions to your remarks:

As I was not sure the figure quality was good enough for publication, I removed them from the manuscript and loaded them separately.

\begin{tabular}{|r|l|l|}
\hline 1. & Corrections Reviewer 1 & Answers \\
\hline bullet and (b) change "less" to "least" in the fifth bullet. & \multicolumn{1}{|c|}{} \\
\hline 2. & Page 1. Six lines from the beginning of the abstract, change "experimentations" to "experiments". \\
\hline 3. & Page 1. Nine lines from the beginning of the abstract, change "in ink line" to "in an ink line". \\
\hline 4. & $\begin{array}{l}\text { Page 1. Nine to ten lines from the beginning of the abstract, change "other stable" to "stable volatile". } \\
\text { There are two reasons for this change: one is that saying "using other stable" implies that PE is stable and } \\
\text { the other is that the stable compound used must be one that gives a GC signal (i.e., it is volatile). }\end{array}$ \\
\hline 5. & $\begin{array}{l}\text { Page 2. The term "ageing kinetics" is used eight times in the manuscript. This term (or even "ageing } \\
\text { mechanisms") may not be the appropriate term to use as it implies chemical reactions. This reviewer } \\
\text { strongly suggests using "ageing dynamics" since this term covers physicochemical processes such as } \\
\text { solvent evaporation, solvent penetration/migration, and molecular adhesion, but it also includes } \\
\text { chemical processes such as hydrogen bonding, photodegradation, and demethylation of methyl violet } \\
\text { dyes. }\end{array}$ & All these corrections were applied \\
\hline 6. & $\begin{array}{l}\text { Page 2. The first sentence of the second paragraph reads better as follows: Recent research has focused } \\
\text { mainly on developing methods based on the ink volatile compounds [6-14,16,21-26,28,33,34,40-50]. }\end{array}$ \\
\hline 7. & $\begin{array}{l}\text { Page 2. Fourteen lines from the bottom, change "two samples" to "two samples (which, ideally, contain } \\
\text { the same amount of ink)". The reason for this change is obvious. }\end{array}$ \\
\hline
\end{tabular}


Page 2. Toward the bottom there is a reference [50] (to work by LF Stewart). This work does not determine the "quantity of PE" but, rather, it is perhaps the first to consider a vehicle-to-vehicle ratio (which is the essence of RPA in the manuscript).

9.

10 inks must have been in pen cartridges (rather than in a bottle).

11.

. Again, at the end of the first paragraph under section 2.2, change "(fast, middle, slow)" to "(middle, slow, and fast, respectively)". By doing this, the reader now knows the identity of the ink that dries (ages) at a fast, slow, and middle rate. (See also page 14 under section 3.3.1. where these associations are explicitly stated.)

12

Page 4. Here and elsewhere all

For example, $\mathrm{ml}$ should be $\mathrm{mL}$.

13. Page 5. Indicate that the dwell time is in milliseconds (ms), if that is, in fact, the case.

Page 6. Six lines from the top, "stable" needs to be defined. This reviewer suggests using the following

in the sentence following Eqn. 4: ... and $Y$ is a stable compound (i.e., it is stable over time and thus does not change with age); it includes the internal standard PE-D2 and ink volatile components such as those listed in Table 1, provided they are shown to be stable (this is considered in section 3.2).

Page 6. Two lines below Eqn. 5, insert "the" before "ageing".

Page 6. Regarding Equations 7, 8, and 9, this reviewer finds the wording of two sentence fragments a bit confusing (and not quite correct) and suggests the following wording: more than $1 \pm 0.5 \%)$ :
Dear reviewer, you are right: even if he is the first author to propose to monitor solvent, he indeed suggested the direct use of a Vehicle-to-vehicle ratio instead of only the solvent. The reference was not appropriate and we deleted it. 


\begin{tabular}{|c|c|c|}
\hline 19. & $\begin{array}{l}\text { Page 7. Table } 1 \text { needs the following five corrections: (a) correct the spelling of benzyl alcohol; (b) remove } \\
\text { the accent from dipropylene (in two places); (c) replace "Target cible" with "mass of target ion"; (d) } \\
\text { change } 94 \text { to } 182 \text { for the mass of PEE (or explain why } 94 \text { is used); and (e) remove the colon (:) in the } \\
\text { footnote (where Internal Standard is mentioned). }\end{array}$ & $\begin{array}{l}\text { The different points were corrected. } \\
\text { For point } d \text {, the following sentence was } \\
\text { also added in the text explaining why the } \\
\text { calculation of the peak area of ion } 94 \mathrm{~m} / \mathrm{z} \\
\text { was chosen for PEE instead of } 182 \mathrm{~m} / \mathrm{z} \\
\text { (molecular ion): } \\
\text { "The peak areas (PA) of the ink solvents } \\
\text { were calculated using the selected target } \\
\text { ions (see Error! Reference source not } \\
\text { found.), They were chose because they } \\
\text { represented the most abundant ion of } \\
\text { the compound spectra and remained } \\
\text { characteristic of the molecule. }\end{array}$ \\
\hline 20 & $\begin{array}{l}\text { Page } 8 \text {. In the last row of Table } 2 \text {, change " }(t=0) \text { " to " }(t=7 \text { days }) \text { " to be consistent with what the text } \\
\text { states. }\end{array}$ & $\begin{array}{l}\text { There was a mistake in the text, the text } \\
\text { was then corrected. }\end{array}$ \\
\hline 21. & $\begin{array}{l}\text { Page 9. There is no mention of how the samples were prepared for obtaining Figure } 2 \text { A. Explain how the } \\
\text { ink samples were removed from an ink line and extracted. Since the measurements are dependent on } \\
\text { the amount of ink removed, it is very likely that a method was used that attempts getting the same } \\
\text { amount of ink each time. Please explain this (perhaps in section 2.2., the Sample Preparation section). }\end{array}$ & $\begin{array}{l}\text { Dear reviewer, the samples were } \\
\text { recovered on an ink line as mentioned on } \\
\text { section } 2.2 \text {. Those lines were drawn by } \\
\text { the same operator with a ruler but } \\
\text { without controlling writing pressure. As } \\
\text { in reality the amount of ink cannot be } \\
\text { controlled, no other precaution was } \\
\text { taken, thus we considered the "natural" } \\
\text { pressure variation in the figure 2A. In } \\
\text { order to explain this the following } \\
\text { sentence was added in section } 2.2 \\
\text { "Lines were drawn on a white copy paper } \\
\text { of } 80 \text { g/m }{ }^{2} \text { (Xerox Business paper) with a } \\
\text { ruler by the same operator. The pressure } \\
\text { was not controlled in order to remain } \\
\text { close to the real cases conditions" }\end{array}$ \\
\hline
\end{tabular}




\begin{tabular}{|c|c|c|}
\hline 22. & $\begin{array}{l}\text { Page } 9 \text {. In Figure } 2 \mathrm{~A} \text {, please explain why the curve-fitting equation of the aging curve of the heated } \\
\text { sample has only one exponential term. }\end{array}$ & $\begin{array}{l}\text { Dear reviewer, in a first step two } \\
\text { exponential decays were applied on the } \\
\text { heated data, but the results showed that } \\
\text { only the first decay explained the data. } \\
\text { Then only one exponential was used. }\end{array}$ \\
\hline 23. & $\begin{array}{l}\text { Page 10. Figure } 2 \text { (which is the first figure involving aging curves) is first mentioned on this page. Please } \\
\text { explain why error bars (at some level of confidence) are not used. Error bars are quite helpful in } \\
\text { determining if two means are statistically the same or different. If the values for the parameters given } \\
\text { throughout the text as [A plus/minus B] are taken to be substitutes for confidence limits (error bars), } \\
\text { then state this and indicate the confidence level used (e.g., is it at the } 95 \% \text { confidence level or some } \\
\text { other percent confidence level?). }\end{array}$ & $\begin{array}{l}\text { Dear reviewer, we agree that error bars } \\
\text { would be useful to compare the different } \\
\text { ages. However, each point of the graphics } \\
\text { represents only one measurement. Thus } \\
\text { the calculation of error bars is not } \\
\text { possible. It was possible to extrapolate } \\
\text { error curves based on the regression } \\
\text { model. But this actually saturated the } \\
\text { graphs and made the information } \\
\text { impossible to read. Therefore errors are } \\
\text { stated in tables } 3,4 \text { and } 5 \text { based on } \\
\text { replicate measurements made at } \\
\text { different selected ages. }\end{array}$ \\
\hline 24. & $\begin{array}{l}\text { Page 10. The section "Quantity of PE" mentions Figure } 4 \text { (before Figure } 3 \text { is mentioned) and Table } 4 \\
\text { (before Table } 3 \text { is mentioned). Please address this. This reviewer suggests that just stating that these are } \\
\text { found latter in this section (i.e., in section 3.2.) may be sufficient to fix this problem. For example, } \\
\text { change "(see Figure 4)" to "(see Figure } 4 \text { found later under this section, 3.2.)" in line three from the top } \\
\text { of the paragraph (under Quantity of PE) and change "(see Table } 4 \text { )" to "(see Table } 4 \text { found later under } \\
\text { this section, 3.2.)" in line four from the top. That should be all that is needed. This should avoid moving } \\
\text { figures and tables and renumbering them. }\end{array}$ & These corrections were applied \\
\hline 25. & $\begin{array}{l}\text { Page } 10 . \text { In the text three quarters down the page, there are two corrections that need to be made: (a) } \\
\text { change "Eq. } 4 \text { " to "Eq. } 5 \text { " and (b) remove the "o" from the subscript of PE. }\end{array}$ & $\begin{array}{l}\text { Indeed the text was not clear, it was } \\
\text { modified as following: YO Eq. } 6\end{array}$ \\
\hline 26. & $\begin{array}{l}\text { Page 10. Three lines from the bottom, the end of the sentence reads better as follows: showing that the } \\
\text { method of collecting samples (as shown in Figure 1) helped, to a certain extent, reduce the } \\
\text { "inhomogeneity" of ink lines for a given batch of samples. }\end{array}$ & \multirow[t]{2}{*}{ All these corrections were applied } \\
\hline 27. & Page 11 . The last column of Table 3 (labeled as R\%ratio) should be labeled simply as R\%*. & \\
\hline
\end{tabular}




\begin{tabular}{|c|c|c|}
\hline 28. & $\begin{array}{l}\text { Page } 11 \text {. Figure } 3 \text {, there seem to be some outliers around } 250 \text { days that line up horizontally close the } \\
\text { those found within } 25 \text { days. Again, error bars would help interpreting these results. Please comment. }\end{array}$ & $\begin{array}{l}\text { Dear reviewer, the samples around } 250 \\
\text { days are not statistical outliers. I agree } \\
\text { that the } 250 \text {-days-samples are especially } \\
\text { high. However those three points were } \\
\text { not analysed at the same time, nor from } \\
\text { the same samples for the three inks, It } \\
\text { may be explained by the fact that writing } \\
\text { pressure was not controlled and is thus } \\
\text { part of the error rate for such } \\
\text { measurements (see also Table } 3 \text { : the } \\
\text { measurement errors can be relatively } \\
\text { high). }\end{array}$ \\
\hline 29. & Page 12. In the middle of the page, change "nominator" to "numerator". & \multirow{3}{*}{ All these corrections were applied } \\
\hline 30. & Page 12. Toward the bottom of the page, change "Eq. 2" to "Eq. 4". & \\
\hline 31. & $\begin{array}{l}\text { Page 13. In the three graphs, change "SI" to "IS" and indicate in the figure caption that IS stands for } \\
\text { internal standard which is PE-D2. }\end{array}$ & \\
\hline 32. & $\begin{array}{l}\text { Page 13. In Figure } 4 A \text {, it would be quite useful to include for benzyl alcohol the point at time zero where } \\
\text { (according to the text) the RPA is } 2.4 \text {. This would clearly shows the rapid evaporation (that occurs in } \\
\text { three days) mentioned in the text. }\end{array}$ & $\begin{array}{l}\text { Dear reviewer, I understand your } \\
\text { suggestion. However if I add } t=0 \text { for BA, I } \\
\text { should do it for the other solvents in } \\
\text { order to remain consistent. As the RPA at } \\
t=0 \text { for PE and PEE are really high (up to } \\
12 \text { ) the scale would not allow anymore } \\
\text { seeing the difference between } 1 \text { and } 365 \\
\text { for the solvent in low concentrations. } \\
\text { Therefore, it would not improve the } \\
\text { actual figure and I chose to indicate the } \\
\text { numbers in the text. }\end{array}$ \\
\hline 33. & $\begin{array}{l}\text { Page } 14 . \text { Somewhere in the paragraph under section R\%*, indicate the important fact that the equation } \\
\text { for R\%* follows the same equation for R\%, but now the normal and heated entries are RPAs and are thus } \\
\text { mass independent. }\end{array}$ & \multirow{2}{*}{ All these corrections were applied } \\
\hline 34. & $\begin{array}{l}\text { Page } 14 . \text { Toward the bottom, change "Table } 6 \text { " to "Table } 4 \text { ". This error seems to appear in several other } \\
\text { pages. It appears again on page } 15 \text { (once) and page } 16 \text { (four times). }\end{array}$ & \\
\hline
\end{tabular}




\begin{tabular}{|c|c|c|}
\hline 35. & $\begin{array}{l}\text { Page 15. Change "Figure 1B and C" to "Figure 4B and C" in two places. These are found in the seventh } \\
\text { and twelfth line of the paragraph under "Relative peak areas between compounds (RPA)". }\end{array}$ & \\
\hline 36. & $\begin{array}{l}\text { Page 16. On the top of the page, clarify "Figure 1" (this is not the right figure for this) and "Figure 5D" } \\
\text { (there is no such figure). }\end{array}$ & \\
\hline 37. & $\begin{array}{l}\text { Page 18. On Table 4, the title "100 - } 365 \text { days" needs to be centered. Note also that " } 356 \text { " needs to be } \\
\text { changed to " } 365 \text { ". }\end{array}$ & \\
\hline 38. & $\begin{array}{l}\text { Page } 20 . \text { The term } \mathrm{R} \% / \mathrm{R} \%{ }^{*} \text { is used here and in } 12 \text { other places. Though it is not meant to be the ratio of } \\
\mathrm{R} \% \text { and } \mathrm{R} \% * \text {, writing it this way gives that impression. This reviewer suggests either: (a) stating at the } \\
\text { outset (here on page } 20 \text { ) that this term shall be used to indicate } \mathrm{R} \% \text { and } \mathrm{R} \% * \text { or changing all } \mathrm{R} \% / \mathrm{R} \% * \\
\text { (there are } 13 \text { of these) to } \mathrm{R} \%\left(\mathrm{R} \%{ }^{*} \text { ) or } \mathrm{R} \% \text { and } \mathrm{R} \% * \text {. }\right.\end{array}$ & \\
\hline 39. & Page 21. In the caption of Table 5, separate 1688 and at (it appears as 1688at). & \\
\hline 40. & Page 23. First sentence under 3.3.3., insert "the" before "solvent". & \\
\hline 41. & $\begin{array}{l}\text { Page } 27 . \text { In Table } 7 \text {, the components (PEnormal and PEheated) of the solvent loss ratio R\% are indeed } \\
\text { mass dependent, but when the condition is imposed that the heated and normal sample be taken to be } \\
\text { as close to being equal as possible, this makes R\% be pretty close to being mass independent. This } \\
\text { reviewer suggests the authors put an asterisk by "no" and explain as a footnote that when the sample } \\
\text { collection procedure (Figure } 1 \text { ) is followed, R\% is close to being mass independent. }\end{array}$ & $\begin{array}{l}\text { Dear reviewer, I thank you for your } \\
\text { remark that really made us think on the } \\
\text { subject. We finally decided that this } \\
\text { matter could be the subject of a debate. } \\
\text { In our opinion, taking samples as close as } \\
\text { possible only assures that we have } \\
\text { samples as equal as possible. The size } \\
\text { (length) of the sample would indeed be } \\
\text { pretty close to be equal within one } \\
\text { sample. However, we compare draw } \\
\text { aging curves and saw that such samples } \\
\text { are not mass independent between } \\
\text { different samples drawn with different } \\
\text { pressures and thickness (as proven by our } \\
\text { results). We think it is mainly length- } \\
\text { independent. } \\
\text { Then, for us the R\% can only be mass } \\
\text { independent within samples and not } \\
\text { between samples. }\end{array}$ \\
\hline 42. & $\begin{array}{l}\text { Page } 26 . \text { On Table } 6 \text {, the title " } 100 \text { - } 365 \text { days" needs to be centered. Note also that " } 356 \text { " needs to be } \\
\text { changed to " } 365 \text { ". }\end{array}$ & \multirow[t]{2}{*}{ All these corrections were applied } \\
\hline 43. & Page 27. In Table 7, remove the footnote as it is already explained in the title of the table. & \\
\hline
\end{tabular}




\begin{tabular}{|c|c|c|}
\hline 44. & Page 27. In Table 7, insert "(RSD)" after "reproducibility". & \\
\hline 45. & $\begin{array}{l}\text { Page } 27 \text {. In Table 7, the reproducibility for } \mathrm{R} \% \text { should be } 12<\mathrm{x}<38 \% \text { and the reproducibility of R\%* } \\
\text { should be } 2<x<16 \% \text {. This is according to what is found on Table } 3 \text {. }\end{array}$ & \\
\hline 46. & Page 27. Section 3.1 should be section 3.4. (i.e., it is mislabeled). & \\
\hline 47. & $\begin{array}{l}\text { Page 29. Ten lines from the bottom, insert "for slow, medium, and fast drying inks" after "values". By } \\
\text { doing this, the authors do not have to necessarily cite that vehicle-to-vehicle ratios (RPAs) have been } \\
\text { determined by others (e.g., Stewart and Aginsky) as their work only covered one or two inks and did they } \\
\text { not specifically target slow, medium, and fast drying inks. }\end{array}$ & \\
\hline 48. & $\begin{array}{l}\text { Page } 30 . \text { It is important to bring out again one key statement made on page } 14 \text { (at the end of the first } \\
\text { paragraph). This reviewer suggests that the following two sentences be added before the last paragraph } \\
\text { of page 30: The parameters RPA and R\%* (which is built from RPAs) require the identification of a stable } \\
\text { volatile component in the ink being analyzed. This requirement is the most demanding task for using } \\
\text { these parameters. }\end{array}$ & \\
\hline \multirow[t]{2}{*}{ 49. } & $\begin{array}{l}\text { Page 31. Reference } 9 \text { cites Dr. César Costa Vera. His last name is Costa Vera (both names are used; } \\
\text { similar to Hicks Champod). Thus, change his name to C. Costa Vera. It can also be hyphenated as is the } \\
\text { case in reference } 30 \text { (C. Costa-Vera). }\end{array}$ & \\
\hline & Corrections Reviewer 2 & Answers \\
\hline 50. & - page 3, top line: "sensitivity" may be more suitable instead of "sensibility". & We applied the corresction. \\
\hline 51. & $\begin{array}{l}\text { - page 3, 4th par.: Lit } 54 \text { is outdated soon, as the ENFSI homepage is renamed; citation of internet } \\
\text { adresses are generally not very long lasting information. }\end{array}$ & $\begin{array}{l}\text { You are right and we'll check it during the } \\
\text { proofs. - Howeveruntil now, we can write } \\
\text { the address indicating the last visited } \\
\text { date. This is the usual way to cite internet } \\
\text { pages. }\end{array}$ \\
\hline 52. & $\begin{array}{l}\text { - page } 3 \text {, last line: "being genrally extremely inhomogeneous" is not true, still is an assumption, and has } \\
\text { to be proven yet; should be written as an opinion or an impression. }\end{array}$ & \multirow{3}{*}{ We applied the correction. } \\
\hline 53. & - page 4, last line: omit Lit 57 (double). & \\
\hline 54. & - page 6, second line: "7.42" instead of "7.4" (see table, 2 digits). & \\
\hline 55. & $\begin{array}{l}\text { - page 6, line 6: define the meanging of "stable compound" more precisely, as there are two different } \\
\text { types of stability: stability in its concentration on paper, or stability in chemical terms, like photostability, } \\
\text { which is an issue in ink dating also. Moreover, the term "natural" sample is somehow uncommon; it } \\
\text { would be better to write "unheated". }\end{array}$ & $\begin{array}{l}\text { the first remark meets a remark (5) of } \\
\text { reviewer } 1 \text {. It was modified consequently. } \\
\text { It is our choice to use the term "natural" } \\
\text { as it refers to the naturally aged samples. } \\
\text { We thank you for your comprehension. }\end{array}$ \\
\hline 56. & - page 7 , table 1,3 rd column: meaning of the word "cible"? & $\begin{array}{l}\text { It was corrected accordingly (see also } \\
\text { remark 19) }\end{array}$ \\
\hline
\end{tabular}




\begin{tabular}{|c|c|c|}
\hline 57. & $\begin{array}{l}\text { - page } 10,2 \text { nd par.: first sentence needs to be rewritten; like: "solvent loss monitoring with respect to } \\
\text { the quantitiy of PE is a fundamental and much used parameter for investigating ink aging". }\end{array}$ & $\begin{array}{l}\text { I thank you for the suggestion, but we } \\
\text { preferred to keep the current phrasing as } \\
\text { it corresponds to our style. }\end{array}$ \\
\hline 58. & $\begin{array}{l}\text { - page 10, } 3 \text { rd par., first sentence: as solvent loss ratio needs measurements of two samples its original } \\
\text { intention was NOT to reduce the ink line inhomogeneity or to reach mass independence, but to generally } \\
\text { measure an aging behaviour of ink samples, which cannot be done using only one sample. This thought } \\
\text { should be considered also in the following paragraphs. }\end{array}$ & $\begin{array}{l}\text { Indeed, the measurement of two samples } \\
\text { allows measuring ink ageing over time. } \\
\text { This does not exclude the fact that it also } \\
\text { allows a normalisation that is supposed } \\
\text { to reduce the ink mass effect.. So the } \\
\text { sentence was modified as follows: } \\
\text { "The calculation of the ageing parameter } \\
\text { referred in the literature as the solvent } \\
\text { loss ratio (R\%) [14,21,41] theoretically } \\
\text { aims at measuring the ageing while } \\
\text { minimizing the variability due to ink line } \\
\text { inhomogeneity through normalisation" }\end{array}$ \\
\hline 59. & $\begin{array}{l}\text { - page 10, last sentences: the conclusion, how a correlation of PE quantities points to attenuation of } \\
\text { inhomogeneity of ink lines through sample collection, is unlcear. }\end{array}$ & $\begin{array}{l}\text { Dear reviewer, this sentence have been } \\
\text { removed }\end{array}$ \\
\hline 60. & - page 12,2 nd par., 2 nd sentence: leave out Lit 51 here. & \multirow{3}{*}{ We applied the correction. } \\
\hline 61. & $\begin{array}{l}\text { - page } 12,2 \text { nd par.: "Ideally, .... a compound that decreases over time...:" is not correct; it should be: "the } \\
\text { nominator is the concentration of a compound decreasing over time .... while the denominator should be } \\
\text { the concentration of a compound remaining stable over time". }\end{array}$ & \\
\hline 62. & - page 12: "phthalic" instead of "phtalic" & \\
\hline 63. & $\begin{array}{l}\text { - page 12: "PEE aged...", should be better: "PEE evaporated .....", as PEE does not "age", only its } \\
\text { concentration changes. }\end{array}$ & $\begin{array}{l}\text { Dear reviewer, as the phrasing was not } \\
\text { optimal, the verb "age" have been } \\
\text { replaced by "dry" }\end{array}$ \\
\hline 64. & - page 12, last par.: "8.8+- 0.6 " should be "7.3+- 0.8 " ?; and "(Figure 3C)" should be "(Figure 2C)". & \multirow[b]{2}{*}{ We applied the corrections. } \\
\hline 65. & $\begin{array}{l}\text { - page 13: please name the abbreviations (PE, PEE, HG, etc.) in the figure captions. Makes figure reading } \\
\text { easier. }\end{array}$ & \\
\hline 66. & $\begin{array}{l}\text { - page 14: for the sake of clarity, please give the formula of R\%*; Concerning table } 3 \text { : is R\% ratio the same } \\
\text { as R\%* ? Please explain. }\end{array}$ & $\begin{array}{l}\text { This meets remark } 33 \text { and it has been } \\
\text { corrected }\end{array}$ \\
\hline 67. & - page 16 , first sentence: Figure 5D is not existent. & \multirow{3}{*}{ We applied the corrections. } \\
\hline 68. & - page 25 , top par.: "For ink 1688 ....." leave out the word "with" & \\
\hline 69. & - page 25 , last par.: please specify the set-up of the climatic chamber (with/without fan, etc.). & \\
\hline
\end{tabular}




\begin{tabular}{|r|l|l|}
\hline 70. & - page 29, last par.: "extend" instead of "extent" & \\
\hline 71. & $\begin{array}{l}\text { - page 30: rephrase the conclusion; "the calculation of RPA proved .. most promising ...., while the least } \\
\text { reliable..."; it is not logic to draw a conclusion regarding "promise" and "reliability", especially when } \\
\text { reliability is more or less one of the assumptions made above; furthermore, it should be added to the } \\
\text { assumptions that a good aging parameter should be applicable to as many ink formulations as possible. }\end{array}$ & $\begin{array}{l}\text { Dear reviewer, this remark meets remark } \\
48 \text { and the conclusion was modified in } \\
\text { order to take both remarks into } \\
\text { consideration. }\end{array}$ \\
\hline 72. & - page 35, Lit 56: this lit is still "in press" but published in 2012 ?? & We applied the corrections. \\
\hline
\end{tabular}

